\author{
UNIVERSIDADE DE SÃO PAULO \\ ESCOLA DE ENGENHARIA DE SÃO CARLOS \\ DEPARTAMENTO DE ENGENHARIA DE PRODUÇÃO
}

Elaine Maria dos Santos

AVALIAÇÃO DA INFLUÊNCIA DOS ESTILOS COGNITIVOS
NO PERFIL DO ALUNO DE EDUCAÇÃO A DISTÂNCIA

São Carlos - SP 
Elaine Maria dos Santos

\section{AVALIAÇÃO DA INFLUÊNCIA DOS ESTILOS COGNITIVOS NO PERFIL DO ALUNO DE EDUCAÇÃO A DISTÂNCIA}

Dissertação apresentada à Escola de Engenharia de São Carlos da Universidade de São Paulo, como parte dos requisitos para a obtenção do título de Mestre em Engenharia de Produção.

Área de Conhecimento: Gestão do Conhecimento e Sistemas de Informação.

Orientador: Prof. Dr. José Dutra de Oliveira Neto.

São Carlos - SP

2007 
AUTORIZO A REPRODUÇÃO E DIVULGAÇÃO TOTAL OU PARCIAL DESTE TRABALHO, POR QUALQUER MEIO CONVENCIONAL OU ELETRÔNICO, PARA FINS DE ESTUDO E PESQUISA, DESDE QUE CITADA A FONTE.

Ficha catalográfica preparada pela Seção de Tratamento da Informação do Serviço de Biblioteca - EESC/USP

S237a

Santos, Elaine Maria dos

Avaliação da influência dos estilos cognitivos no perfil do aluno de educação a distância / Elaine Maria dos Santos ; orientador José Dutra de Oliveira Neto. -São Carlos, 2007.

Dissertação (Mestrado) - Programa de Pós-Graduação em Engenharia de Produção e Área de Concentração em Gestão do Conhecimento e Sistemas de Informação - - Escola de Engenharia de São Carlos da Universidade de São Paulo.

1. Estilos cognitivos. 2. Alunos de EAD. 3. Perfil do aluno. I. Título. 
FOLHA DE JULGAMENTO

Candidata: Tecnóloga ELAINE MARLA DOS SANTOS

Disscrtação defendida e julgada em 02/03/2007 perante a Comissăo Julgadora:

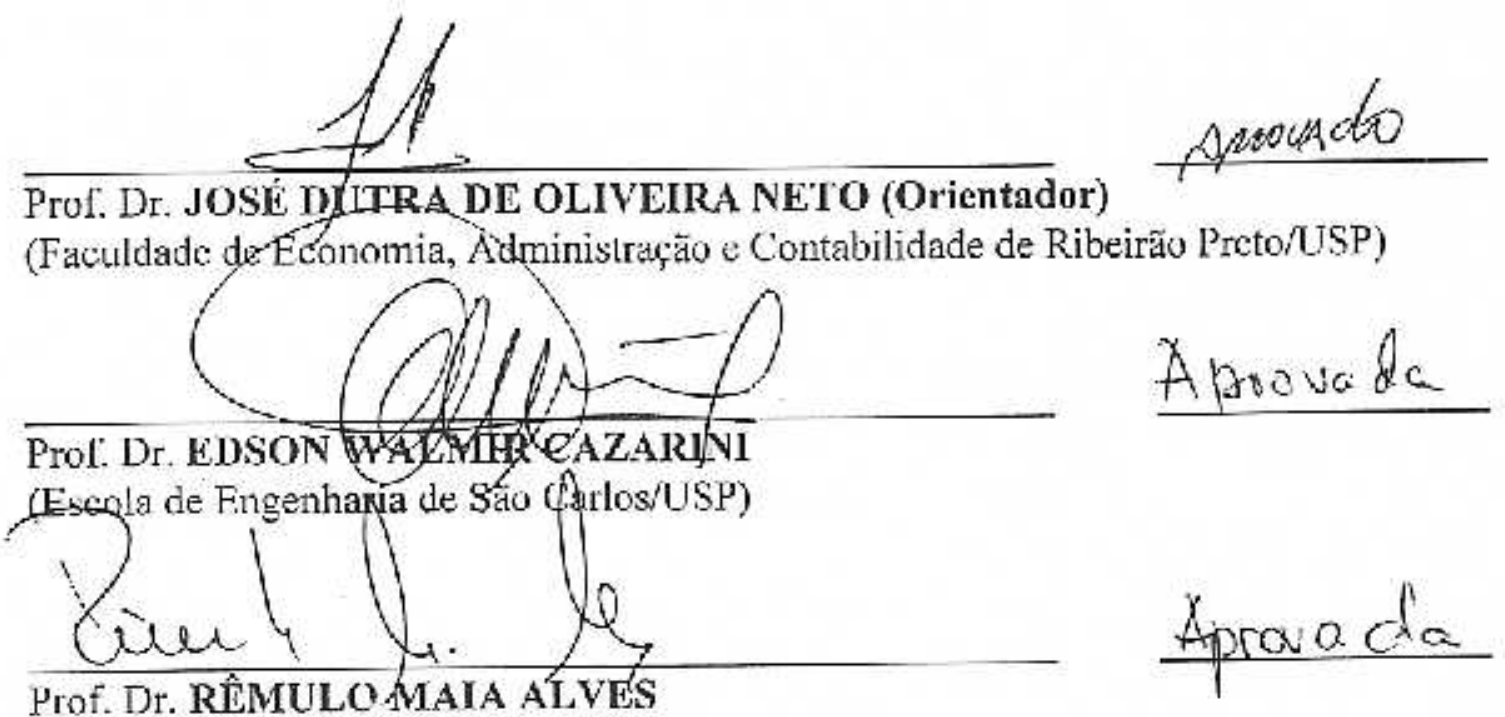

(Universidade Fedaral de Lavras/UFLA)

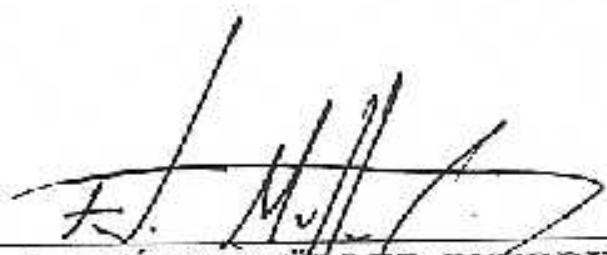

Prof. Assuciado FÁBIO MÜLL ĹR GEERRINI

Courdenador do Programad de Poj-Graduação em

Engenharia de \rođução

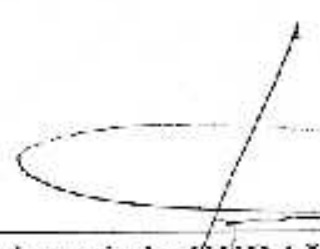

Prof: Associado GERAYDO ROBERTO MARTINS DA COSTA Presidenté da Comissão da Pós-Graduação da EESC 
Ao Juliano, companheiro de todos os momentos, que, mesmo a distância, se fez sempre presente incentivando-me e dividindo comigo todas as expectativas e conquistas. 


\section{AGRADECIMENTOS}

A Deus, pelo dom da vida.

Aos meus pais, José e Cida, que são meu exemplo de vida e meu "porto seguro", principalmente por terem me ensinado a ser forte e persistente na busca dos meus objetivos.

Às minhas irmãs, Joselaine e Mayele, pelo incentivo, amor e carinho sempre a mim dedicados.

Ao professor Dutra, pelo auxílio rápido em todos os momentos que precisei e pelas inúmeras contribuições.

A todos do Centro Universitário onde desenvolvi a pesquisa.

Aos coordenadores dos cursos que pesquisei, pela atenção e colaboração.

Ao Prof. Dyjalma, Alessandra, Jones, Valnei, Gabriel e todos que, direta ou indiretamente, me auxiliaram na pesquisa de campo.

Agradecimento especial a Nilvânia, pela ajuda incondicional no levantamento dos dados.

À amiga e companheira de “kit”, Janaína, pelos momentos de descontração e convívio.

A todos os colegas da pós-graduação, que alegraram e preencheram minha vida, neste período em São Carlos.

Aos funcionários do Departamento de Engenharia de Produção, José Luiz, Fábio, Daniel, Silvana, Sueli e Luiz Fernando, pela atenção e disposição com que me ajudaram sempre que precisei.

À CAPES pelo auxílio financeiro durante a realização deste estudo. 


\section{SUMÁRIO}

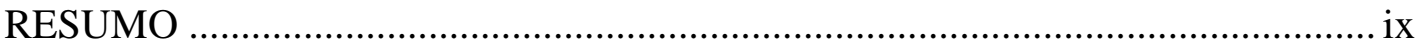

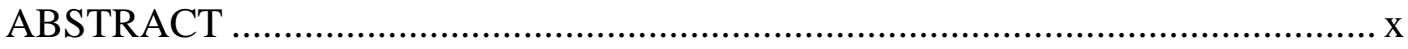

LISTA DE ABREVIAÇÕES E SIGLAS …………………………………….......

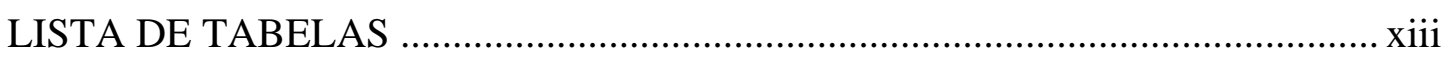

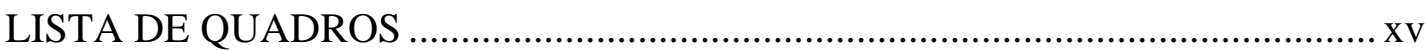

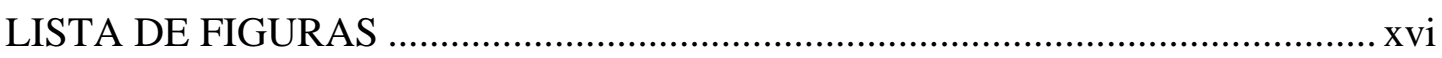

LISTA DE GRÁFICOS .............................................................................................

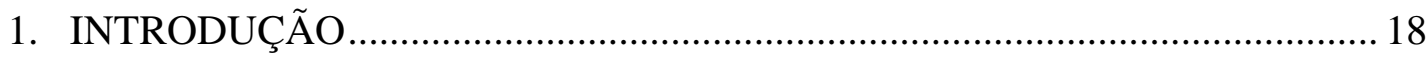

1.1. Delimitação da pesquisa .............................................................................. 19

1.2. Problema de pesquisa ............................................................................... 20

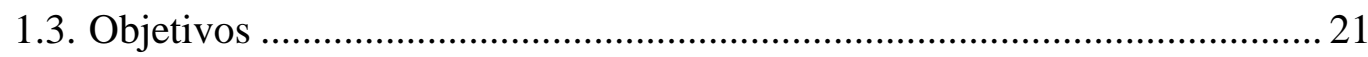

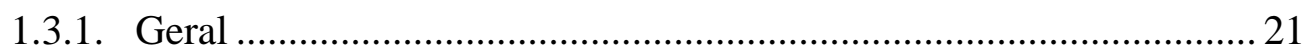

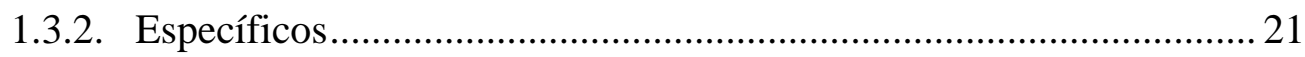

1.4. Justificativa.......................................................................................... 21

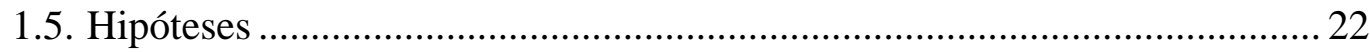

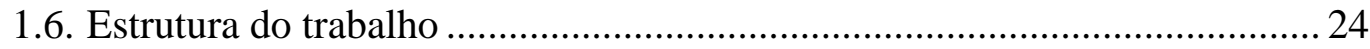

2. EDUCAÇÃO A DISTÂNCIA ………………………………............................ 25

3. ESTILOS DE APRENDIZAGEM E ESTILOS COGNITIVOS …………............37

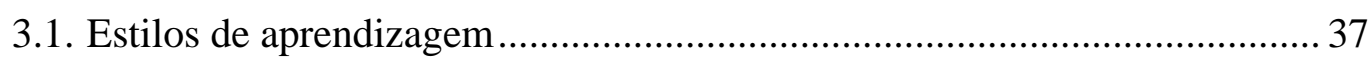

3.2. Estilos cognitivos ................................................................................... 42

3.3. Estilos cognitivos e estilos de aprendizagem em EAD …………………..... 55

3.4. Instrumentos psicométricos ........................................................................ 58

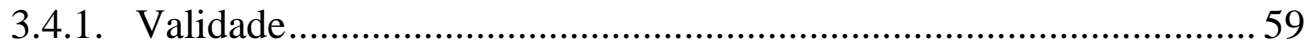

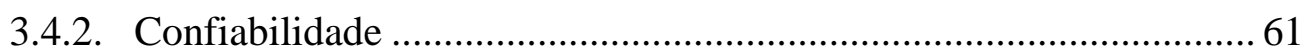

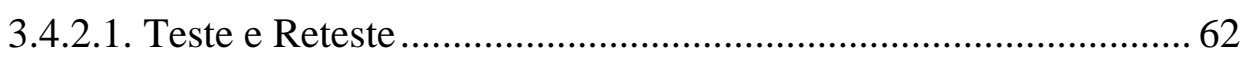

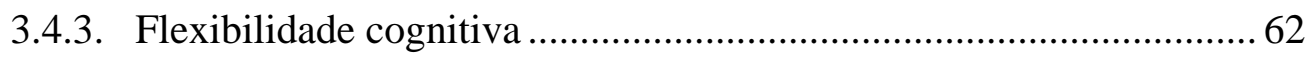

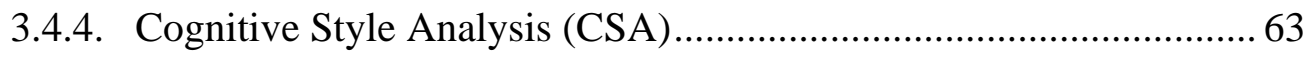

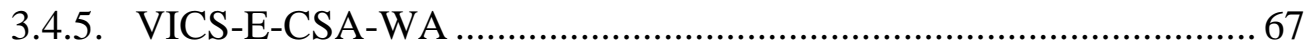

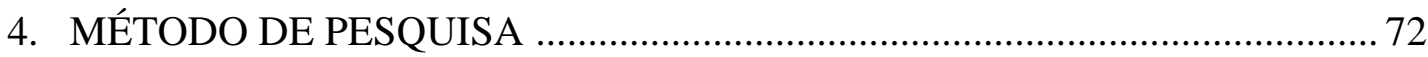

4.1. Local da pesquisa ................................................................................... 72

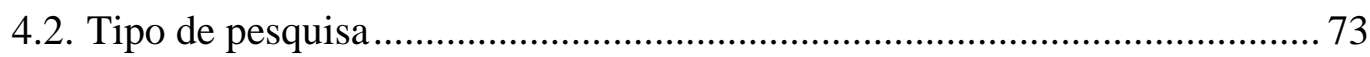




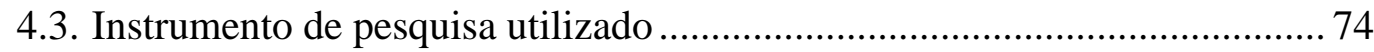

4.4. Caracterização da amostra da pesquisa ................................................... 74

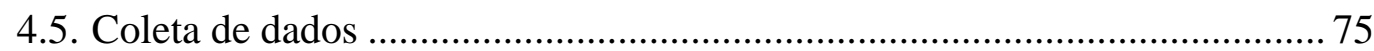

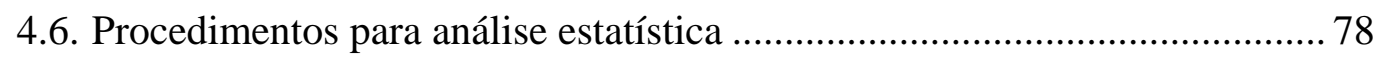

5. APRESENTAÇÃO DOS RESULTADOS E DISCUSSÃO .............................. 79

5.1. Estilos cognitivos dos estudantes .............................................................. 79

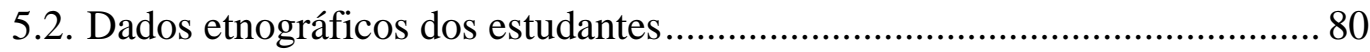

5.3. Análise das variáveis dependentes e independentes................................... 82

5.4. Análise dos dados etnográficos segundo as dimensões cognitivas .............. 91

5.5. Estilos cognitivos e comparações entre cursos........................................... 96

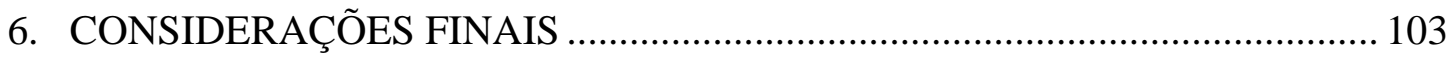

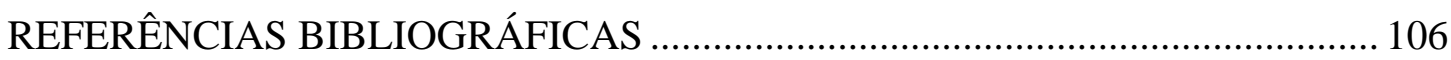

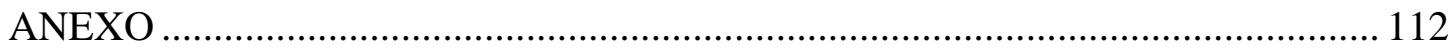

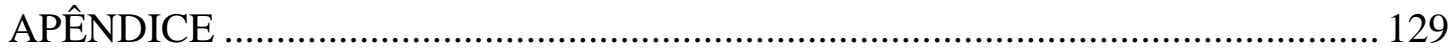




\section{RESUMO}

\section{SANTOS, E.M. Avaliação da influência dos estilos cognitivos no perfil do aluno de}

educação a distância. 2007. 130 p. Dissertação (Mestrado) - Escola de Engenharia de São Carlos, Universidade de São Paulo, São Carlos, 2007.

Com o significativo crescimento da Educação a Distância (EAD) surge uma preocupação, que é a validação da qualidade dos cursos e da aprendizagem dos alunos. Uma alternativa promissora é a criação de cursos mais customizados, mas para isso é necessário conhecer as preferências individuais dos alunos, e uma das ferramentas é a identificação de seus estilos cognitivos. Nesse sentido, o objetivo deste estudo foi avaliar a influência dos estilos cognitivos no perfil do aluno de cursos da modalidade a distância. Optou-se por uma pesquisa exploratório-descritiva, visando obter maior familiaridade com o problema e possibilidades para descrever o fenômeno dos estilos cognitivos na EAD, utilizando um instrumento psicométrico traduzido. A amostra foi constituída por 103 alunos, distribuídos entre os cursos de Administração, Tecnólogo em Gestão Financeira e Computação. Os resultados confirmam que os alunos possuem estilos cognitivos diferentes, o que reforça a necessidade de cursos mais individualizados, com estratégias de aprendizagem diversificadas, respeitando e valorizando as características individuais dos estudantes. São discutidas as implicações dos achados, bem como as diferenças significativas entre os estilos cognitivos e o perfil dos alunos nos três cursos estudados.

Palavras-chave: Educação a Distância (EAD); Estilos cognitivos; Perfil do aluno; Estratégias de Aprendizagem. 


\section{ABSTRACT}

SANTOS, E.M. Evaluating the influence of cognitive styles on the profiles of distancelearning students. 2007. 130 p. Dissertação (Mestrado) - Escola de Engenharia de São Carlos, Universidade de São Paulo, São Carlos, 2007.

With the significant increase in Distance Learning (DL), a new concern arises: the validation of programs' quality standards and students' learning. A promising alternative is the design of more customized programs for which purpose it is necessary to learn about students' individual preferences, and one of the tools that can be used is the identification of cognitive styles. Hence, this study aimed at evaluating the influence of cognitive styles on the profile of students in DL programs. An exploratory descriptive investigation was conducted for better acquaintance with the problem and the possibility to describe the cognitive style phenomenon in DL by using a translated psychometric instrument. The sample consisted of 103 students from the Business Administration, Financial Management and Information Technology DL programs. The results confirmed that students have different cognitive styles, which reinforces the need for more individualized programs with diversified learning strategies that respect and value students' individual characteristics. Implications of the findings as well as the significant differences between cognitive styles and the profiles of students from the three programs studied are discussed.

Key words: cognitive styles, distance-learning students, students' profiles, learning strategies. 


\section{LISTA DE ABREVIATURAS E SIGLAS}

\begin{tabular}{|c|c|}
\hline EAD & Educação a Distância \\
\hline UNED & Universidad Nacional de Educación a Distancia \\
\hline TGF & Tecnólogo em Gestão Financeira \\
\hline LMS & Learning Management System \\
\hline INEP & Instituto Nacional de Estudos e Pesquisas Educacionais Anísio Teixeira \\
\hline TIC’s & Tecnologias de Informação e Comunicação \\
\hline $\mathrm{UAB}$ & Universidade Aberta do Brasil \\
\hline SEED & Secretaria de Educação a Distância \\
\hline MEC & Ministério da Educação \\
\hline CSI & Cognitive Style Index \\
\hline MSP & Motivational Style Profile \\
\hline ASSIST & Approaches and Study Skills Inventory for Students \\
\hline GSD & Gregore's Mind Styles Model and Style Delineator \\
\hline HBDI & Herrmann’s Brain Dominance Instrument \\
\hline LSQ & Learning Styles Questionnaire \\
\hline LSP & Learning Styles Profiler \\
\hline LSI & Learning Style Inventory \\
\hline MBTI & Myers-Briggs Type Indicator \\
\hline CSA & Cognitive Style Analysis \\
\hline TSI & Thinking Styles Inventory \\
\hline ILS & Inventory of Learning Styles \\
\hline
\end{tabular}

VICS-E-CSA-WA Verbal-Imagery Cognitive Style Test (VICS) e Extended Cognitive Style Analysis (CSA) - Wholist-Analytic (WA) Test 
V

I

W

A

$\mathrm{V} / \mathrm{I}$

W/A

GEFT

IBGE
Verbal

Imagético

Holístico

Analítico

Verbal/Imagético

Holístico/Analítico

Group Embedded Figures Test

Instituto Brasileiro de Geografia e Estatística 


\section{LISTA DE TABELAS}

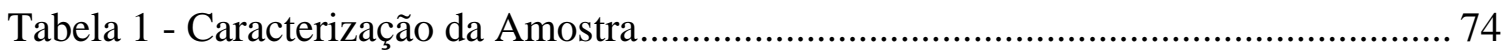

Tabela 2 - Estilos cognitivos dos estudantes de EAD por curso ..................................... 79

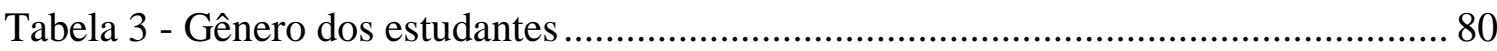

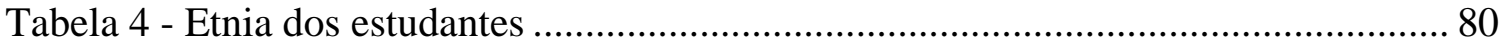

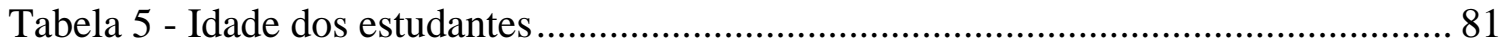

Tabela 6 - Estilos cognitivos dos estudantes de EAD nas dimensões verbal e imagético $(\mathrm{V} / \mathrm{I})$ 83

Tabela 7 - Estilos cognitivos dos estudantes de EAD nas dimensões holístico e analítico (W/A) 84

Tabela 8 - Diferenças significativas nas dimensões verbal e imagético (V/I) (Administração) 85

Tabela 9 - Diferenças significativas nas dimensões verbal e imagético (V/I) (Computação)

Tabela 10 - Diferenças significativas nas dimensões holístico e analítico (W/A) (Computação) 87

Tabela 11 - Características das dimensões cognitivas para variáveis dependentes. 88 Tabela 12 - Diferenças significativas nas dimensões verbal e imagético (V/I) no curso TGF. 89

Tabela 13 - Diferenças significativas nas dimensões cognitivas para a variável gênero, no curso de Administração 91

Tabela 14 - Diferenças significativas nas dimensões cognitivas para a variável gênero, no curso de Computação 92 
Tabela 15 - Diferenças significativas nas dimensões cognitivas para a variável gênero, no curso TGF

Tabela 16 - Diferenças significativas nas dimensões cognitivas para a variável etnia, no curso de Administração 93

Tabela 17 - Diferenças significativas nas dimensões cognitivas (V/I) para a variável etnia, no curso de Computação 94

Tabela 18 - Diferenças significativas nas dimensões cognitivas (W/A) para a variável etnia, no curso de Computação 95

Tabela 19 - Diferenças significativas nas dimensões cognitivas para a variável etnia, no curso TGF 95 


\section{LISTA DE QUADROS}

Quadro 1 - Distribuição dos alunos matriculados por localização geográfica da Instituição

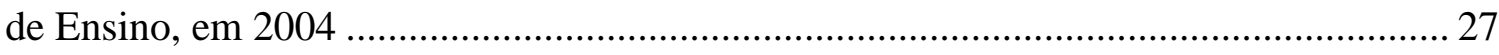

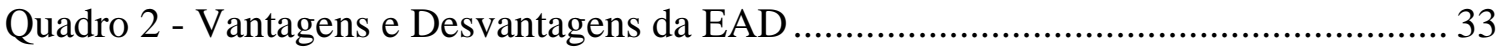

Quadro 3 - Dimensões de Estilos Cognitivos ................................................................. 46

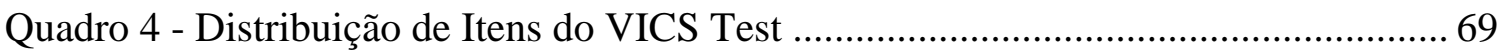

Quadro 5 - Distribuição de Itens do Extended CSA-WA Test........................................ 69

Quadro 6 - Categorização das mensagens do fórum de discussão .................................. 77

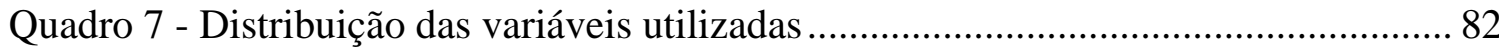

Quadro 8 - Quantificação das variáveis numéricas e independentes................................ 90

Quadro 9 - Síntese das diferenças significativas entre os cursos por variável ................. 97 


\section{LISTA DE FIGURAS}

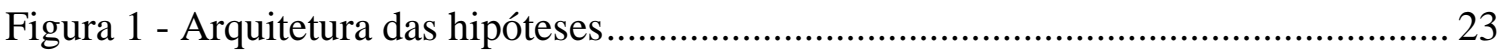

Figura 2 - Síntese das dimensões utilizadas nos Estilos Cognitivos segundo a literatura 53

Figura 3 - Derivação do VICIS-E-CSA-WA do CSA..................................................... 67

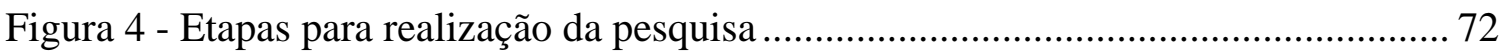




\section{LISTA DE GRÁFICOS}

Gráfico 1 - Evolução do Número de Cursos de Graduação no Brasil.............................. 26 


\section{INTRODUÇÃO}

A Educação a Distância (EAD) vem crescendo em todo o mundo. Incentivados pelas possibilidades decorrentes das tecnologias de informação e comunicação e por sua inserção em todos os processos produtivos, cada vez mais cidadãos e instituições vêem nessa forma de educação um meio de democratizar o acesso ao conhecimento e de expandir oportunidades de trabalho e aprendizagem ao longo da vida.

No Brasil, assim como em vários outros países, a Educação a Distância teve um significativo crescimento, seja em cursos informais, coorporativos e principalmente formais, ou seja, aqueles que exigem aprovação do Ministério da Educação (MEC). E diante desta ampla gama de cursos, surge um importante fenômeno para a EAD, que é a validação da qualidade percebida destes cursos juntamente com a qualidade da aprendizagem dos alunos, pois, em um futuro não muito distante, onde haverá grande oferta de instituições com diversos cursos na modalidade a distância, o diferencial será a qualidade dos mesmos, e será por meio deste diferencial que os estudantes escolherão onde estudar, pois já não mais existirá fronteira geográfica.

No Brasil, em 2005, segundo o ANUÁRIO Brasileiro Estatístico de Educação Aberta e a Distância (2006), quinhentas e quatro mil (504.000) pessoas usaram o ensino a distância, somente em faculdades autorizadas pelo Ministério de Educação. Na graduação e na pósgraduação, dobrou o número de estudantes matriculados nessa modalidade entre 2003 e 2004. Em 2003, havia setenta e seis mil setecentos e sessenta e nove (76.769) alunos matriculados nessas modalidades; no ano seguinte, o número saltou para cento e cinqüenta e nove mil trezentos e sessenta e seis (159.366). Somando todos os níveis de ensino, o número de alunos passa de um milhão. Observou-se, ainda, um crescimento de 62,6\% em 2005 com relação ao ano de 2004. 
E, considerando esta demanda, a Educação a Distância tem buscado suporte em novos paradigmas teóricos, pedagógicos e tecnológicos para criar condições de aumentar a eficácia e a eficiência dos processos e produtos educacionais em EAD, uma vez que o desenvolvimento científico e tecnológico atual aponta para a necessidade de novos modelos educacionais, a fim de atender as profundas modificações e novas exigências da sociedade, principalmente no que diz respeito à diversificação dos espaços educacionais (TAKAHASHI, 2000).

Considerando estes novos paradigmas, destacam-se também as propostas baseadas em um processo cujo tratamento ao aluno seja personalizado, que se conheça individualmente cada um, visando proporcionar-lhe motivação, satisfação, aproveitamento e autonomia em seus estudos. Com isso, o estilo cognitivo é visto como uma maneira de adequar o curso ao perfil de cada aluno, possibilitando novas estratégias de ensino mais apropriadas às características peculiares de cada estudante, de forma a melhorar a qualidade da aprendizagem.

Para isto, vários estudos no campo da percepção, psicologia da personalidade e processamento da informação têm procurado explicar o "como” e o "porquê" das diferenças individuais (PENNINGS; SPAN, 1991), pois faltava um recurso que auxiliasse a elaboração de técnicas educativas adaptadas ao desenvolvimento mental, social e afetivo de cada aluno.

\subsection{Delimitação da Pesquisa}

Sabe-se que as pessoas possuem diferentes formas e preferências para aprender, e cada um desenvolve estratégias próprias para receber nova informação, processá-la, responder a ela, internalizá-la entre outras ações.

Acredita-se que as pessoas diferem umas das outras em vários aspectos, pois cada uma pensa e sente as situações com as quais se depara, de maneiras diferenciadas, uma vez que 
cada ser é único. Assim, ter conhecimento das diferentes formas de ensinar e de aprender e respeitá-las é um aspecto que atinge diretamente a aprendizagem. O educador que considera o estilo e o perfil de seu aluno tem condições de adequar diferentes formas de apresentar informações para geração de conhecimento, e o aluno que conhece seu estilo, tem condições de adotar estratégias que favoreçam sua aprendizagem.

Entretanto, muitas vezes, as situações de aprendizagem não são pensadas, não levando em conta as características dos aprendizes, e isso prejudica o processo educativo, uma vez que o que se deseja, especialmente no âmbito da educação a distância, é que os alunos realmente aprendam e desenvolvam suas habilidades.

Tendo em vista que se trata de um tema muito amplo, reforça-se a necessidade de se delimitar com precisão a esfera de atuação da pesquisa. Nesse estudo, os focos centrais de investigação são os estilos cognitivos e a influência que eles podem causar no perfil dos alunos de educação a distância, mais precisamente nos cursos de Administração, Computação e Tecnólogo em Gestão Financeira (TGF) de um Centro Universitário do interior do Estado de São Paulo.

\subsection{Problema de Pesquisa}

É neste contexto de educação a distância via internet e estilos cognitivos que surge o problema de pesquisa: “Os estilos cognitivos influenciam o perfil e o desempenho dos alunos de EAD?”.

Este estudo verificará se existe alguma influência dos estilos cognitivos em alunos de cursos a distância via internet, pois, a partir do conhecimeto do perfil destes alunos, diferentes estratégias pedagógicas poderão ser adotadas, tanto no tocante à elaboração de material didático quanto ao relacionamento professor-aluno e aluno-aluno, pois cada um conhecerá seu 
estilo e, a partir disso, poderá explorar mais aquele estilo que lhe é favorável, assim como poderá/deverá estimular e assimilar aqueles que não lhe são muito desenvolvidos.

\subsection{Objetivos}

\subsubsection{Geral}

Avaliar a influência dos estilos cognitivos no perfil dos alunos de cursos da modalidade a distância.

\subsubsection{Específicos}

- Identificar os estilos cognitivos dos alunos em função do curso matriculado.

- Identificar o perfil dos alunos (por meio de variáveis sóciodemográficas e varáveis do Learning Management System (LMS).

- Comparar os estilos cognitivos e o perfil dos alunos dos cursos de Administração, Computação e Tecnólogo em Gestão Financeira (TGF).

\subsection{Justificativa}

Sabe-se que o Ensino a Distância é parte integrante do contexto mundial da Educação, e conhecer o perfil individual e o estilo cognitivo pode facilitar a adequação de estratégias pedagógicas que favoreçam a aprendizagem do maior número possível de estudantes.

Sabe-se, também, da preocupação com a efetividade da aprendizagem; daí a importância de se ter conhecimento das diferentes formas de ensinar e de aprender. Neste sentido, o profissional que considerar os estilos cognitivos de seus alunos terá condições de ajustar formas diferenciadas de apresentar informações de maneira a favorecer a 
aprendizagem. Já o aluno, conhecendo seu estilo cognitivo e seu perfil torna-se também responsável por seu conhecimento, o que pode estimular um comportamento estratégico para a aprendizagem.

\subsection{Hipóteses}

$\mathrm{H}_{1}$ - Os alunos dos diferentes cursos de EAD têm estilos cognitivos diferentes.

$\mathrm{H}_{2}$ - O estilo cognitivo do aluno de EAD é influenciado pelo gênero.

As hipóteses seguintes serão avaliadas separadamente para o curso de Administração, Computação e Tecnólogo em Gestão Financeira. Analisar-se-á influência do estilo cognitivo no perfil do aluno de EAD, sendo perfil aqui representado por média obtida, número de acessos à sala virtual, quantidade de mensagens postadas no portfólio, quantidade de mensagens postadas no fórum, quantidade de mensagens postadas na lista, quantidade de sugestões dadas no fórum, quantidade de perguntas feitas no fórum, quantidade de respostas dadas no fórum, quantidade de questões para discussão proposta no fórum, quantidade de argumentação dada no fórum, quantidade de contra-argumentação dada no fórum e quantidade de mensagens categorizadas como diversas dadas no fórum. Seguem abaixo as hipóteses $\mathrm{H}_{3}$ a $\mathrm{H}_{14}$.

$\mathrm{H}_{3}$ - A média obtida pelo aluno de EAD é influenciada pelo seu estilo cognitivo.

$\mathrm{H}_{4}$ - $\mathrm{O}$ número de acessos à sala virtual do aluno de EAD é influenciado pelo seu estilo cognitivo.

$\mathrm{H}_{5}$ - A quantidade de mensagens postadas no portfólio pelo aluno de EAD é influenciada por seu estilo cognitivo.

$\mathrm{H}_{6}$ - A quantidade de mensagens postadas no fórum pelo aluno de EAD é influenciada pelo seu estilo cognitivo.

$\mathrm{H}_{7}$ - A quantidade de mensagens postadas na lista pelo aluno de EAD é influenciada pelo seu 
estilo cognitivo.

$\mathrm{H}_{8}$ - A quantidade de sugestões manifestadas no fórum pelo aluno de EAD é influenciada por seu estilo cognitivo.

$\mathrm{H}_{9}$ - A quantidade de perguntas feitas no fórum pelo aluno de EAD é influenciada por seu estilo cognitivo.

$\mathrm{H}_{10}$ - A quantidade de respostas dadas no fórum pelo aluno de EAD é influenciada por seu estilo cognitivo.

$\mathrm{H}_{11}$ - A quantidade de questões para discussão propostas no fórum pelo aluno de EAD é influenciada por seu estilo cognitivo.

$\mathrm{H}_{12}$ - A quantidade de argumentações dadas no fórum pelo aluno de EAD é influenciada por seu estilo cognitivo.

$\mathrm{H}_{13}$ - A quantidade de contra-argumentações dadas no fórum pelo aluno de EAD é influenciada por seu estilo cognitivo.

$\mathrm{H}_{14}$ - A quantidade de mensagens categorizadas como diversa dada no fórum pelo aluno de EAD é influenciada por seu estilo cognitivo.

A Figura 1 apresenta a arquitetura das hipóteses.

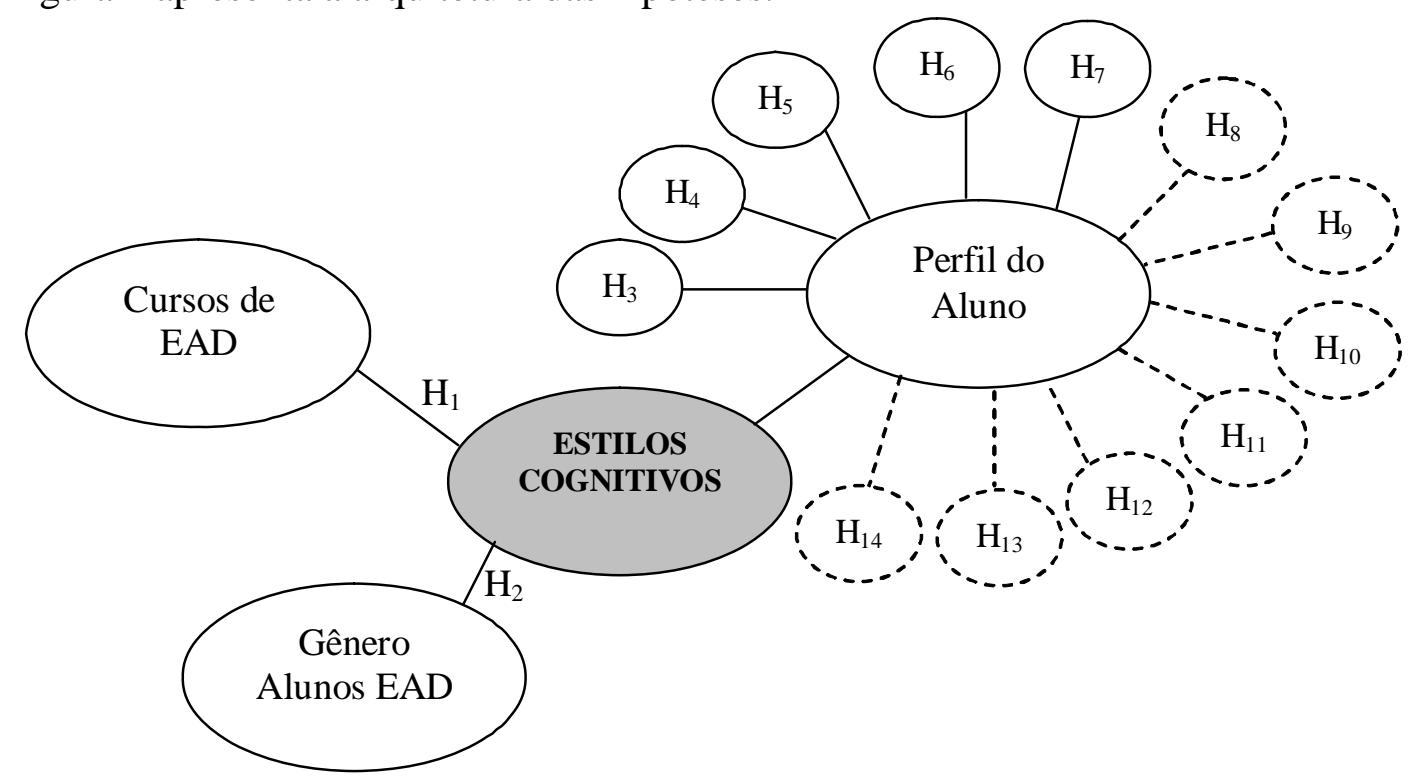

Figura 1 - Arquitetura das hipóteses 


\subsection{Estrutura do Trabalho}

Este trabalho será desenvolvido em cinco capítulos. O primeiro, ou seja, a Introdução, é subdividida em delimitação do tema, problema de pesquisa, justificativa, hipóteses e descrição da estrutura do trabalho, que apresenta uma visão geral do assunto, enfatizando a importância do tema no contexto atual. O segundo e terceiro capítulo são formados pela revisão da literatura, que consiste em uma pesquisa a respeito do que vem sendo pesquisado e publicado no Brasil e no mundo sobre Educação a Distância, Estilos Cognitivos e Estilos de Aprendizagem até o momento; para isso, serão utilizados trabalhos de pesquisadores e de instituições que desenvolvem estudos sobre o tema em questão. O quarto capítulo é formado pelo método de pesquisa que apresenta as etapas do desenvolvimento deste estudo. O quinto capítulo refere-se à apresentação e discussão dos resultados obtidos. O sexto e último capítulo é formado pelas considerações finais da pesquisa e sugestões; apresentam-se as descrições e comentários dos pontos mais representativos no estudo. Encerrando o trabalho, são apresentadas as referências bibliográficas consultadas, anexo e apêndice, referentes ao desenvolvimento da pesquisa. 


\section{EDUCAÇÃO A DISTÂNCIA}

É bastante significativo o crescimento e a diversidade da educação a distância - no número de tipos de indivíduos que aprendem fora das salas de aula tradicionais, na variedade dos que prestam esse serviço e a efetividade das novas tecnologias que servem como ferramentas de ensino. A educação a distância está se tornando cada vez mais global, criando uma enorme quantidade de novas alianças graças à associação de instituições educacionais tradicionais com empresas, governos e organizações internacionais para oferecer e utilizar o ensino a distância.

A educação a distância se aplica em uma grande variedade de ambientes e para uma ampla faixa de objetivos. As universidades a usam para aumentar o número de estudantes que têm acesso à sua educação superior; as empresas, para aprimorar as habilidades de seus trabalhadores e mantê-los a par das tecnologias que avançam rapidamente; os indivíduos, para o seu próprio desenvolvimento profissional e para melhorar as oportunidades de sua carreira; e os governos, para proporcionar treinamento, em ambiente de trabalho, a professores e outros colaboradores, com vistas à melhora da qualidade do ensino fundamental, médio e superior e para levar a instrução a áreas rurais remotas que, de outra maneira, dificilmente seriam atingidas. No entanto, para atingir estes objetivos, várias tecnologias têm sido utilizadas.

Segundo Potashnik e Capper (1998), numerosos estudos foram realizados para avaliar a efetividade da educação a distância, embora se deva ainda pesquisar a capacitação ministrada via Internet, no que diz respeito aos benefícios da comunicação on-line com os estudantes, tendo em vista que foram necessários mais de setenta (70) anos de pesquisa sobre cursos por correspondência impressa para documentarem coerentemente a sua efetividade em comparação com os cursos ministrados em ambientes convencionais de sala de aula. Pesquisas sobre o uso de pacotes de treinamento por computador, dirigido a adultos e 
atingindo uma ampla faixa de ambientes, constatou, de forma consistente, que aqueles que aprendem a distância, por meio de computadores, aprendem tão bem, ou melhor, do que os alunos que aprendem nas salas de aula tradicionais e, em alguns casos, aprendem mais rapidamente e a um custo substancialmente menor do que estes últimos (CAPPER, 1990).

No contexto mundial, especificamente nos Estados Unidos da América, no ano de 2003, 578.000 estudantes estavam engajados em algum curso on-line. Naquela data, já se previa que no ano de 2005, 90\% dos universitários americanos estariam matriculados em algum curso a distância; daí a importância de se investigar a qualidade e a efetividade da aprendizagem (ALLEN e SEAMAN, 2003; CHARP, 2002).

No Brasil, houve também uma significativa expansão no número de cursos ofertados pelas instituições oficialmente autorizadas, conforme se observa no Gráfico 1.

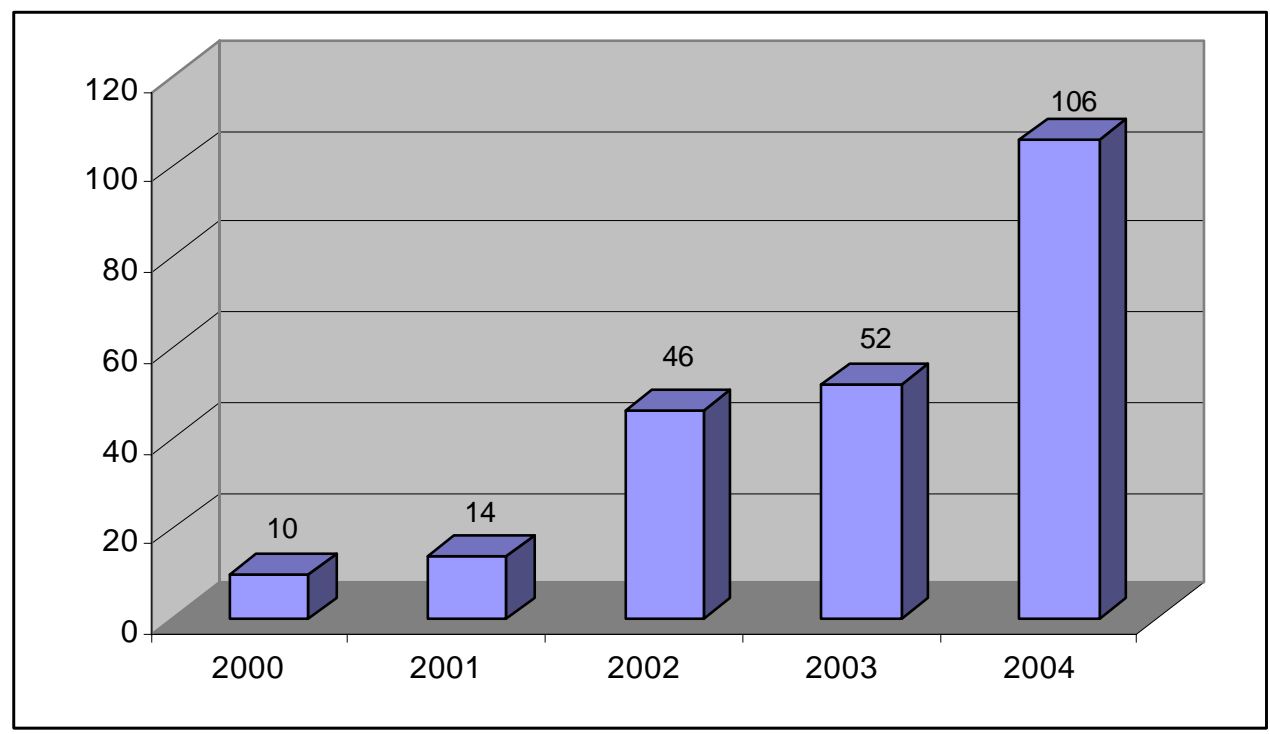

\section{Gráfico 1 - Evolução do Número de Cursos de Graduação no Brasil}

Fonte: ANUÁRIO Brasileiro Estatístico de Educação Aberta e a Distância (2005).

Observa-se também um número expressivo de alunos matriculados em instituições de ensino credenciadas oficialmente para ministrar cursos de Educação a Distância (Quadro 1). Entretanto, pode-se perceber uma distribuição não uniforme, seja em função da enorme área 
geográfica brasileira, seja em função de outros fatores relacionados à políticas públicas. No entanto, cabe ressaltar que a EAD pode ser uma alternativa para suprir a demanda não atendida pelo sistema presencial.

\begin{tabular}{|lcc|}
\hline \multicolumn{1}{|c}{ Região geográfica } & Número de matrículas* & \% Total de matrículas \\
Norte & 10.371 & $5 \%$ \\
Nordeste & 37.967 & $19 \%$ \\
Centro-Oeste & 21.115 & $10,5 \%$ \\
Sudeste & 116.822 & $58 \%$ \\
Sul & 14.930 & $7,5 \%$ \\
& $\mathbf{2 0 1 . 2 0 5}$ & $\mathbf{1 0 0 \%}$ \\
\hline Quadro 1 - Distribuição dos alunos matriculados por localização geográfica da \\
Instituição de Ensino, em 2004
\end{tabular}

* Número referente à amostra pesquisada.

Fonte: ANUÁRIO Brasileiro Estatístico de Educação Aberta e a Distância (2005).

Segundo o Censo Escolar de 2006 (preliminar) disponível no sitio do Instituto Nacional de Estudos e Pesquisas Educacionais Anísio Teixeira (INEP), o Brasil tem dez milhões, seiscentos e cinqüenta e quatro mil cento e quarenta e sete alunos matriculados no Ensino Médio, os quais estão distribuídos entre ensino médio regular, supletivo presencial, supletivo semipresencial.

Com base no gráfico 1, no quadro 1 e nos dados preliminares do Censo 2006, pode-se inferir que existe no Brasil um forte potencial para a EAD.

Percebe-se ainda, pela significativa expansão da EAD, que existe uma demanda reprimida, em que milhares de brasileiros buscam uma formação, principalmente de nível superior, seja para atender aos requisitos de mercado, seja para realização pessoal. No entanto, pode-se deduzir que, em período não muito longo, esta demanda reprimida se diluirá. Nesse momento, caberá às instituições de ensino que ministram cursos na modalidade EAD “buscar seus alunos” e, para consegui-los, as instituições de ensino deverão ter comprovada qualidade. 
De acordo com Vianey (Org.) (2003), consta que a primeira experiência com Educação a Distância surgiu no Brasil em 1904 com o ensino por correspondência, iniciativa de instituições privadas, ofertando iniciação profissional em áreas técnicas, modelo esse consagrado em 1939 pelo Instituto Monitor e pelo Instituto Universal Brasileiro em 1941.

A partir da década de sessenta, em função do regime militar instalado no Brasil, um conjunto de princípios, dos quais o professor deveria valer-se para a elaboração de objetivos de ensino instrucionais, conteúdos de caráter acrítico, metodologia baseada em técnicas de ensino e avaliação quantitativa, instalou-se no Brasil (ARAÚJO, 1991). Esta situação retardou o avanço da EAD.

No entanto, Souza (2005) relata que os materiais e recursos empregados na Educação a Distância, ao longo do tempo, foram sendo cada vez mais aprimorados, desde a utilização de material impresso, como livros, cadernos, módulos e guias que sustentaram as propostas iniciais, à utilização do rádio e da TV nos anos 70, aos áudios e vídeos dos anos 80. No Brasil, nas décadas de 1970 e 1980, houve o início das ofertas de cursos supletivos a distância, com aulas via satélite, acompanhadas por material impresso. Somente na década de 1990, houve a inserção das tecnologias de informação e comunicação (TICs) em projetos de EAD.

Para Peters (2003), a Educação a Distância, entre os anos de 1970 e 1980, teve uma importância como nunca, impulsionada, principalmente, pelo uso de meios de comunicação de massa, eletrônicos e analógicos, inicialmente o rádio e a televisão e, mais tarde, o vídeo e as fitas cassetes. Paralelo a isso, financiamentos governamentais e a criação de universidades autônomas melhoraram a imagem pública da EAD.

Embora o Brasil apresentasse iniciativas em Educação a Distância, ainda, atualmente, encontra-se em significativa desvantagem ao que vem acontecendo no panorama internacional. O assunto somente começou a ser discutido no país com o interesse e a seriedade necessários, de maneira ampla, praticamente a partir de 1995. Antes disto, a 
Educação a Distância era discutida de maneira pontual e era vista no contexto educacional como ensino de segundo plano.

Em 2005, o Ministério da Educação criou o Projeto Universidade Aberta do Brasil (UAB) sob a coordenação da Secretaria de Educação a Distância (SEED), cujo objetivo era criar um sistema nacional de educação superior a distância, em caráter experimental, para sistematizar as ações, programas, projetos, atividades pertencentes às políticas públicas. Buscava ampliar e interiorizar a oferta do ensino superior gratuito e de qualidade no Brasil (MEC, 2006).

O Sistema é uma parceria entre consórcios públicos nos três níveis governamentais (federal, estadual e municipal), e tem a participação das universidades públicas e demais organizações interessadas. A experiência brasileira se inspirou em outras experiências internacionais como a espanhola UNED (Universidad Nacional de Educación a Distancia) e a Open (The Open University, United Kingdom).

Em meio à expansão e consolidação da Educação a Distância, várias são as definições e conceitos sobre a temática.

De acordo com Lei de Diretrizes e Bases da Educação Nacional (BRASIL, 1996):

“Educação a Distância é uma forma de ensino que possibilita a auto-aprendizagem, com a mediação de recursos didáticos sistematicamente organizados, apresentados em diferentes suportes de informação, utilizados isoladamente ou combinados, e veiculados pelos diversos meios de comunicação”.

Para Litto (2006a, b):

“Educação a Distância é um sistema de aprendizagem, no qual o aluno está distante do professor ou da fonte de informação em termos de espaço, ou tempo, ou ambos, durante toda ou a maior 
parte do tempo da realização do curso ou da avaliação do conhecimento, sempre utilizando meios de comunicação convencionais (como material impresso, televisão e rádio) ou tecnologias mais novas, para superar essas barreiras tendo, atrás de si, uma ou mais Instituições de apoio responsáveis por seu planejamento, implementação, controle e avaliação.”

Por sua vez, Moran (2002) ressalta que Educação a Distância é o processo de ensinoaprendizagem, mediado por tecnologias, cujos professores e alunos estão separados espacial e/ou temporalmente. É ensino-aprendizagem cujos professores e alunos não estão normalmente juntos, fisicamente, mas podem estar conectados, interligados por tecnologias, principalmente as telemáticas, como a Internet. Mas também podem ser utilizados o correio, o rádio, a televisão, o vídeo, o CD-Rom, o telefone, o fax e tecnologias semelhantes.

Para Volery e Lord (2000) a Educação a Distância pode ser definida como toda a aproximação de instrução que substitui tempo, espaço e ambiente face-a-face de uma sala de aula tradicional.

Existe uma diversidade de definição e conceitos para a Educação a Distância, mas observa-se que todas dizem a mesma coisa de forma diferente, convergindo sempre para a independência e autonomia do aluno em relação à responsabilidade pela sua aprendizagem, dispondo para isto de fontes de ensino mediadas pela tecnologia, além do respeito ao tempo e espaço de cada um. Corroborando com este ponto de vista, Niskier (1999) afirma que as conceituações diferem apenas em sua forma de expressão, mas todas convergem para a organização sistemática da auto-educação, com a aplicação de meios de comunicação. 


\section{Vantagens e Desvantagens da EAD}

Como era de se esperar, em EAD também existem muitos pontos positivos e negativos, e, para concluir alguma coisa a respeito, é preciso conhecê-los. Para isto, Niskier (1999) lista algumas vantagens:

- Abertura: eliminação ou redução das barreiras de acesso aos cursos ou nível de estudos. Diversificação e ampliação da oferta de cursos. Oportunidade de formação adaptada às exigências atuais, às pessoas que não puderam freqüentar a escola tradicional.

- Flexibilidade: ausência de rigidez quanto aos requisitos de espaço (onde estudar?), assistência às aulas e tempo (quando estudar?) e ritmo (em que velocidade aprender?). Permanência do aluno em seu ambiente profissional, cultural e familiar. Formação fora do contexto da sala de aula.

- Eficácia: o aluno, centro do processo de aprendizagem é sujeito ativo de sua formação, vê respeitado o seu ritmo de aprender. Formação teórico-prática, relacionada à experiência do aluno, em contato imediato com a atividade profissional, que se deseja melhorar.

- Formação permanente e pessoal: Atendimento às demandas e às aspirações dos diversos grupos, por intermédio de atividades formativas ou não. Aluno ativo: desenvolvimento da iniciativa, de atitudes, interesses, valores e hábitos educativos.

- Economia: redução de custos em relação aos dos sistemas presenciais de ensino, ao eliminar pequenos grupos, ao evitar gastos de locomoção de alunos, ao evitar o abandono do local de trabalho para o tempo extra de formação, ao permitir a economia em escala.

Complementando a relação de vantagens da EAD, esta pesquisadora acrescenta o fato da EAD permitir atendimento a um público muito maior e mais variado que os cursos tradicionais. Público esse que não teria como estudar, voltar a estudar ou continuar a estudar 
sem a EAD. Entretanto, ressalta a importância de um curso bem planejado e com acompanhamento adequado aos alunos com vista à qualidade e efetividade da aprendizagem.

E dentre as desvantagens, Niskier (1999) destaca:

- Limitação em alcançar o objetivo da socialização, pelas escassas ocasiões para interação dos alunos com o docente e entre si.

- Empobrecimento da troca direta de experiências proporcionada pela relação educativa pessoal entre professor e aluno.

- A retroalimentação ou feedback e a retificação de possíveis erros podem ser mais lentos, embora os novos meios tecnológicos reduzam estes inconvenientes.

- Todos aprendem o mesmo, por um só pacote instrucional, conjugado a poucas ocasiões de diálogo aluno/docente; no entanto, isso pode ser evitado e superado com a elaboração de materiais que proporcionem a espontaneidade, a criatividade e a expressão das idéias do aluno.

- Para determinados cursos, há necessidade de o aluno possuir elevado nível de compreensão de textos e saber utilizar os recursos da multimídia, ainda que se afirme ser possível alfabetizar à distância, por rádio.

- Os resultados da avaliação à distância são menos confiáveis do que os da Educação Presencial, considerando-se as oportunidades de plágio ou fraude, embora estes fatos também possam ocorrer na modalidade presencial.

- A ambição de pretender alcançar muitos alunos provoca numerosos abandonos, deserções ou fracassos, por falta de um bom acompanhamento do processo, embora deva ser feita a devida distinção entre "abandono real" e "abandono sem começar", o daqueles alunos que não fazem sequer uma primeira avaliação.

Amaral (2004) afirma que não há, "operacionalmente", empecilhos para ensinar a distância. "A dificuldade geral, hoje, é manter o mesmo nível de qualidade presente no ensino 
tradicional, uma vez que, em termos gerais, é tudo muito novo, e fica difícil estabelecer parâmetros para comparar". Assim, um "problema" que não pode ser visto propriamente como desvantagem, é o alto custo da produção de material teórico, uma vez que "adaptação do conteúdo didático para novas mídias é muito caro, requer linguagem específica e recursos visuais. Tudo isso é feito por pessoas especializadas que trabalham em parceria com os professores. Mais uma vez, a mão-de-obra é mais cara. Além disso, hoje é imprescindível o uso do computador".

Fiscina (2003) apresenta um quadro-resumo (Quadro 2) das vantagens e desvantagens da EAD com base em trabalhos de Gutierrez e Prieto (1991) e Aretio (1995):

\begin{tabular}{|c|c|}
\hline & \\
\hline $\begin{array}{l}\text { - } \text { O público é diversificado; } \\
\text { - A individualização da aprendizagem; } \\
\text { - } \text { Menor custo fixo por usuário; } \\
\text { - Aumento do público; } \\
\text { - A autodisciplina de estudo; } \\
\text { - A eliminação ou redução das barreiras de } \\
\text { acesso aos cursos ou nível de estudo; } \\
\text { - A diversificação e ampliação da oferta de } \\
\text { cursos; } \\
\text { - A oportunidade de formação adaptada às } \\
\text { exigências atuais, as pessoas que não } \\
\text { puderam freqüentar a escola tradicional; } \\
\text { A flexibilidade existente na ausência de } \\
\text { rigidez quanto aos requisitos de onde } \\
\text { estudar, quando estudar e em que ritmo } \\
\text { estudar; } \\
\text { A eficaz possibilidade de combinação de } \\
\text { estudo e trabalho; }\end{array}$ & $\begin{array}{l}\text { - A industrialização do ensino; } \\
\text { - Institucionalização do ensino; } \\
\text { - } \text { O fortalecimento do ensino consumista; } \\
\text { - A massificação do ensino; } \\
\text { - Limitação em alcançar o objetivo da } \\
\text { socialização, pelas escassas ocasiões para } \\
\text { interação dos alunos com o docente e } \\
\text { entre si; } \\
\text { - Limitação em alcançar os objetivos da } \\
\text { área afetiva/atitudinal, assim como os } \\
\text { objetivos da área psicomotora, a não ser } \\
\text { por intermédio de momentos presenciais } \\
\text { previamente estabelecidos para o } \\
\text { desenvolvimento supervisionado de } \\
\text { habilidades manipulativas; } \\
\text { - Empobrecimento da troca direta de } \\
\text { experiências; } \\
\text { A retroalimentação ou feedback e a } \\
\text { retificação de possíveis erros podem ser } \\
\text { mais lentos; }\end{array}$ \\
\hline
\end{tabular}


- A permanência do aluno em seu ambiente profissional, cultural ou familiar;

- A eficácia de ter o aluno no centro do processo de aprendizagem e sujeito ativo de sua formação, vendo e respeitando o seu ritmo de aprendizado;

- A formação teórico-prática relacionada à experiência do aluno, em contato imediato com a atividade profissional que se deseja melhorar;

- Conteúdos instrucionais elaborados por especialistas e a utilização de recursos multimídia;

- Comunicação freqüente, garantindo uma aprendizagem dinâmica e inovadora;

- Formação permanente e pessoal atendendo às demandas e às aspirações dos diversos grupos, por intermédio de atividades formativas ou não;

- A presença do aluno ativo contribuindo para o desenvolvimento da iniciativa, de atitudes, interesses, valores e hábitos educativos;

- Redução de alguns custos em relação aos dos sistemas presenciais de ensino, ao eliminar pequenos grupos, ao evitar gastos de locomoção de alunos, ao evitar o abandono do local de trabalho para o tempo extra de formação, ao permitir a economia de escala.
- Necessidade

de

um

rigoroso planejamento em longo prazo;

- Perigo da homogeneidade dos materiais instrucionais, nos quais todos aprendem o mesmo, por um só pacote instrucional, conjugado a poucas ocasiões de diálogo aluno/docente;

- Para determinados cursos, há necessidade de o aluno possuir elevado nível de compreensão de textos e saber utilizar os recursos multimídia;

- Excetuando-se as atividades presenciais de avaliação, os resultados de avaliação a distância são menos confiáveis do que os da Educação Presencial, considerando-se as oportunidades de plágio e fraude, embora estes fatos também possam ocorrer na modalidade presencial;

- Os numerosos abandonos, deserções ou fracassos, por falta de um bom acompanhamento do processo, embora deva ser feita a devida distinção entre o abandono real e abandono sem começar, o daqueles alunos que não fazem sequer uma primeira avaliação;

- Os custos iniciais altos para a implantação de cursos a distância, que diluem ao longo de sua aplicação.

\section{Quadro 2 - Vantagens e Desvantagens em EAD}

Fonte: FISCINA, 2003. 
Ao analisar a colocação de Fiscina a respeito de que "para determinados cursos, há necessidade de o aluno possuir elevado nível de compreensão de textos e saber utilizar os recursos multimídia”, Riding e Rayner (1998) ressaltam que existem diferentes modos de apresentação da informação, sejam eles verbais, visuais, auditivos...., havendo diferentes estilos que têm preferências por tipos particulares de apresentação. Ao atender esta necessidade, muito provavelmente o aluno encontrará uma mídia particular que considere mais fácil para aprender do que aqueles que não tiveram suas necessidades respeitadas e/ou atendidas.

Volery e Lord (2000), em seu estudo sobre os fatores críticos de sucesso da educação a distância, identificaram seis (6) fatores-chave para a efetividade da EAD:

1. Facilidade no acesso e navegação: ressalta a importância de proporcionar facilidade de acesso ao site e ao ambiente de aprendizagem, para que o aluno não se sinta frustrado em suas tentativas de navegação.

2. Interface: ressalta que a estrutura visual, o design do curso, além das dimensões ergonômicas é de suma importância, uma vez que o aluno passa horas no website.

3. Interação: comenta sobre a necessidade de existência de interação entre aluno e o professor, de forma que não sejam apenas depositados os materiais do curso, mas que haja interação entre as partes.

4. Atitudes para os estudantes: mostra que a abordagem pessoal do instrutor, a maneira de ensinar e motivar os alunos são importantes, ou seja, é fundamental que o instrutor demonstre empatia pelos alunos no espaço virtual.

5. Competência técnica do instrutor: comenta sobre a importância da habilidade do instrutor para usar e promover a efetividade da Internet, encorajando os alunos ao uso da tecnologia. Sugere também que o professor não seja somente um repositório de conhecimento, mas que estimule a "navegação" do conhecimento pela Internet. 
6. Interação da Sala de Aula: relata sobre a habilidade do professor de incentivar os estudantes a participar e interagir na sala de aula virtual.

Analisando o fator interação, percebe-se que isso facilita e desperta a sociabilidade entre os alunos de EAD.

Considerando estes fatores-chave para a efetividade da EAD, nota-se que a Internet é uma poderosa ferramenta, com um forte potencial para a comunicação, colaboração e cooperação, podendo facilitar a aprendizagem. 
Quanto a estilos cognitivos e estilos de aprendizagem, optou-se por abordá-los separadamente, uma vez que alguns autores os consideram como termos intercambiáveis, e outros os identificam com o próprio conceito de inteligência. Desta forma, percebe-se a importância de estudos e pesquisas que se propõem a compreender mais amplamente as formas de estratégias cognitivas que os indivíduos utilizam na codificação da informação (estilos cognitivos), como também a predisposição ou forma que o sujeito adota na abordagem de tarefas de aprendizagem (estilos de aprendizagem).

\subsection{Estilos de Aprendizagem}

Sabe-se que identificar os estilos de aprendizagem dos estudantes é importante e interessante, uma vez que pode explicar o porquê de certas estratégias de aprendizagem funcionarem bem e outras não funcionarem.

Felder (2006) chama de estilos de aprendizagem uma preferência característica e dominante na forma como as pessoas recebem e processam informações, considerando os estilos como habilidades passíveis de serem desenvolvidas. Afirma que alguns aprendizes tendem a focalizar mais fatos, dados e algoritmos, enquanto outros se sentem mais confortáveis com teorias e modelos matemáticos. Alguns também podem responder preferencialmente a informações visuais, como figuras, diagramas e esquemas, enquanto outros conseguem mais a partir de informações verbais - explanações orais ou escritas. Uns preferem aprender ativa e interativamente, outros já têm uma abordagem mais introspectiva e individual. 
Embora existam várias outras concepções sobre estilos de aprendizagem com indícios de pressupostos comuns, estes pressupostos têm fomentado discussões específicas. Neste sentido, Pennings e Span (1991), relatam que tais pressupostos são: (1) os seres humanos procuram adaptar-se aos seus ambientes, tentando alcançar um ajustamento ótimo com o meio e, para isso, os sujeitos processam a informação ambiental que, por sua vez, conduz à aquisição de estruturas de conhecimento utilizadas para regular seu comportamento; (2) as capacidades incluem: a motricidade, a atenção, a percepção, a aprendizagem, a memória, o pensamento e a resolução de problemas; isto se aplica a todas as situações relacionadas a estas funções; (3) os seres humanos manifestam-se como únicos no uso destas capacidades, e sua individualidade poderá ser caracterizada por padrões típicos de adaptação, denominados “estilos”, apesar destes não serem observados diretamente; (4) o desenvolvimento dos estilos resulta de repetidas utilizações de estratégias em diferentes tarefas, com exigência e condições adaptativas similares; (5) as pessoas são mais eficientes nas situações diárias que evocam suas capacidades adaptáveis e menos eficientes naquelas que revelam suas fraquezas; (6) uma adaptação a longo prazo é otimizada se aparece complementada por uma modificação do estilo não dominante.

Para Dunn e Dunn (1987), estilos de aprendizagem referem-se a um conjunto de condições por meio das quais os indivíduos começam a concentrar-se, absorver, processar e reter informações e habilidades novas ou difíceis. Ou seja, é a forma como os indivíduos respondem a estímulos ambientais, emocionais, sociais e físicos, condições estas que afetam a aprendizagem.

Neste sentido, quando um estudante prefere trabalhar sozinho em vez de participar de um grupo, ou ainda, prefere concluir um projeto antes de iniciar outro em vez de trabalhar em vários projetos paralelos, não é apenas uma curiosidade interessante - é uma informação 
valiosa que o professor pode usar no aprimoramento da eficácia da aprendizagem (KURI, 2004).

Para Pacheco (2001), treinar professores em novos estilos de apresentação da matéria sem treinar os alunos nos correspondentes estilos de aprendizagem pode significar grande avanço em técnicas pedagógicas sem melhoria real na qualidade do ensino. Ainda, sabe-se que as pessoas aprendem de formas diferenciadas conforme estilo próprio e são influenciadas pelo meio, pela experiência, pela motivação para o assunto, entre outras.

Neste contexto, Oliveira e Chadwick (2001) ressaltam a importância da estrutura da estratégia de aprendizagem, uma vez que os métodos a que o educador dá preferência determinarão, em grande parte, como seus alunos armazenam, estruturam no cérebro e recuperam a informação aprendida. O ponto mais importante a ser considerado, quando se trata de estrutura de uma aula, é que os estímulos e métodos adotados devem orientar-se pelas formas de aprendizagem mais adequadas aos alunos, de forma a maximizar os resultados.

Com isso, verifica-se que a estratégia de aprendizagem adotada pelo professor deve estar em harmonia com a estratégia do aluno, uma vez que cada um tem uma maneira de organizar suas idéias para processar a informação, combinando seu raciocínio de forma a gerar conhecimento.

Lombardi (2006) defende que uma das maiores diferenças entre os estudantes eficientes e os não eficientes é a sua compreensão e o uso de boas estratégias de aprendizagem. Kuri (2004) corrobora, relatando que, à medida que o professor toma consciência de que cada estudante tem sua própria maneira de aprender e de se relacionar, passa a promover um ensino orientado, utilizando para isso estratégias que promovam um aprendizado mais eficaz e duradouro.

A importância de estudos acerca da cognição ultrapassa seu próprio conhecimento, favorecendo também o desenvolvimento de ferramentas que venham melhor aproveitar o 
potencial de processamento de informações pelo cérebro. Neste sentido, observa-se que os modelos de estilos de aprendizagem têm sido amplamente utilizados com o objetivo de prever e comprovar o aprimoramento das estratégias de aprendizagem.

O professor que conhece o estilo de aprendizagem dos alunos, assim como seu próprio estilo, tem condições de adotar estratégias de trabalho diferenciadas e mais individualizadas, pois esta atitude dará, à sua prática educativa, mais significado e um elemento motivador para os alunos.

Existe, na literatura, uma vasta gama de modelos e instrumentos de estilos de aprendizagem. Assim Coffield et al. (2004) apresentam uma relação dos principais modelos e instrumentos de estilos de aprendizagem, focando sempre para a validade, confiabilidade e aplicação:

- Allinson and Hayes' Cognitive Style Index (CSI): apresenta uma única dimensão bipolar para análise da intuição, que os autores afirmam servir de base para outros aspectos do estilo de aprendizagem.

- Apter’s Motivational Style Profile (MSP): dispõe de uma estrutura para entendimento do comportamento humano de forma flexível em termos de “tipos” de personalidade. Apresenta quatro domínios da experiência em que há uma interação entre a emoção, a cognição e a vontade, em que a teoria da reversão constrói uma ponte entre a biologia e a experiência vivida.

- Dunn and Dunn's model and instruments of learning styles: inclui fatores motivacionais, interações sociais e elementos psicológicos e ambientais. Apresenta preferências elevadas ou baixas para 22 diferentes fatores que são identificados por estudantes. As preferências fortes dão base para que os professores adotem técnicas específicas ou façam mudanças ambientais.

- Entwistle's Approaches and Study Skills Inventory for Students (ASSIST): tem como 
objetivo dispor de abordagens para aprendizagem, estratégias de estudo, desenvolvimento das habilidades intelectuais e atitudes na educação superior. Avalia as orientações de ensino/aprendizagem, abordagens para estudo e preferências para organização e instruções de cursos.

- Gregorc's Mind Styles Model and Style Delineator (GSD): possui duas dimensões: concreto-abstrato e seqüencial-aleatório; os indivíduos tendem a ser mais fortes em uma ou duas das quatro categorias: concreto-seqüencial, concreto-aleatório, abstrato-seqüencial e abstrato-aleatório.

- Herrmann's Brain Dominance Instrument (HBDI): embora originalmente baseado na inteligência, incorpora crescimento e desenvolvimento, especialmente da criatividade. Os estilos de aprendizagem não são fixados em traços de personalidade, mas em padrões de comportamento.

- Honey and Mumford's Learning Styles Questionnaire (LSQ): examina as atitudes e comportamentos que determinam as preferências acerca da aprendizagem. É utilizado para desenvolvimento pessoal e organizacional e não avalia/seleciona, não é um instrumento psicométrico, mas um check-list de como as pessoas aprendem.

- Jackson's Learning Styles Profiler (LSP): é um instrumento sofisticado em termos de base teórica e formato computadorizado, planejado para uso em empresas e na educação. Descreve quatro estilos: iniciador, analista, racional e implementador.

- Kolb’s Learning Style Inventory (LSI): os estilos de aprendizagem não são fixados por traços de personalidade, mas por padrões estáveis de comportamento. Baseia-se na teoria da aprendizagem experencial que incorpora crescimento e desenvolvimento.

- Myers-Briggs Type Indicator (MBTI): fornece uma visão geral da personalidade, incluindo aprendizagem. Baseia-se nas quatro escalas bipolares da teoria de Jung que produzem dezesseis tipos de personalidade. 
- Riding's Cognitive Styles Analysis (CSA): aborda que as estratégias de aprendizagem podem ser aprendidas e melhoradas. Possui duas dimensões que são independentes da inteligência: holistic-analytic (estilo com que organiza a informação) e verbaliser-imager (estilo com que a informação é representada).

- Sternberg's Thinking Styles Inventory (TSI): apresenta treze estilos de pensamentos, baseados em funções, formas, níveis, escopo e aprendizagem de comandos. Fundamentase na nova teoria do "auto-comando" mental.

- Vermunt's Inventory of Learning Styles (ILS): procura integrar processos cognitivos, afetivos e metacognitivos. Inclui estratégias de aprendizagem, motivação para a aprendizagem e preferências por organizar a informação.

Contudo, usar qualquer um dos modelos e/ou instrumentos para identificar o estilo de aprendizagem do aluno não resolverá todos os problemas, principalmente da Educação a Distância, mas, certamente, ajudará a melhorar a aprendizagem à medida que o professor propuser não só atividades que vão ao encontro do estilo de aprendizagem preferencial do aluno, como também propuser estratégias que desafiem e estimulem os estilos menos desenvolvidos dos mesmos.

\subsection{Estilos Cognitivos}

Estilo cognitivo é um componente da diferenciação psicológica que determina as respostas individuais em numerosas situações. Representa uma dimensão das diferenças individuais e inclui atitudes estáveis, escolhas e estratégias habituais relacionadas a um estilo individualizado de perceber, relembrar, pensar e resolver problemas (SARACHO, 1998).

Para Ausubel e Sullivan (1970), o estilo cognitivo diz respeito às diferenças individuais autoconsistentes na organização cognitiva, como reflexo da organização da 
personalidade. As variáveis do estilo cognitivo indicam o modo de organização e funcionamento cognitivo como os mecanismos de armazenamento e processamento de informações que caracterizam os seres humanos.

Nesta mesma linha de raciocínio Goldstein e Blackman (1978) argumentam que estilo cognitivo é um construto hipotético que tem sido desenvolvido para explicar o processo de mediação entre estímulos e respostas. O termo estilo cognitivo se refere às características preferenciais com que o indivíduo se organiza no ambiente.

Messick (1976) define estilo cognitivo em termos de padrões consistentes para “organizar e processar a informação”, ou seja, está relacionado com a maneira ou a forma consistente das atitudes estáveis, preferências ou estratégias habituais, modo típico de perceber, recordar, pensar e resolver problemas, independentemente do conteúdo da cognição ou do grau de habilidade de um indivíduo.

O termo estilo cognitivo também é usado para denotar consistência nos modos de funcionamento de uma variedade de situações comportamentais (Coop; Sigel ${ }^{1}$, 1971 apud GOLDSTEIN; BLACKMAN, 1978).

Para Fierro (1996), estilos cognitivos são padrões diferenciais e individuais de reação diante da estimulação recebida, de processamento cognitivo da informação e, em definitivo, de aprendizagem e de enfrentamento cognitivo da realidade.

A cognição está relacionada à forma como as pessoas adquirem, armazenam e usam conhecimento (HAYES; ALLINSON, 1994). Segundo os autores, por volta de meados da década de 1950, os pesquisadores começaram a se interessar por diferenças no processamento de informações (estilo cognitivo) em oposição a estudos de habilidade cognitiva (nível cognitivo). Enquanto diferentes níveis de habilidades cognitivas podem levar a diferentes

\footnotetext{
${ }^{1}$ GOLDSTEIN, K.; BLACKMAN, S. (1978). Cognitive style: five approaches and relevant research. New York: John Wiley.
} 
níveis de desempenho, estilos não têm relação com eficácia ou eficiência e podem ser julgados mais ou menos adequados a determinadas situações.

Segundo Riding e Cheema (1991), o termo “estilo cognitivo” foi cunhado por Allport (1937), designando abordagens individuais para resolver problemas, receber e recuperar informações memorizadas. No entanto, de acordo com Peters (2003), o estilo cognitivo enquanto construto, foi empregado nos anos 40, com a função de designar a forma como o indivíduo se organiza para lidar com seus valores e necessidades individuais.

Embora existam algumas contradições sobre o tema, uma forma de estudar as diferenças individuais e sua influência na aprendizagem é mediante os estilos cognitivos, os quais dão suporte ao estudo das diferentes formas de representações mentais, ou seja, devem servir para acessar, de maneira mais sistematizada, as formas pelas quais se apreende o conhecimento.

Estilo cognitivo tem sido definido como diferenças individuais estáveis na preferência por modos de obter, de organizar e utilizar a informação na tomada de decisões (KIRTON, 1976).

No entanto, Messick (1984) relata que o estilo se refere às diferenças individuais consistentes nas propriedades da estrutura cognitiva, assim como o grau de diferenciação conceitual, de discriminação ou argumentação, ou a integração hierárquica das unidades cognitivas.

Neste sentido, Bariani (1998), citando o mesmo autor, e considerando a variedade de caracterização de estilo cognitivo, propõe três alternativas para as diferentes conceituações conforme abaixo.

A primeira alternativa descreve a propriedade estrutural do próprio sistema cognitivo, ou seja, refere-se às diferenças individuais consistentes em propriedades da estrutura cognitiva, tais como grau de diferenciação conceitual, de discriminação ou de articulação, ou 
da integração hierárquica das unidades cognitivas. A segunda entende os estilos cognitivos como modos característicos autoconsistentes de percepção, recordação, pensamento e solução de problema. Já a terceira alternativa relata que os estilos cognitivos são definidos como preferências cognitivas, referindo-se aos modos característicos como as pessoas preferem conceituar e organizar os estímulos do mundo.

De acordo com Bariani (1998), de um modo ou de outro, todas as concepções alternativas implicam que estilos cognitivos são diferenças individuais consistentes nos modos de organizar e processar informações e experiências.

Estilos cognitivos são compreendidos como formas relativamente estáveis referentes às características da estrutura cognitiva de uma pessoa, que são definidas, em parte, por fatores biológicos, sendo influenciadas pela cultura, ou seja, são modificadas a partir da influência direta ou indireta de novos eventos (BARIANI, 1998).

Percebe-se que o estilo cognitivo está relacionado ao modo de percepção dos dados e a formulação de conhecimento a partir dos dados assimilados. Assim, identificando o estilo cognitivo do aluno é possível verificar suas preferências para elaboração de estratégias de aprendizagem mais eficazes.

Neste contexto, Bariani (1998) corrobora, relatando que, apesar dos estudos sobre estilos cognitivos se dedicarem a diversos aspectos, o foco principal das discussões recai sobre o favorecimento ou não do processo ensino-aprendizagem, quando ocorre adaptação ou não aos estilos dos estudantes.

Diante das expectativas de que os estilos cognitivos são educacionalmente importantes, Messick (1984) apresenta seis contribuições potenciais dos estilos para a educação, tais como:

1. Melhoria nos métodos instrucionais.

2. Aprimoramento das concepções e comportamento dos professores. 
3. Aumento da aprendizagem e estratégias de pensamento do estudante.

4. Expansão da orientação e tomada de decisão vocacional.

5. Ampliação dos objetivos e resultados educacionais.

6. Refinamento das demandas relativas aos estilos ambientes de aprendizagem.

Embora tais benefícios sejam bastante desejados, na prática são bastante limitados e, segundo o mesmo autor, as principais causas são: (1) dificuldade de implementação - em função da necessidade de pesquisas para medição, desenvolvimento e aplicação dos estilos de aprendizagem, as quais são complexas, difíceis e consomem muito tempo; (2) incompatibilidade dos métodos instrucionais com as características dos alunos ou dos estilos dos professores, ou a tecnologia utilizada (...) ou mesmo a combinação de diferentes fatores.

Considerando a existência de um número significativo de dimensões de estilos cognitivos, Shirahige (1999) apresenta um glossário de vinte (20) dimensões (Quadro 3); em seguida, Bariani (1998) destaca as quatro dimensões que julga mais importante e, posteriormente, apresenta-se Riding e Cheema (1991) que trabalham com duas dimensões em seu instrumento, Cognitive Style Analysis (CSA).

\begin{tabular}{|c|c|}
\hline Dimensão & Descrição \\
\hline $\begin{array}{c}\text { Nivelamento e } \\
\text { aguçamento }\end{array}$ & $\begin{array}{l}\text { Refere-se à variação individual na assimilação da memória. As } \\
\text { pessoas que apresentam o nivelamento extremo, ao recordar suas } \\
\text { experiências prévias, tendem a reunir objetos ou eventos } \\
\text { percebidos como semelhantes não idênticos, perdendo ou } \\
\text { atenuando suas particularidades. Os aguçados, por outro lado, } \\
\text { são menos propensos a confundir objetos semelhantes, podendo } \\
\text { até aumentar pequenas diferenças, além de exacerbar a } \\
\text { diferenciação entre as experiências passadas com as presentes. }\end{array}$ \\
\hline $\begin{array}{c}\text { Estilos de } \\
\text { conceituação }\end{array}$ & $\begin{array}{l}\text { Referem-se às consistências individuais no uso de propriedades } \\
\text { particulares de estímulo, que se relacionam e servem de base } \\
\text { para a formação de conceitos. Denomina-se conceituação } \\
\text { relacional quando há utilização habitual da temática ou } \\
\text { estabelecimento de relações funcionais entre os estímulos, } \\
\text { conceituação analítico-descritiva, quando analisa os atributos } \\
\text { descritivos ou, ainda, conceituação categorial-inferencial, em } \\
\text { caso de inferência de membros da classe. Do ponto de vista do } \\
\text { envolvimento, essas três bases formais aparecem ordenadas: as }\end{array}$ \\
\hline
\end{tabular}


crianças mais novas utilizam, caracteristicamente, conceituação relacional; a analítico-descritiva é característica de crianças, enquanto que a categorial-inferencial é mais típica de adultos.

Extensão de categorização ou classificação de equivalências

\section{Diferenciação} conceitual

Compartimentalização

Articulação conceitual ou discriminação conceitual

Integração conceitual ou complexidade integrativa

\section{Complexidade} cognitiva e simplicidade ou abstrato e concreto
É a consistência na preferência para a ampla abrangência, em oposição à restrita exclusividade na classificação de categorias específicas. Essas distintas preferências são reflexos de diferentes níveis de tolerância, para os diferentes tipos de erros, em que os categorizadores amplos toleram os erros de inclusão enquanto os restritos toleram os de exclusão, ou seja, os desvios.

Diz respeito às diferenças individuais na tendência para categorizar semelhanças e diferenças entre os estímulos em termos de conceitos ou dimensões diferenciais. É solicitado ao sujeito que classifique, espontaneamente, diferentes estímulos tais como objetos, pessoas, comportamentos, etc., dentro de um número não restrito de itens, mais ou menos relacionados.

É a tendência consistente para isolar idéias e objetos dentro de categorias discretas e relativamente rígidas, o que ocasiona uma certa inércia no pensamento e a limitação na produção de idéias diversificadas.

Diz respeito às diferenças individuais no trato de estímulos ou itens de informações, em termos dimensionais em lugar de categorias. Trata-se da extensão em que os exemplos de um conceito são discriminados individualmente, num número de intervalos ou categorias ordenadas dentro de uma referência de conceitos, estando relacionada, assim, com a "extensão das categorias”.

Refere-se à consistência do indivíduo em perceber as categorias ou as dimensões da informação, como inter-relacionadas de maneiras múltiplas e diferentes. O alto nível de integração envolve o estabelecimento de várias combinações de interrelações, as quais podem ser, posteriormente, comparadas, sintetizadas e relacionadas hierarquicamente. Além disso, esse estabelecimento poderia gerar uma perspectiva alternativa sobre um determinado domínio.

São as diferenças individuais na forma de interpretação do mundo, particularmente do mundo social, de maneira multidimensional e discriminativa. Dizem que o sistema conceitual de um indivíduo é complexo altamente diferenciado, consistindo de um grande número de dimensões ou de conceitos distintos, ou é altamente articulado quando discrimina magnitude de estímulos variados e flexivelmente integrados, estando as dimensões inter-relacionadas de uma forma múltipla e permitindo a formação de perspectivas ou esquemas de 
organização alternativas. A distinção entre a complexidade e a simplicidade cognitiva requer combinação de critérios de dimensão, articulação e hierarquia de integração. Os indivíduos que apresentam complexidade cognitiva, por estarem mais afinados com a diversidade, conflito e inconsistência, são mais eficientes no trato com as informações dissonantes. Já as pessoas que apresentam simplicidade cognitiva, por serem mais afetadas pelas consistências e regularidades do meio ambiente, mostramse mais seguras e discriminam melhor as informações consonantes.

Exame cuidadoso

Refere-se às diferenças individuais na intensidade e extensão da atenção, que levam às variações individuais na vivência da experiência e no momento da consciência. Esta dimensão está associada com meticulosidade, com atenção a detalhes e com forma ampla de atenção incidental. Um exame meticuloso extremo está relacionado ao mecanismo de defesa, tanto de projeção ou de isolamento, servindo a diferentes propósitos sob circunstâncias diversas. O mecanismo de defesa preferido dos obsessivos é o que está associado com o isolamento, ocorrendo o “exame meticuloso” na procura de informações, as mais exatas possíveis, a fim de confirmar suas dúvidas e incertezas. A associação com a projeção é o mecanismo de defesa preferido dos paranóicos, que o utilizam para detectar sinais de perigo e para confirmar suas suspeitas e desconfianças. $\mathrm{O}$ exame atento pode ocorrer, no primeiro caso, dentro de um foco amplo e, no último, de um foco limitado.

Ponderação e impulsividade

Diz respeito às consistências individuais quanto à rapidez e adequação no processo de formulação de hipóteses e de informações. Os indivíduos impulsivos tendem a fornecer a primeira resposta que ocorre, mesmo sendo a incorreta, enquanto os indivíduos ponderados pesam várias possibilidades antes da decisão. Assim, esta dimensão está concernente com o grau em que um indivíduo pondera a validade de suas hipóteses para a solução de problemas, cujas respostas apresentam dúvidas.

Correr risco e ser

Diz respeito às diferenças individuais consistentes na escolha ponderado espontânea de oportunidades, para consecução de seus desejos e objetivos, em contraposição à postura de certezas, para evitar expor-se às situações de risco. Os indivíduos que se arriscam, diferentemente dos cautelosos, estão conjeturando sobre itens difíceis de múltipla escolha, especulando ou apostando, expressando confiança em seu próprio julgamento, além de autoavaliarem em termos extremos. Preferem alternativas de baixa probabilidade, mas de alto retorno, às de alta probabilidade, porém de baixo retorno. Essas tendências gerais não se apresentam uniformemente devido à interferência da ansiedade e da defesa. As pessoas altamente ansiosas e defensivas são mais 
propensas a correr riscos generalizados ou a precaver-se, enquanto as pouco ansiosas e defensivas estão mais centradas nas estratégias da tarefa e apresentam consistência em sua atitude de cautela e de arriscar-se em tarefas semelhantes e não em diferentes.

Tolerância às experiências não realísticas

Controle rígido e flexível

Automatização forte e
fraca

Refere-se à dimensão quanto ao grau de aceitação das percepções e idéias, variáveis provenientes da experiência convencional. O indivíduo tolerante apresenta predisposição para aceitar e relatar eventos ou idéias que são marcadamente diferentes do convencional, enquanto o intolerante permanece estritamente orientado para a realidade e prefere idéias convencionais. Em situações experimentais, os tolerantes, diferentemente dos companheiros, apresentam uma gama ampla de movimentos quando expostos à luz, são mais rápidos para reverter as figuras invertidas, estabelecem associações mais longas e em maior número nos testes de associação de palavras.

São as diferenças individuais quanto à suscetibilidade para discussão e interferência cognitiva, ou seja, a extensão com que um indivíduo restringe sua atenção aos aspectos relevantes, inibindo respostas competitivas aprendidas em situação de resolução de problemas.

Refere-se à habilidade relativa do indivíduo para desempenhar tarefas repetitivas simples, comparando-se com o que é esperado dele de acordo com seu nível geral de habilidade. Esta dimensão difere da anterior (controle rígido e flexível) por apresentar caráter intra-individual e não normativo, representando uma dimensão da organização da personalidade. Na realização de tarefas simples de automatização, tem sido encontrada uma facilidade relativa em oposição às tarefas de dificuldades relativas, como na de análise perceptual e de encaixe, gerando uma bipolaridade intra-individual entre automatização e reestruturação. A tarefa simples e repetitiva requer uma resposta automática às propriedades evidentes dos estímulos, diferentemente da situação em que esses atributos em foco precisam ser deixados de lado ou reestruturados para se chegar a uma solução. A tendência automática em responder torna-se não funcional, nesta situação. As investigações mostram que as pessoas com nível de automatização forte têm tido grau mais alto de ocupação do que os de automatização fraca.

Dominância conceitual e perceptomotora
Trata-se do aspecto intra-individual diante de tarefas novas e difíceis. Nessas situações, indivíduos com dominância conceitual mostram relativa especialização dos comportamentos conceituais e uma relativa deficiência dos comportamentos percepto-motores. Ocorre o inverso com os indivíduos com 
dominância percepto-motora.

Preferências por modalidade sensorial

Convergência e Divergência

Dependência e Independência de campo

Articulação de campo
Diz respeito às consistências individuais na utilização de determinadas modalidades sensoriais para experienciar o mundo. Basicamente são três as modalidades sensoriais implicadas na interação com o meio ambiente e na organização das informações: a cinestésica ou ativa - denominada pensamento físico ou motor; a visual ou icômica - denominada pensamento figural ou especial e a auditiva ou simbólica - denominada pensamento verbal. Há mudança progressiva na utilização dessas modalidades ao longo do desenvolvimento do indivíduo; numa tenra idade predomina, preferencialmente, a cinestésica, passando, em seguida, para a visual e, por último, para a auditiva. Da mesma forma, observa-se um aumento progressivo em sua capacidade de coordenar e integrar informações obtidas de diferentes modalidades. $\mathrm{Na}$ fase adulta, todas as três modalidades funcionam paralelamente, de tal maneira que a informação proveniente de uma clarifica e suplementa informações provenientes de outras. As pessoas diferem quanto ao uso de uma ou de outra dessas três modalidades sensoriais, o que resulta em características distintas na aprendizagem e no estilo de pensamento.

Diz respeito ao grau de confiança individual quanto ao pensamento convergente, dirigido às conclusões lógicas e unicamente corretas ou a resultados convencionalmente melhores, em oposição ao pensamento divergente, dirigido à variedade e quantidade de “output” relevantes. Esta dimensão tem sido estudada como uma manifestação da inteligência e criatividade, na qual há ênfase na fluência de idéias na produção de respostas únicas, originais ou novas, como típico da criatividade. Estas duas posições da dimensão têm sido vistas como reflexo dos sistemas rivais, relacionados com a ciência e com a arte.

Refere-se à autoconsistência no modo analítico de aproximação do ambiente em oposição ao global. $\mathrm{O}$ indivíduo com independência de campo articula figuras como distintas de seu contexto e apresenta facilidade em diferenciar objetos de seu contexto circundante, enquanto o indivíduo com dependência de campo apresenta tendência a experienciar eventos globalmente, de um modo não diferenciado. No primeiro caso, há uma combinação da função analítica com uma orientação impessoal, enquanto a dependência de campo reflete uma correspondência menos competente na função analítica, combinada com uma grande orientação social e atividades sociais.

Refere-se ao modo relativamente independente de perceber arranjos complexos de estímulos. Ocorre a articulação de 
elementos, quando envolve os elementos discretos contidos no modelo; e articulação da forma, quando focaliza formas grandes contra o fundo padronizado.

Intolerância à

Diz respeito à manifestação característica das pessoas com a ambigüidade "mente fechada" e com alto nível de ansiedade. As pessoas exigem respostas claras e imediatas e são impacientes, além de evidenciarem conflitos e manifestarem impulsividade ou cautela excessiva em situação de tomada de decisões. Em situação de teste de reconhecimento de um objeto, tanto as pessoas cautelosas como as impulsivas apresentam respostas perseverantes e de latência mais curta do que a média do grupo (retirado de Ausubel; Sullivan, 1970).

\section{Quadro 3 - Dimensões de Estilos Cognitivos}

Fonte: Messick² (1976 apud Shirahige, 1999).

No entanto, considerando que as investigações têm se concentrado nas quatro principais dimensões: Dependência de Campo verso Independência de Campo, Reflexividade verso Impulsividade de Resposta, Divergência verso Convergência de Pensamento e Holista verso Serialista, Bariani (1998) apresenta uma descrição das quatro dimensões, conforme segue.

\section{Dependência - Independência de Campo}

Dependência de Campo: indivíduos com campo dependente contam com uma estrutura externa de referência e assim preferem conteúdo e seqüência previamente organizados; requerem mais “reforçamento” extrínseco. São hábeis em situações que demandam percepção pessoal e habilidades interpessoais; preferem uma interação professoraluno mais informal e gostam de aprender em grupo, porém, relutam em dar feedback crítico.

Independência de Campo: as pessoas com campo independente contam com uma estrutura interna de referência, preferindo envolver-se na organização e seqüenciação de

\footnotetext{
2 SHIRAHIGE, E.T. (1999). Estilo cognitivo: uma proposta de estudo no cotidiano da escola, junto a uma classe de $4^{\mathrm{a}}$ série. Tese (Doutorado) - Faculdade de Educação, Universidade de São Paulo, São Paulo, 1999.
} 
conteúdos; respondem a "reforçamento" intrínseco. Sentem-se melhor em situações que requerem uma análise impessoal; facilmente corrigem o outro e expõem por que errou; preocupam-se mais com o conteúdo do que com a interação professor-aluno e preferem aprender independentemente e individualizadamente.

Impulsividade - Reflexividade de Resposta

Impulsividade: pessoas impulsivas detêm-se pouco em ponderação e organização prévia de uma resposta.

Reflexividade: as pessoas cujos pensamentos são mais organizados, seqüenciados e que fazem ponderação prévia a uma resposta são consideradas reflexivas.

\section{Convergência - Divergência de Pensamento}

Pensamento convergente: identifica-se com o pensamento lógico, com raciocínio. As pessoas com pensamento convergente são hábeis em lidar com problemas que requerem uma clara resposta convencional (uma solução correta), a partir das informações fornecidas. Preferem problemas formais e tarefas melhor estruturadas, que demandam mais as habilidades lógicas. São inibidos emocionalmente, sendo identificados como mais conformistas, disciplinados e conservadores.

Pensamento divergente: é associado à criatividade, a respostas imaginativas, originais e fluentes. São indivíduos que preferem problemas menos estruturados, que são hábeis em tratar de problemas que demandam a generalização de várias respostas igualmente aceitáveis, cuja ênfase está na quantidade, variedade e originalidade das respostas. Socialmente são considerados como irritados, disruptivos e até ameaçadores. 


\section{Holista - Serialista}

Holista: os indivíduos holistas dão maior ênfase ao contexto global desde o início de uma tarefa; preferem examinar uma grande quantidade de dados, buscando padrões e relações entre eles. Usam hipóteses mais complexas, às quais combinam diversos dados.

Serialista: dão mais ênfase a tópicos separados e a seqüências lógicas, buscando, posteriormente, padrões e relações no processo, para confirmar ou não suas hipóteses. Assim, usam hipóteses mais simples e uma abordagem lógico-linear (passo a passo).

Entretanto, Riding e Cheema (1991), após várias revisões, concluíram que estas dimensões poderiam ser agrupadas em apenas duas: Verbal-Visual - em que os indivíduos são inclinados a representar a informação durante o pensamento verbalizado ou em figuras mentais; Holístico-Analítico - os indivíduos tendem a organizar as informações no todo ou em parte; e, partindo disto, criaram um teste computadorizado denominado Cognitive Style Analysis (CSA), o qual será discutido adiante.

Essas abordagens de diferentes dimensões podem ser sintetizadas na figura 2:

20 Dimensões

Mesick (1976 apud Shirahige,1999)

4 Dimensões

Bariani (1998)

2 Dimensões - (CSA)

Riding; Cheema (1991)

Figura 2: Síntese das dimensões utilizadas nos Estilos Cognitivos segundo a literatura

Diante do exposto, observa-se que o estudo e a análise dos estilos cognitivos, aliados 
ao perfil dos alunos propiciam, indicadores que ajudam a direcionar as interações com as realidades existentes entre cada indivíduo, facilitando o encontro de um caminho de autoconhecimento.

Neste sentido, Roberts (2006), em sua investigação sobre como os aspectos particulares dos estilos cognitivos podem impactar o desempenho dos estudantes de arquitetura, utilizou para esta verificação, o instrumento Cognitive Style Analysis (CSA) (RIDING, 1991), considerando somente as dimensões Wholist e Analytic. O teste foi administrado em 190 estudantes do primeiro, segundo e terceiro anos de arquitetura. Embora a literatura sugira que estudantes com tendência para pensamento holístico tenham uma certa vantagem na aprendizagem em comparação com os estudantes analíticos, os resultados obtidos não comprovam evidências desta assertiva. Além disso, sugerem que aqueles estudantes categorizados como analíticos tiveram desempenho melhor do que os outros grupos, especialmente nos primeiros anos do curso de arquitetura. Já os estudantes classificados como intermediários tenderam a um desempenho razoavelmente consistente em todos os três anos do estudo; possivelmente este resultado é em função de suas facilidades de acesso a diferentes modos de pensamento. Enfim, considera que o estilo cognitivo individual é apenas um estágio inicial dentro do processo educacional do estudante e, à medida que vai avançando no curso, desenvolverá estratégias que contornarão as deficiências do seu estilo.

Também Parkinson e Redmond (2002) aplicaram três testes psicométricos: o Group Embedded Figures Test (GEFT), o Kirton's Adaptative-Innovator Inventory (KAI) e o Cognitive Style Analysis (CSA) para verificar se os quatro estilos cognitivos afetam o desempenho dos aprendizes em três ambientes educacionais: tratamento de texto, CD-Rom e Internet, aplicados em 47 alunos do último ano de Computação, em um curso introdutório de Inteligência Artificial. Encontraram interação somente com o campo dependenteindependente em todo processo de desempenho da aprendizagem, confirmados 
estatisticamente. No entanto, ao avaliar os ambientes separadamente, os resultados sugerem que os verbais possuem um desempenho melhor do que os visuais no ambiente da Internet, enquanto o desempenho dos analíticos é superior ao dos holísticos, no ambiente de CD-Rom. Concluíram ainda que os estilos cognitivos afetam o desempenho dos aprendizes em diferentes meios computacionais, onde o ambiente de aprendizagem corretamente planejado e bem estruturado tem forte potencial para oferecer apoio pedagógico, se o propósito for entender os estilos cognitivos individuais.

Mediante estes dois estudos, verifica-se que os analíticos obtiveram maior desempenho em relação aos holísticos, o que contradiz a literatura. Neste sentido, é interessante avaliar se este resultado prevalecerá ao estudar alunos de EAD.

\subsection{Estilos cognitivos e estilos de aprendizagem em EAD}

Embora, neste estudo, estilos cognitivos sejam tratados como sendo diferentes de estilos de aprendizagem, são apresentados abaixo estudos relacionados às duas categorias com aplicação em EAD.

Alstete e Beutell (2004), em sua investigação sobre os indicadores de desempenho de estudantes de graduação e pós-graduação em cursos a distância de Administração, em uma faculdade particular dos Estados Unidos, sugerem alguns estudos, dentre esses, os estilos psicológicos de aprendizagem de maneira a auxiliar os coordenadores de cursos a distância a formularem melhores estratégias e políticas que maximizem a aprendizagem dos estudantes.

Esta colocação dos autores, Alstete e Beutell (2004) reforça a importância de se averiguar se há ou não influência dos estilos cognitivos e das características individuais no perfil dos alunos de EAD dos cursos de Administração, Computação e Tecnólogo em Gestão Financeira. 
Um estudo sobre o impacto dos estilos de aprendizagem, características individuais, atitudes e etnografia na efetividade da educação continuada de profissionais de saúde pública, por meio da aprendizagem a distância, mostrou que existe significativa diferença nos resultados cognitivos considerando as etnias, embora o pesquisador tenha utilizado apenas duas categorias étnicas, o que reforça a necessidade de outras verificações. Encontrou também que fatores que mensuravam individualismo e auto-motivação possuíam significativa correlação com o resultado cognitivo bem sucedido, além de comprovar que as atitudes não provocaram impactos nos resultados cognitivos (KRANC, 1997).

Já o estudo de Neuhauser (2002), que comparou duas seções de um mesmo curso, sendo uma on-line e outra face a face, para examinar gênero, idade, preferências de aprendizagem e estilos, efetividade das tarefas e efetividade do curso, notas dos testes e notas finais, revelou que a média do grupo on-line para as variáveis em estudo obteve um resultado levemente superior em relação ao outro grupo, e $96 \%$ dos estudantes avaliaram o curso online como efetivo ou mais efetivo que a aprendizagem típica do curso face a face. No entanto, concluíram estatisticamente que não há diferenças significativas entre a efetividade do curso on-line e do curso face a face.

As pesquisas acima mostram a divergência de resultados obtidos. Com isso verifica-se a necessidade de outros estudos, principalmente na realidade brasileira, para se averiguar se as preferências de aprendizagem provocam ou não impacto no desempenho e perfil dos alunos de EAD.

Munro e Rice-Munro (2004) comentaram que a demanda por tempo nas organizações, assim como a necessidade constante de novos conhecimentos e habilidades possibilitam o uso cada vez maior da EAD; e em seu estudo sobre treinamento baseado na tecnologia em organizações financeiras, comenta as vantagens dos cursos e-learning, mas ressaltam que alguns tópicos de certos cursos são mais bem aproveitados/aprendidos em ambiente presencial 
(em sala de aula) onde pode haver maior efetividade e eficiência da aprendizagem.

Ao analisar a ressalva feita pelos autores, observa-se que no Brasil já existe esta preocupação, mesmo que em aspecto diferente, pois conforme legislação nacional, as avaliações devem ser presenciais, e verifica-se que muitas instituições possuem encontros presenciais de tempo em tempo (geralmente um mês) para realização das avaliações e fixação de tarefas, fortalecendo a relação professor-aluno e aluno-aluno.

Terrell e Dringus (2000) ao identificarem que poucos estudos têm se dedicado a investigar o impacto direto que os estilos de aprendizagem têm no desempenho de estudantes de ambiente on-line de aprendizagem, propuseram investigar o efeito do estilo de aprendizagem na retenção dos estudantes em nível de graduação oferecido em ambiente online. Para isso utilizaram o Kolb Learning Style Inventory e concluíram que a maioria dos estudantes pode ter sucesso no ambiente on-line desde que sejam respeitados seus estilos de aprendizagem. Com isso sugerem que as instituições que oferecem cursos a distância devem estar cientes destas diferenças e devem preparar seus cursos com base nos diferentes estilos de aprendizagem.

Esta investigação reforça a proposta deste estudo, que é avaliar a influência dos estilos cognitivos no perfil de alunos de EAD.

As atitudes dos estudantes com relação à educação a distância são indicadores tão importantes quanto o seu desempenho para a identificação da eficácia dos cursos realizados na modalidade a distância (VALENTA et al, 2001).

Esta colocação dos autores mostra que as atitudes definem o comportamento do aluno no curso, e isso clarifica as implicações para o desenvolvimento de cursos na modalidade EAD, mostrando que os esquemas representativos do curso influenciam as atitudes dos alunos, forçando os dirigentes de cursos EAD a planejar e executar cursos mais eficazes, uma 
vez que segundo Fiske; Taylor $^{3}$ (1984 apud Steil; Barcia, 2006) os esquemas são organizações cognitivas que representam o conhecimento sobre um conceito desenvolvido pela experiência passada, as quais influenciam a forma pela qual novas informações e situações são organizadas. Como os esquemas representam uma relação prototípica, eles conduzirão o indivíduo a comparar e a julgar todas as suas experiências educacionais futuras com relação ao seu esquema.

Drago e Wagner (2004) desenvolveram um estudo que examinava o nível percebido de efetividade de um curso baseado na preferência fisiológica do estilo de aprendizagem de estudantes, para determinar se alunos com certos estilos sentem maior ou menor satisfação nos cursos a distância. Utilizaram para isso um instrumento denominado VARK (visual, auditivo, leitor/escritor e cinestésico). Constataram que, quanto mais tipos de estilo o aluno tiver, mais tendência ele tem de ter uma visão de maior efetividade e satisfação pelo curso.

Diante desta investigação e considerando a proposta desta pesquisa, nota-se que será possível identificar os estilos dos alunos de EAD, com possibilidade de explorar as preferências mais acentuadas, e estimular aquelas menos desenvolvidas. Com estas informações, a instituição de ensino terá condições de elaborar um material didático mais adequado, assim como o professor, terá condições de elaborar estratégias pedagógicas mais eficazes que atendam aos estilos identificados.

\subsection{Instrumentos Psicométricos}

Segundo Durling (1996), existem vários instrumentos psicométricos que têm potencial para avaliar estilos e podem fornecer descrições detalhadas da cognição dos

\footnotetext{
3 STEIL, A.V.; BARCIA, R.M. (2006). Atitudes de alunos e professores com relação a cursos de mestrado em engenharia de produção a distância. Gestão \& Produção, São Carlos, v.13, n.1, p.141-149, abr.
} 
indivíduos. Os instrumentos podem ser classificados segundo o seu foco de interesse, em:

- $\quad$ instrumentos de tipos personalidade;

- instrumentos de estilos de aprendizagem;

- instrumentos de estilos cognitivos.

O mesmo autor também estabelece que qualquer instrumento psicométrico deve estar em conformidade com os seguintes critérios:

- tenha uma base teórica robusta;

- demonstre evidência de confiabilidade (obtenha resultados consistentes);

- $\quad$ seja bem validado (alcance o que foi pretendido fazer);

- $\quad$ esteja apto para diferenciar os indivíduos entre si;

- seja associado com um grande corpo de resultados consistentes e que mostre claramente as diferenças entre grupos profissionais;

- seja associado com estilos de ensino e aprendizagem bem definidos e que seja capaz de ser implementado;

- esteja em uma forma na qual poderá ser, na prática, implementado em sistema de instrução assistida por computador, para classificar aprendizes individuais;

- tenha correlações válidas e úteis com outras escalas psicométricas.

\subsubsection{Validade}

Para Richardson (1999), a validade de um instrumento de medição é a característica de maior importância para avaliar sua efetividade, pois o instrumento é válido quando ele mede o que se deseja. O instrumento para ser válido deve ser confiável.

A validade de um instrumento pode ser definida como a capacidade de realmente 
medir aquilo a que se propõe medir (KELSEY ${ }^{4}$ et al, (1996) citado por GALETTI, 2006).

Para Galetti (2006), a validade apresenta: (1) um aspecto conceitual que depende do julgamento subjetivo do pesquisador se o instrumento mede o que deveria e é influenciado pelo panorama de conceitos e teorias aceitas na época; (2) um aspecto operacional, que pode ser avaliado com métodos estatísticos. Esta última é geralmente medida comparando-se o instrumento com outra medida externa já existente e considerada “padrão ouro” (Menezes; Nascimento $^{5}$, 2000 citado por GALETTI, 2006) e denomina-se validade convergente ou validade cruzada.

Ainda de acordo com Galetti, (2006), dentro do aspecto conceitual deve-se considerar a validade aparente. A validade aparente (face validity) é o grau com que uma medida intuitivamente parece avaliar o que se propõe. Diz respeito a um critério de credibilidade na formulação dos itens. O item deve ser formulado de modo que não pareça ridículo, despropositado ou infantil (PASQUALI, 2000).

A validade de construto é a presença de uma correlação positiva entre um grupo de características ou variáveis e a entidade principal que está sendo medida. Diz respeito à construção dos itens, sob embasamento teórico, a partir das características do que se pretende medir (GALETTI, 2006).

A validade diz respeito ao aspecto da medida ser congruente com a propriedade medida dos objetos e não com a exatidão com que a mensuração deste objeto é feita. A validade existe quando o procedimento faz exatamente o que ele propõe fazer (CARMINES;

\footnotetext{
${ }^{4}$ GALETTI, A.M. (2006). Desenvolvimento e avaliação psicométrica da escala de seguimento de jogadores: uma medida de avaliação para jogadores patológicos em tratamento. Dissertação (Mestrado) Faculdade de Medicina, Universidade de São Paulo, São Paulo, 2006.

${ }^{5}$ GALETTI, A.M. (2006). Desenvolvimento e avaliação psicométrica da escala de seguimento de jogadores: uma medida de avaliação para jogadores patológicos em tratamento. Dissertação (Mestrado) Faculdade de Medicina, Universidade de São Paulo, São Paulo, 2006.
} 
ZELLER, 1979).

\subsubsection{Confiabilidade}

A confiabilidade ou fidedignidade ou precisão de um teste diz respeito à característica que ele deve possuir - a de medir sem erros, ou seja, o mesmo teste, medindo os mesmos sujeitos em ocasiões diferentes, ou testes equivalentes medindo os mesmos sujeitos na mesma ocasião produzem resultados idênticos - correlação 1 (PASQUALI, 1997).

Neste sentido, a confiabilidade de um instrumento pode ser definida como sendo a probabilidade de produtos e/ou processos desempenharem as funções para as quais foram projetados, em um determinado instante ou intervalo de tempo.

Segundo Galetti, (2006), a confiabilidade refere-se a capacidade do instrumento de reproduzir uma mesma medida, isto é, ao grau de concordância entre múltiplas medidas de um mesmo objeto. A consistência interna (alfa Cronbach) é um escore sumário de confiabilidade geral de um instrumento. O escore pode variar de zero a um e, por convenção, o escore mínimo aceitável para a consistência interna é 0,70; um escore bom gira em torno de 0,80, e um escore de 0,90 é considerado excelente. Contudo, um alfa muito próximo de 1 indica co-variância, sugerindo que possivelmente o conjunto de itens em questão poderia ser substituído por apenas 1, aquele que for mais representativo. Assim sendo, é desejável que os itens de cada uma das escalas apresentem boa consistência interna, porém que não seja demasiada elevada para garantir uma complementariedade entre os mesmos e uma avaliação abrangente.

Segundo Menezes; Nascimento ${ }^{6}$ (2000) citados por Galetti, (2006), os tipos de

6 GALETTI, A.M. (2006). Desenvolvimento e avaliação psicométrica da escala de seguimento de jogadores: uma medida de avaliação para jogadores patológicos em tratamento. Dissertação (Mestrado) Faculdade de Medicina, Universidade de São Paulo, São Paulo, 2006. 
confiabilidade avaliados são: a confiabilidade entre os diferentes avaliadores, em que os mesmos sujeitos são avaliados por dois ou mais avaliadores e a confiabilidade teste-reteste, em que um grupo de sujeitos é avaliado em dois momentos diferentes.

\subsubsection{Teste e Reteste}

Um dos métodos mais conhecidos para estimar a confiabilidade de um instrumento é o método teste-reteste, o qual se refere à correlação entre escores ou valores de duas aplicações do mesmo teste ou instrumento ao mesmo grupo de sujeitos (RICHARDSON, 1999).

Ainda, segundo o mesmo autor, o método do reteste para medir a confiabilidade é considerado um índice de estabilidade do instrumento; quando é aplicado duas vezes a um mesmo grupo de sujeitos, supõe-se que as habilidades requeridas para responder a ele não variem, embora os sujeitos possam responder de forma diferente em ambas as ocasiões.

\subsubsection{Flexibilidade cognitiva}

Por flexibilidade cognitiva entende-se a capacidade de reestruturar de forma espontânea o próprio conhecimento, para responder às necessidades de situações de mudança, tanto em função da forma como se representa o conhecimento, como dos processos que operam nas representações mentais realizadas. Esta teoria apresenta-se, por isso, como uma referência para a organização de informação em ambientes de aprendizagem pouco estruturados. A idéia de flexibilidade surge da necessidade de formar pessoas para que possam dar resposta a situações que habitualmente têm soluções muito variadas (YOKAICHIYA, 2005).

De acordo com o que já foi apresentado, existem vários modelos e instrumentos para testar os estilos das pessoas; entretanto, neste estudo, optou-se por utilizar o VICS-E-CSAWA, o qual foi derivado do CSA, conforme abordagem que se segue. 


\subsubsection{Cognitive Style Analysis (CSA)}

Riding e Cheema (1991) comentam que o Cognitive Style Analysis (CSA) é um teste computadorizado, o qual avalia as dimensões Wholist-Analytic (Holístico-Analítico) e Verbal-Imagery (Verbal-Imagético). Possui subtestes que avaliam a dimensão verbal-visual, apresentando sentenças com um tempo para julgar se são verdadeiro ou falso. Metade das sentenças contém informações sobre categorias conceituais, enquanto o restante descreve a aparência, o aspecto dos itens. As sentenças são metade do tipo verdadeiras e a outra metade falsas. Foi assumido que as pessoas visuais deveriam responder mais rapidamente às figuras mentais, e a informação para comparação poderia ser obtida direta e rapidamente das imagens. No caso dos itens da categoria conceitual, foi assumido que as pessoas verbais iriam ter um tempo de resposta menor por causa da semântica conceitual do grupo. O computador registra o tempo de resposta de cada uma das sentenças e calcula a relação: relação maior que um corresponde a verbal, e menor que um corresponde a visual. Nesta etapa os participantes lêem itens visuais e verbais, sendo que este instrumento não é um teste para habilidade de leitura nem de velocidade de leitura.

O outro subteste avalia a dimensão Wholist-Analytic; o primeiro dos itens apresentados contém pares de figuras geométricas complexas; o respondente responderá se são as mesmas figuras ou se são diferentes. Esta tarefa envolve julgamento sobre a completa similaridade das duas figuras; foi assumido que uma resposta relativamente rápida poderia ser possível para os holísticos. No segundo: cada item apresentado é comparado com uma forma geométrica simples e com uma figura geométrica complexa; o sujeito é solicitado a indicar se a forma simples está ou não contida na figura complexa. Esta tarefa requer um grau de combinação da forma simples dentro da figura geométrica complexa, foi assumido que os analíticos poderiam ser relativamente mais rápidos nesta etapa. O computador registra a 
freqüência de respostas e calcula relação de holísticos-analíticos. Relação menor que um (1) corresponde a um holístico, e relação maior que um (1) a analítico.

A dimensão Wholist-Analytic (WA) (Holístico-Analítico) do estilo cognitivo deriva do trabalho de Witkin e outros que tratam de campo dependente/independente. O campo dependente tende a perceber e aderir a algo existente, externamente imposto por uma estrutura, enquanto o campo independente tende a reestruturar a informação percebida dentro de diferentes estruturas. O holístico, como o termo sugere, tende a ver a situação como um todo, tem uma perspectiva geral e aprecia o contexto total. Ao contrário, o analítico vê a situação como uma coleção de partes e freqüentemente foca em uma ou duas no intervalo de tempo, descartando as outras. Uma implicação para a instrução será que os holísticos necessitarão de ajuda para compreender a estrutura e as seções do material de aprendizagem e para dividir o todo em partes. Já os analíticos irão requerer uma visão geral unificada para fornecer uma ordem integrada das seções dentro da visão do todo (RIDING; WATTS, 1997).

Em relação à dimensão Verbal-Imagery (Verbal-Imagético), segundo os mesmos autores, os aprendizes visuais são melhores em apresentações ilustradas com figuras, enquanto os aprendizes verbais são melhores em formas textuais.

O CSA é bastante popularizado entre instituições de ensino e organizações na Europa, mas pouco difundido nos EUA e assim, Rezael e Katz (2004), em um estudo com alunos canadenses, realizado em três momentos e em três situações diferentes, para avaliar a confiabilidade e validade do Cognitive Style Analysis, obteveram resultados que levaram a questionar a confiabilidade do teste, em função da baixa correlação dos coeficientes entre os escores dos construtos, o que levou os autores a declararem que o CSA não é suficientemente confiável para ser utilizado como base para design de cursos, desta forma, sugeriram algumas alterações para o mesmo, como seguem:

1. informar aos participantes do teste que o fator tempo influencia seu resultado; 
2. recomendaram que o "result file" possibilite ao pesquisador o status de resposta (correto ou incorreto) além do tempo de reação de cada item;

3. para a dimensão Verbal-Imagery (VI), sugeriram que as perguntas sejam repetidas e os itens sejam apresentados em diferentes perspectivas;

4. geralmente, o tamanho do teste é correlacionado com a confiabilidade do mesmo; assim, recomendaram o aumento do número de itens de cada seção;

5. utilizar uma cor neutra e igual para os botões de certo ou errado (right and wrong), não fazendo alusão a que vermelho seja errado e azul seja certo;

6. respeitar as diferenças culturais para que o problema de ambigüidade seja eliminado;

7. o software verifica o tempo de resposta de cada sentença, mas apresenta somente no final do teste de forma agrupada por dimensão, sugeriram e-se que software apresente o tempo de resposta individualmente para facilitar a investigação do pesquisador e;

8. aumentar o grau de dificuldade da dimensão VI, uma vez que isso pode contribuir para aumentar a confiabilidade do mesmo.

Corroborando com este resultado, Massa e Meyer (2005), em sua revisão, sumarizam que no subteste Verbal-Imagery do Cognitive Style Analysis faltam três tipos de validade: (1) validade aparente: as características são superficiais e não parecem ser relacionadas a uma teoria fundamentada; (2) validade de construto: que não correlaciona com outras medidas estabelecidas no estilo cognitivo verbal-visual e (3) validade preditiva: que não prevê o comportamento do aprendiz.

Ainda dentro do escopo da confiabilidade do CSA, Parkinson; Mullally e Redmond (2004) em seus dois estudos, sendo o primeiro com 51 alunos de engenharia e ciência da computação e o segundo com 96 estudantes de sistemas de informação, tendo um intervalo entre teste e reteste de 14 dias e 23 meses, respectivamente, obtiveram resultado considerado abaixo do aceitável para confiabilidade, concluindo que o CSA não avalia as dimensões com 
suficiente precisão.

Peterson et al. (2003a), em seu estudo com 50 estudantes de psicologia, examinaram o desempenho do CSA original com uma versão paralela e identificaram que as correlações entre verbal-imagery (VI) e wholist-analytic (WA) das duas versões foram baixas; no entanto, quando o CSA foi combinado com a versão paralela, a análise split-half da dimensão WA foi estável, mas a do VI foi baixa, não sendo confiável.

Ainda dentro desta análise de desempenho do CSA, Davis e Graff (2006) em seu estudo com 193 estudantes de graduação, com objetivo de explorar a influência da abordagem reflexiva-impulsiva no processamento do Wholist-Analytic, por apresentação contrabalanceada de figuras encaixadas e figuras combinadas, obtiveram resultados que revelam que a relação de wholist (holístico) e analitic (analítico) é extremamente sensível na ordem em que cada subteste é apresentado, sendo que a relação é altamente significativa quando as figuras são combinadas e baixa quando são encaixadas. Assim, indivíduos reflexivos foram muito mais analíticos do que os impulsivos, quando as figuras foram combinadas; isso implica que a metodologia do CSA provavelmente aumente as diferenças entre indivíduos holistas e analíticos ao comparar as diferenças em parte e no todo e ao processar informações concomitantes em estilo reflexivo e impulsivo.

Considerando as limitações identificadas na dimensão Verbal-Imagery do Cognitive Style Analysis (CSA), Peterson; Deary e Austin (2005b) propuseram algumas modificações, das quais se originou o Verbal-Imagery Cognitive Style (VICS). O novo teste foi utilizado juntamente com a dimensão W/A do CSA em dois estudos; no primeiro, 50 participantes responderam aos dois testes, obtendo um resultado de alta consistência interna e aceitável confiabilidade no reteste de novo teste VICS; entretanto, obteve baixa consistência interna e confiabilidade no reteste do CSA. Já no segundo estudo, com 100 participantes, o resultado foi confirmado, concluindo que o novo teste VICS tem uma medição confiável para o estilo 
cognitivo verbal-imagery.

\subsubsection{VICS-E-CSA-WA}

O VICS-E-CSA-WA é um teste psicométrico que possui duas dimensões: (1) VerbalImagery: preferência por informações representadas por palavras ou figuras e (2) WholisticAnalytic: preferência por informações que são estruturadas/obtidas de uma grande figura ou de um detalhe.

O VICS-E-CSA-WA foi derivado do Cognitive Style Analysis (CSA) pelo fato de alguns pesquisadores (MASSA; MEYER, 2005; REZAEL; KATZ, 2004) alegarem que a dimensão verbal-imagery do CSA não era confiável e não tinha consistência interna aceitável. Desta forma, corrigiram-se estas deficiências juntamente com as encontradas por Rezael e Katz (2004) no CSA na versão atual do VICS-E-CSA-WA, conforme figura 3.

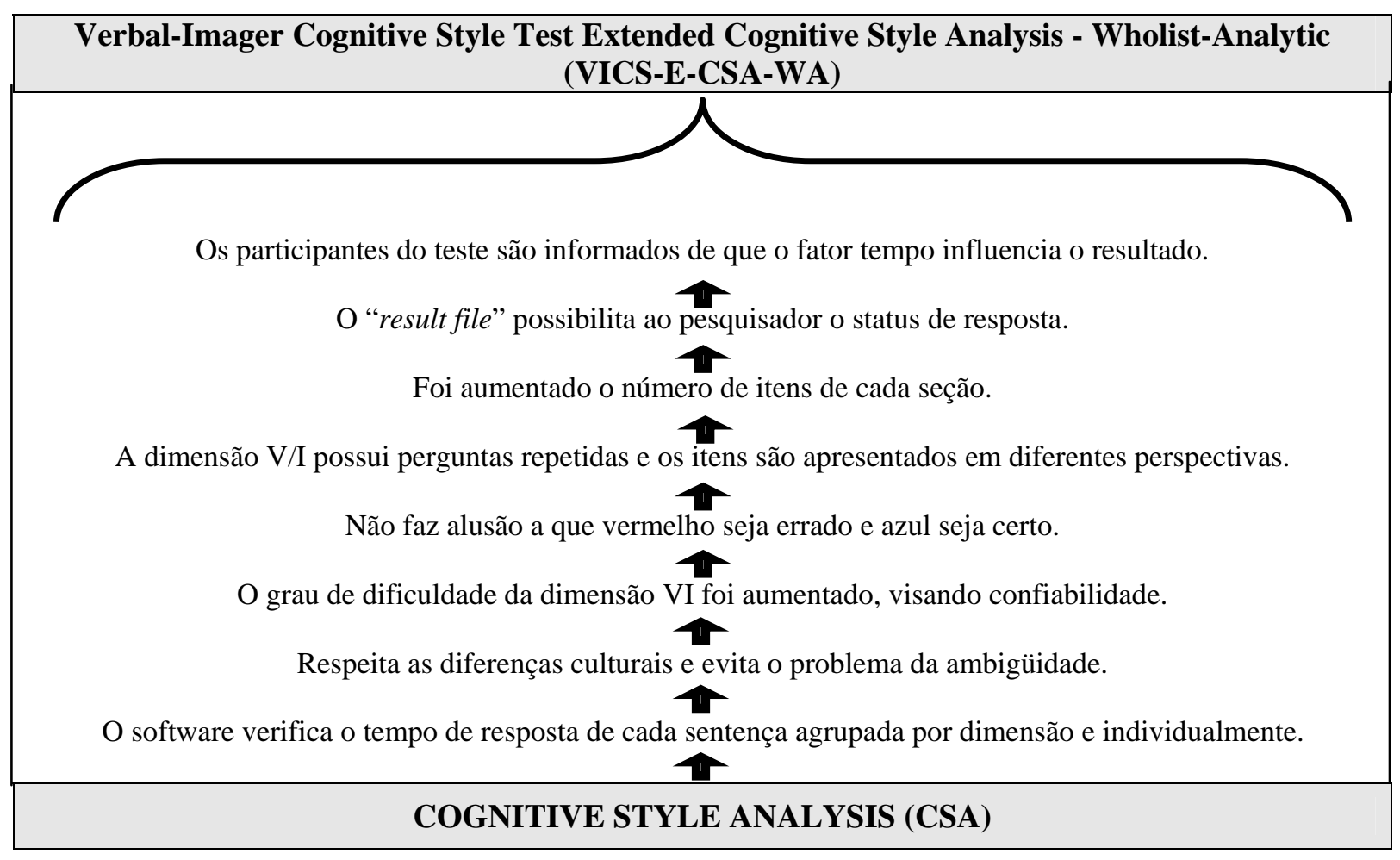

Figura 3 - Derivação do VICIS-E-CSA-WA do CSA 
De acordo com o manual do Verbal-Imager Cognitive Style Test (VICS) e Extended Cognitive Style Analysis (CSA) - Wholist-Analytic (WA) Test (Anexo A), é um teste psicométrico, computadorizado, que funciona em ambiente Windows 95, 98, 2000 e XP, que disponha de drive de CD-Rom e monitor colorido e, preferencialmente, um teclado numérico separado.

O VICS Test mensura as preferências verbais versus as imagéticas (visuais) pela forma com que a informação é apresentada, e o Extended CSA-WA Test mensura as preferências por informações estruturadas no holístico versus o analítico.

Estas duas dimensões do estilo cognitivo (verbal-imagery e wholistic-analytic) foram sugeridas por Riding e Cheema em 1991, seguindo sua revisão sobre a literatura de estilos. Riding (1991) planejou o Cognitive Style Analysis Test (CSA) para mensurar estas dimensões por comparação como rapidez na média de respostas individuais na tarefa verbal comparada com a tarefa visual; e a rapidez na média de respostas para a tarefa holística comparada com a tarefa analítica.

Peterson et al. (2003 a; 2003 b) concluíram, mediante algumas evidências empíricas, que a validade do CSA nas preferências de estilo verbal-imagery e wholistic-analytic têm baixa confiabilidade no reteste ( $r$ 's<.32).

Peterson et al. (2003a) mostraram que uma versão estendida do CSA na dimensão Wholistic/Analytic melhoraria a confiabilidade do teste para um nível satisfatório de (consistência interna $r=.72$; reteste com confiabilidade de $r=.55$ ) e desenvolveram um novo teste para a dimensão verbal-imagery denominado VICS (PETERSON; DEARY e AUSTIN, 2005), o qual tem uma consistência interna aceitável ( $r>.72$ ) e com confiabilidade no reteste $(r=.56)$.

Para assegurar uma avaliação confiável, os participantes devem ser avaliados individualmente, sendo impossibilitados de ver o teste de outra pessoa. Isto é importante 
porque o teste mensura a velocidade natural de resposta dos participantes e, caso ele veja alguém respondendo ao teste mais rápido, isso pode, provavelmente, influenciar na forma que iria responder ao seu teste.

O número de itens utilizados no Verbal Cognitive Styles Test e seus componentes é apresentado nos Quadros 4 e 5.

\begin{tabular}{|ccc|ccc|ccc|ccc|}
\hline \multicolumn{10}{|c|}{ Verbal Imagery Cognitive Style (VICS) Test } \\
(232 itens) \\
\hline \multicolumn{8}{|c|}{ Tarefas Verbais (116) } & \multicolumn{3}{c|}{ Tarefas Visuais (116) } \\
\hline \multicolumn{3}{|c|}{ Palavras (58) } & \multicolumn{3}{|c|}{ Figuras (58) } & \multicolumn{3}{c|}{ Palavras (58) } & \multicolumn{3}{c|}{ Figuras (58) } \\
N & A & Mx & N & M & Mx & M & Me & I & M & Me & I \\
$(26)$ & $(26)$ & $(6)$ & $(26)$ & $(26)$ & $(6)$ & $(26)$ & $(26)$ & $(6)$ & $(26)$ & $(26)$ & (6)
\end{tabular}

\section{Quadro 4 - Distribuição de Itens do VICS Test}

Fonte: Manual VICS-E-CSA-WA

Legenda: $\mathrm{N}=$ Natural, A=Artificial, Mx=Misto, M=Maior, Me=Menor, I=Iguais.

Para o CSA-WA tem-se a seguinte distribuição (Quadro 5).

\begin{tabular}{|cc|cc|}
\hline \multicolumn{2}{|c|}{ Wholistic Task (40 itens) } & \multicolumn{2}{c|}{ Analytic Task (40 itens) } \\
\hline Original CSA & Novo Wholistic & Original CSA & Novo Analytic \\
Itens Wholistic & Itens & Itens Analytic & Itens \\
$(20)$ & $(20)$ & $(20)$ & $(20)$ \\
\hline
\end{tabular}

Quadro 5 - Distribuição de Itens do Extended CSA-WA Test

Fonte: Manual VICS-E-CSA-WA

Seguem algumas telas do instrumento computadorizado, VICS-E-CSA-WA.

\section{Chave}

Estes objetos são naturais?

\section{Sim Não Mistos}

\section{Garrafa}

Tela 1 - obtida do software da dimensão verbal. 


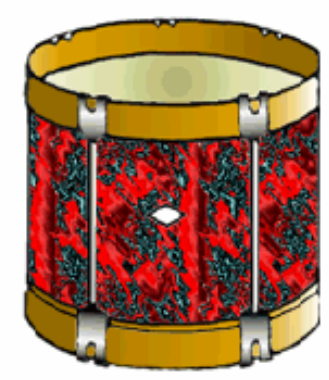

Estes objetos são naturais?

Sim Não Mistos

Tela 2 - obtida do software da dimensão imagético.

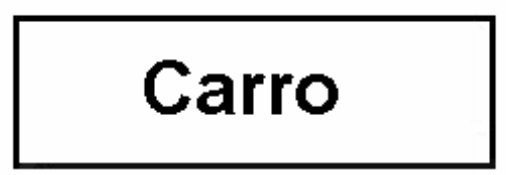

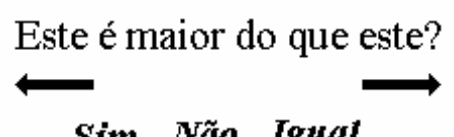

\section{Avião}

Sim Não Iguat

[1] [2] [3]

Tela 3 - obtida do software da dimensão verbal.

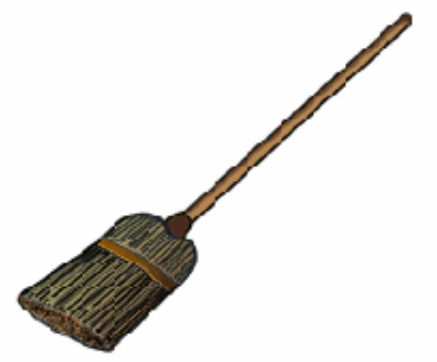

Este é maior do que este?

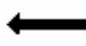

Sim Não Iguat

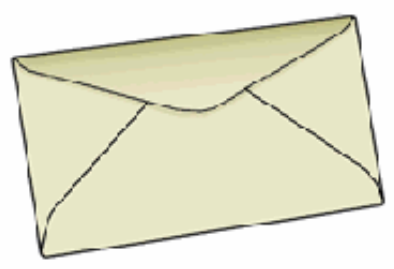

Tela 4 - obtida do software da dimensão imagético.

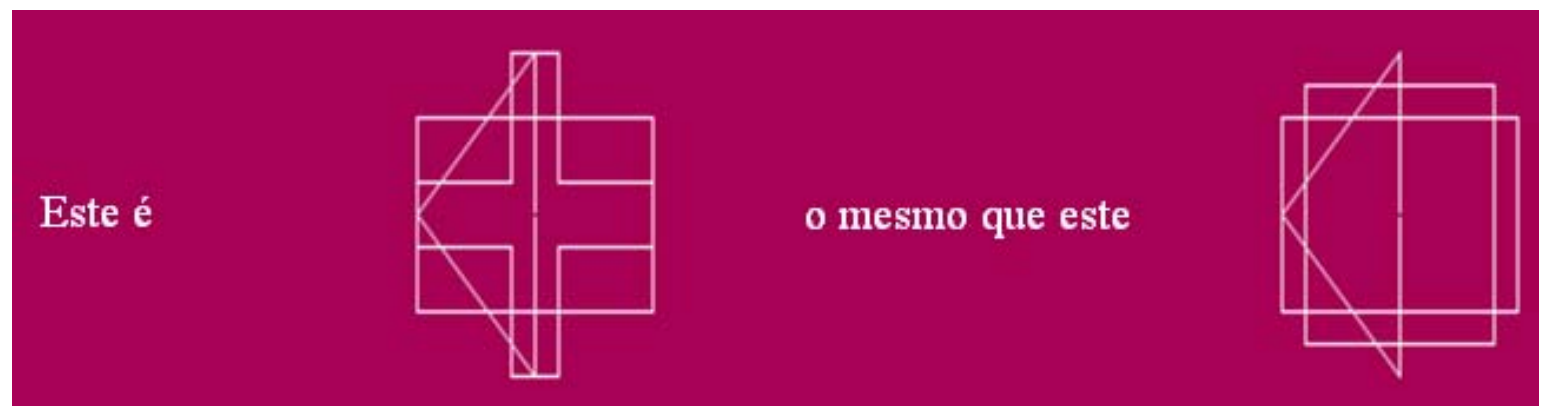

Tela 5 - obtida do software da dimensão holístico/analítico. 


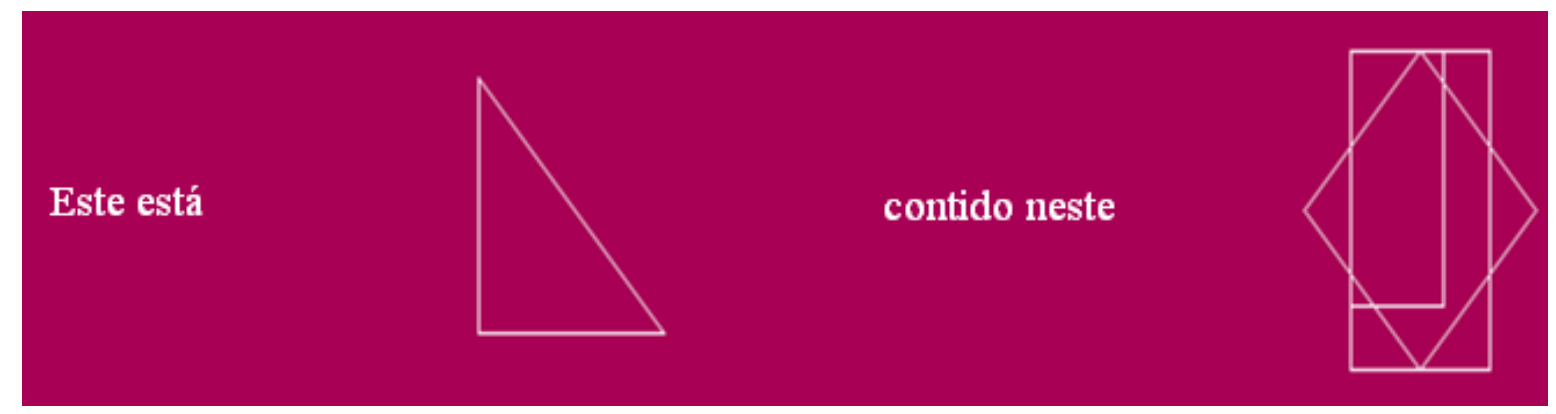

Tela 6 - obtida do software da dimensão holístico/analítico.

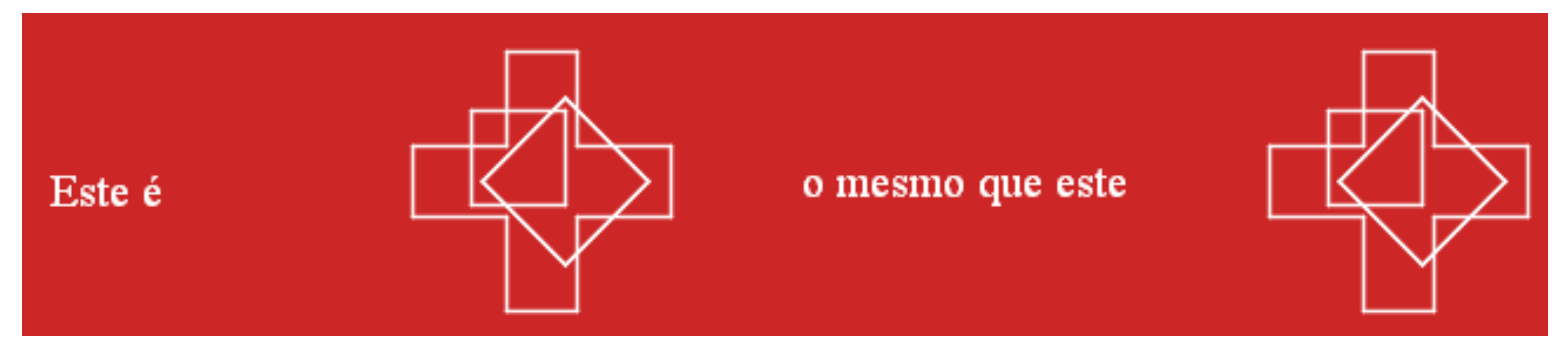

Tela 7 - obtida do software da dimensão holístico/analítico.

O VICS Test e o Extended CSA-WA produzem três tipos de relatórios: (1) Relatório para o Pesquisador, (2) Relatório Sumário e (3) Relatório Sumário Plus, os quais geram proporção de verbais-imagéticos e de holísticos-analíticos, fornecem alguns detalhes adicionais como nome, idade, gênero, etnia e comentários de cada sujeito, fornecem média de tempo de reação e a precisão de cada tipo de tarefa, forma dos estímulos e tipo de item.

Neste estudo foi utilizada a seguinte conversão das dimensões em português: Verbal=Verbal; Imagery=Visual=Imagético (será utilizada a palavra “imagético”); Wholistic=Holístico; Analytic=Analítico . 


\section{MÉTODO DE PESQUISA}

Nesse capítulo está definido local da pesquisa, tipo de pesquisa, a amostragem, caracterização da amostra, os instrumentos e procedimentos de coleta de dados e a forma como esses dados foram tabulados e analisados. As etapas para atingir os objetivos estão descritas na figura 4.

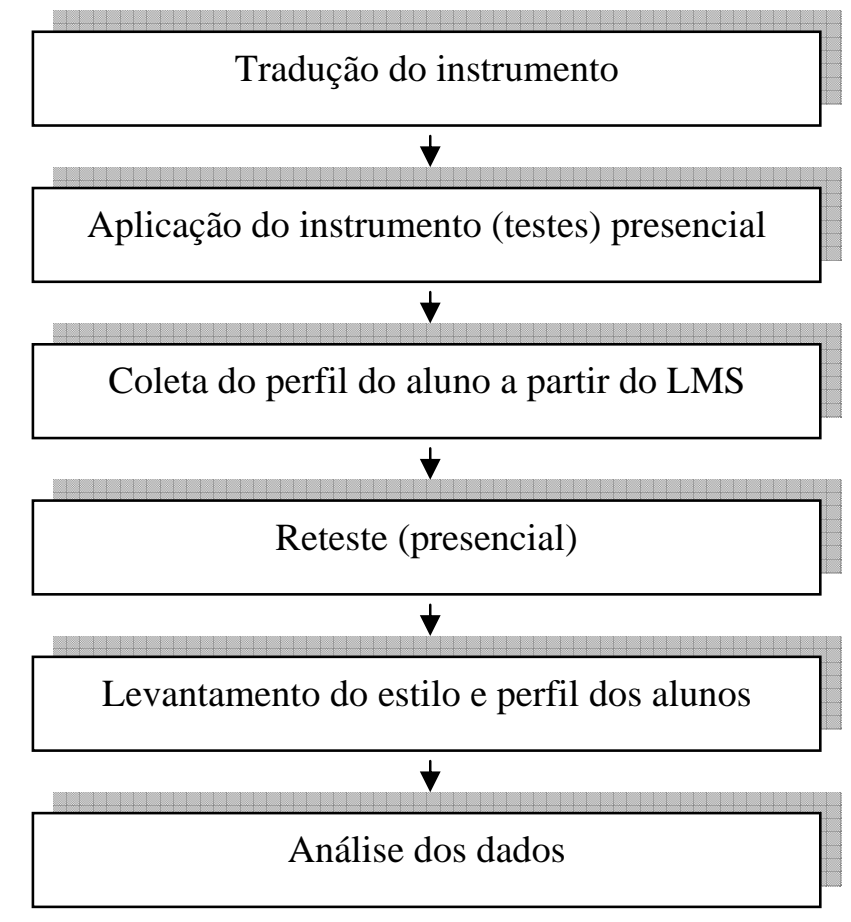

Figura 4 - Etapas para realização da pesquisa

\subsection{Local da Pesquisa}

A pesquisa de campo será realizada em um Centro Universitário localizado no interior do Estado de São Paulo. 


\subsection{Tipo de Pesquisa}

O tipo de pesquisa utilizada no presente estudo, do ponto de vista da sua natureza, pode ser definida como pesquisa aplicada. Conforme Silva e Menezes (2001), a pesquisa aplicada tem como objetivo gerar conhecimentos para aplicação prática direcionada à solução de problemas específicos.

Quanto a seus objetivos, pode ser definida como pesquisa exploratório-descritiva, pois segundo Silva e Menezes (2001), a pesquisa exploratória visa proporcionar maior familiaridade com o problema com vistas a torná-lo explícito. Já a pesquisa descritiva, de acordo com Vergara (1998), expõe características de determinada população ou de determinado fenômeno, podendo estabelecer correlações entre variáveis e definir sua natureza.

Do ponto de vista da forma de abordagem do problema, a pesquisa é classificada como predominantemente quantitativa, com recorte qualitativo. Segundo Silva e Menezes (2001, p.21), pesquisa quantitativa “considera que tudo pode ser quantificável, o que significa traduzir em números opiniões e informações para classificá-los e analisá-los”; e a pesquisa qualitativa “considera que há uma relação dinâmica entre o mundo real e o sujeito, cujo processo e seu significado são os focos principais de abordagem”.

Em relação ao delineamento, trata-se de um levantamento que de acordo Silva e Menezes (2001, p.21), “levantamento é quando a pesquisa envolve a interrogação direta das pessoas cujo comportamento se deseja conhecer”.

Quanto aos meios de investigação, foi utilizada a pesquisa de campo. Conforme Vergara (1998), a pesquisa de campo é uma investigação empírica realizada no local onde ocorre ou ocorreu um fenômeno ou que dispõe de elementos para explicá-lo. Os instrumentos utilizados podem incluir entrevistas, aplicação de questionários, testes e observação. 


\subsection{Instrumento de pesquisa utilizado}

O instrumento utilizado na pesquisa será um teste psicométrico denominado VerbalImagery Cognitive Style - Extended Cognitive Style Analysis - Wholist/Analitic (VICS-ECSA-WA).

O instrumento foi traduzido para o português pela pesquisadora deste estudo, juntamente com seu orientador, com autorização prévia da Universidade de Edinburgh, detentora dos direitos autorais, na pessoa da professora Elizabeth Peterson. O instrumento traduzido para o português foi pré-testado em alunos de pós-graduação em Engenharia de Produção.

O teste foi aplicado no mês de setembro e o reteste em dezembro de 2006.

\subsection{Caracterização da amostra da pesquisa}

A amostra da pesquisa foi constituída por cento e três (103) alunos regularmente matriculados e freqüentes nos curso de Administração (41), Computação (53) e Tecnólogo em Gestão Financeira (TGF) (9), todos da modalidade a distância, totalizando 27 alunos do gênero feminino e 76 do masculino, conforme apresentado na tabela 1.

Tabela 1 - Caracterização da Amostra

\begin{tabular}{lccc}
\hline & Feminino & Masculino & Total \\
\hline Administração & 15 & 26 & 41 \\
Computação & 11 & 42 & 53 \\
TGF & 01 & 08 & 09 \\
Total & 27 & 76 & 103 \\
\hline
\end{tabular}

Todos os alunos dos referidos cursos foram convidados a participar da pesquisa e a participação foi por adesão.

Cada aluno participante assinou um termo concordando/aceitando participar da 
pesquisa.

\subsection{Coleta de Dados}

A estratégia de coleta de dados vem explicada a seguir.

\section{Coleta dos Estilos Cognitivos}

Para identificar os estilos cognitivos dos alunos utilizou-se o instrumento VerbalImagery Cognitive Style - Extended Cognitive Style Analysis - Wholist/Analitic (VICS-ECSA-WA), apresentado neste estudo.

\section{Aplicação do Instrumento}

- O software do instrumento VICS-E-CSA-WA foi enviado aos funcionários responsáveis pela manutenção dos laboratórios de informática do Centro Universitário para sua instalação.

- A aplicação do instrumento foi feita pela pesquisadora, auxiliada por funcionários do Centro Universitário.

- Cada turma teve um horário pré-estabelecido para responder ao teste.

- Cada aluno que aceitou participar da pesquisa assinou um termo de concordância.

- O teste durou em média 25 minutos.

- Ao término da aplicação do teste, os relatórios foram gerados e feitas as cópias necessárias para análise dos dados.

\section{Coleta do Perfil dos Alunos}

O perfil do aluno de EAD será identificado por meio das seguintes variáveis: curso, idade, gênero, etnia, preferências cognitivas (verbal, imagético, holístico ou analítico), média obtida, número de acesso à sala virtual, quantidade de mensagens postadas no portfólio, 
quantidade de mensagens postadas no fórum, quantidade de mensagens postadas na lista, sugestão, pergunta, resposta, questão para discussão, argumentação, contra-argumentação e diversa.

\section{Identificação do perfil dos alunos}

As informações tais como curso, média obtida, número de acesso à sala virtual, quantidade de mensagens postadas no portfólio, quantidade de mensagens postadas no fórum e quantidade de mensagens postadas na lista serão obtidas junto ao Learning Management System (LMS) da Instituição.

De acordo com Almeida (2003), sistemas de gestão da aprendizagem (LMS) podem ser empregados como suporte para sistemas de educação a distância realizados exclusivamente on-line e/ou para apoio às atividades presenciais de sala de aula, permitindo expandir as interações da aula para além do espaço-tempo, do encontro face-a-face ou para suportar atividades de formação semipresencial nas quais o ambiente digital poderá ser utilizado tanto nas ações presenciais como nas atividades a distância.

Os dados referentes aos estilos cognitivos, idade, gênero e etnia serão obtidos por meio do resultado do VICS-E-CSA-WA.

Os dados pessoais dos alunos serão eliminados para garantir a privacidade dos mesmos.

A identificação do perfil dos alunos se deu predominantemente de forma quantitativa, com exceção do fórum. 


\section{$\underline{\text { Recorte qualitativo da pesquisa }}$}

Embora a pesquisa seja predominantemente quantitativa, fez-se necessário um recorte qualitativo, em que as discussões dos alunos no fórum foram categorizadas, conforme quadro 6 e depois, quantificadas.

\begin{tabular}{|c|c|}
\hline Categoria & Descrição \\
\hline Sugestão & $\begin{array}{l}\text { Quando o aluno indica/sugere algo relacionado ao conteúdo } \\
\text { da disciplina. }\end{array}$ \\
\hline Pergunta & $\begin{array}{l}\text { Refere-se a uma pergunta feita pelo aluno relacionada ao } \\
\text { curso e/ou disciplina }\end{array}$ \\
\hline Resposta & $\begin{array}{l}\text { Refere-se à resposta dada a uma pergunta referente ao curso } \\
\text { e/ou disciplina. }\end{array}$ \\
\hline Questão para Discussão & $\begin{array}{l}\text { Refere-se a uma questão/assunto relacionado ao conteúdo da } \\
\text { disciplina proposto para discussão. }\end{array}$ \\
\hline Argumentação & $\begin{array}{l}\text { É uma argumentação sobre o assunto relacionado ao conteúdo } \\
\text { da disciplina proposto para discussão. }\end{array}$ \\
\hline Contra-Argumentação & Refere-se à posição contrária a uma argumentação. \\
\hline Diversa & Utilizada para as mensagens genéricas. \\
\hline
\end{tabular}

Quadro 6 - Categorização das mensagens do fórum de discussão

Fonte: Adaptado de Fuks; Gerosa e Lucena (2002).

Após a adaptação do modelo, escolheu-se uma disciplina já cursada pelos alunos em estudo em cada um dos cursos pesquisados. O critério de escolha adotado foi a disciplina que tivesse maior número de interações e participantes, assim sendo, foram escolhidas as seguintes disciplinas:

- Administração I: para o curso de Administração e TGF.

- $\quad$ Linguagem de Programação Estruturada I: para o $1^{\circ}$ ano de Computação.

- Técnicas de Programação Visual: para o $2^{\circ}$ ano de Computação. 
Cabe ressaltar que, para atender ao critério adotado, fizeram-se necessárias duas disciplinas para o curso de Computação, uma vez que os alunos do $2^{\circ}$ ano do referido curso também participaram do estudo.

Com base na categorização acima citada, classificaram-se todas as mensagens dos fóruns destas disciplinas por aluno, gerando um número total de mensagens por categoria.

\subsection{Procedimentos para Análise Estatística}

A estatística descritiva foi realizada para caracterizar os estilos cognitivos das amostras estudadas; e a univariada e multivariada para verificar a influência dos estilos cognitivos no perfil dos alunos de educação a distância.

Para a análise estatística foram utilizados 1.864 registros de disciplinas cursadas por 103 alunos, sendo 640 disciplinas para Administração, 1.080 para Computação e 144 para TGF.

Foi utilizada a técnica de análise de variância (ANOVA) para análises univariadas e análise de variância (ANOVA) multifatorial, para multivariada, com auxílio do software estatístico SPSS - Statistical Package for the Social Sciences.

Foi adotado um nível de significância, alfa $(\alpha)$ 0,05, ou seja, $\mathrm{p}<0,05$. Nas análises do teste e reteste das variáveis V/I e W/A utilizou-se o método de McNemar.

Para a análise estatística, foram utilizadas informações do teste e do reteste em casos que o aluno não tinha informações de um ou de outro.

Os resultados obtidos com a aplicação das ferramentas estatísticas são expostos e analisados em seguida. 


\section{APRESENTAÇÃO DOS RESULTADOS E DISCUSSÃO}

Nesse capítulo são apresentados e analisados os resultados obtidos com a aplicação do instrumento e ferramentas estatísticas.

Inicialmente foi feita a análise quantitativa dos dados, com verificação dos percentuais obtidos nas variáveis analisadas o que permitiu a identificação dos estilos cognitivos predominantes entre os alunos dos cursos de Administração, Computação e TGF da modalidade a distância (análise descritiva). Logo após, foi feita a análise da influência dos estilos cognitivos no perfil dos alunos, com a utilização do método de análise de variância (ANOVA).

\subsection{Estilos cognitivos dos estudantes}

Mediante a apuração das respostas de todos os alunos participantes da pesquisa é possível conhecer os estilos cognitivos predominantes na amostra (Tabela 2).

Tabela 2 - Estilos cognitivos dos estudantes de EAD por curso e por dimensão

\begin{tabular}{lcccc}
\hline & \multicolumn{2}{c}{ Verbal/Imagético } & \multicolumn{2}{c}{ Holístico/Analítico } \\
& (V) \% & (I) \% & (W) \% & (A) \% \\
\hline Administração & 75,6 & 24,4 & 100 & - \\
Computação & 61,7 & 38,3 & 94,9 & 5,1 \\
TGF & 77,8 & 22,2 & 100 & - \\
\hline
\end{tabular}

Considerando-se as dimensões de estilos cognitivos, verifica-se predominância do estilo verbal sobre o imagético e predominância do holístico sobre o analítico.

A predominância do estilo cognitivo Verbal mostra que os estudantes dos cursos de 
Administração, Computação e TGF privilegiam as informações que são apresentadas em formas textuais, ou seja, aprendem melhor verbalmente.

Cabe ressaltar-se que se utilizaram, para esta análise, somente os dados dos participantes que responderam ao teste; e neste não houve nenhum aluno classificado como analítico.

\subsection{Dados etnográficos dos estudantes}

Mediante as tabelas 3, 4 e 5 será apresentado o perfil etnográfico do grupo pesquisado.

A Tabela 3 apresenta o gênero dos estudantes.

Tabela 3 - Gênero dos estudantes

\begin{tabular}{lcccccc}
\hline & $\mathbf{F}$ & $\mathbf{\%}$ & $\mathbf{M}$ & $\mathbf{\%}$ & Total & $\mathbf{\%}$ \\
\hline Administração & 15 & 14,56 & 26 & 25,24 & 41 & 39,8 \\
Computação & 11 & 10,70 & 42 & 40,78 & 53 & 51,46 \\
TGF & 01 & 0,97 & 08 & 7,77 & 09 & 8,74 \\
Total & 27 & 26,21 & 76 & 73,79 & 103 & 100 \\
\hline
\end{tabular}

A Tabela 4 retrata as etnias dos participantes do estudo.

Tabela 4 - Etnia dos estudantes

\begin{tabular}{lcccccc}
\hline & $\begin{array}{c}\text { Amarela } \\
(\mathbf{\%})\end{array}$ & $\begin{array}{c}\text { Branca } \\
\mathbf{( \% )}\end{array}$ & $\begin{array}{c}\text { Negra } \\
\mathbf{( \% )}\end{array}$ & $\begin{array}{c}\text { Parda } \\
\mathbf{( \% )}\end{array}$ & $\begin{array}{c}\text { Eliminados* } \\
\mathbf{( \% )}\end{array}$ & $\begin{array}{c}\text { Total } \\
(\mathbf{\%})\end{array}$ \\
\hline Administração & 0,97 & 14,56 & 0,97 & 1,94 & 21,4 & 39,80 \\
Computação & - & 31,07 & 2,91 & 3,88 & 13,59 & 51,46 \\
TGF & - & 0,97 & - & 0,97 & 6,80 & 8,74 \\
Total & 0,97 & 46,60 & 3,88 & 6,80 & 41,75 & 100 \\
\hline
\end{tabular}

* Foram eliminados os dados dos alunos que não responderam ou responderam incorretamente. 
Para levantamento da etnia dos participantes, utilizou-se a classificação do Censo do Instituto Brasileiro de Geografia e Estatística (IBGE), que dispõe das seguintes opções: branca, negra, parda, amarela, indígena e outra. Embora orientados, muitos alunos responderam incorretamente, e outros não responderam a esta pergunta, haja vista que esta informação não é muito utilizada no Brasil. A Tabela 5 apresenta a idade do grupo.

Tabela 5 - Idade dos estudantes

\begin{tabular}{lcccc}
\hline & $\begin{array}{c}\text { Geral } \\
(\mathbf{\%})\end{array}$ & $\begin{array}{c}\text { Administração } \\
(\mathbf{\%})\end{array}$ & $\begin{array}{c}\text { Computação } \\
\mathbf{( \% )}\end{array}$ & $\begin{array}{c}\text { TGF } \\
\mathbf{( \% )}\end{array}$ \\
\hline Até 20 anos & 0,97 & 0,97 & - & - \\
De 21 a 30 anos & 30,10 & 7,77 & 21,36 & 0,97 \\
De 31 a 40 anos & 42,72 & 21,36 & 18,45 & 2,91 \\
De 41 a 50 anos & 20,39 & 6,80 & 9,71 & 3,88 \\
Acima 50 anos & 5,82 & 2,91 & 1,94 & 0,97 \\
Total & 100 & 39,81 & 51,46 & 8,73 \\
\hline
\end{tabular}

Observa-se que a maior concentração está entre 31 a 40 anos, o que denota ser uma população ativa, que reflete o panorama brasileiro no qual as pessoas driblam a concorrência e buscam melhores oportunidades. Esta situação tem levado as pessoas a buscar uma formação de nível superior e/ou uma nova capacitação visando novos horizontes.

Um fato importante em relação à idade, que foi discutido por Riding e Al-Sanabani (1998) é que, com o passar do tempo (com a idade), as pessoas desenvolvem estratégias de aprendizagem mais efetivas, utilizando os aspectos positivos de seu estilo. De acordo com este relato, é possível afirmar que esta população estudada já está preparada para desenvolver suas estratégias de aprendizagem. 


\subsection{Análise das variáveis dependentes e independentes}

As variáveis utilizadas no estudo são apresentadas no Quadro 7.

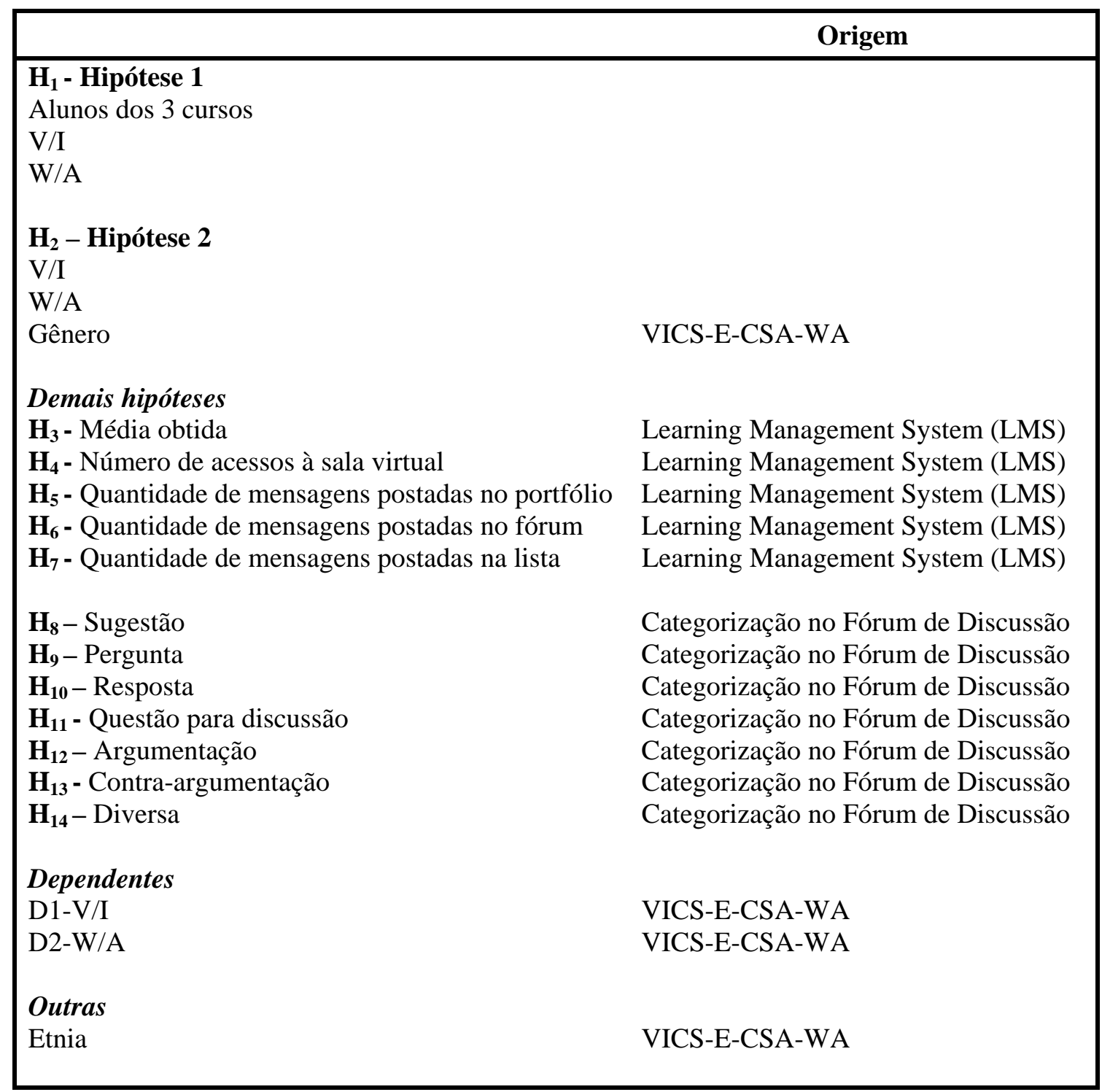

Quadro 7 - Distribuição das variáveis utilizadas

A Tabela 6 apresenta a comparação entre as dimensões cognitivas por curso. 
Tabela 6 - Estilos cognitivos dos estudantes de EAD nas dimensões verbal (V) e imagético (I)

\begin{tabular}{lccc}
\hline & I (\%) & V (\%) & Total (\%) \\
\hline Administração & 24,4 & 75,6 & 100 \\
Computação & 38,3 & 61,7 & 100 \\
TGF & 22,2 & 77,8 & 100 \\
Total & 32,2 & 67,8 & 100 \\
\hline
\end{tabular}

Mediante a realização do teste $\chi^{2}$ para comparar os três cursos na dimensão imagético e verbal, encontra-se diferença significativa, em que os cursos de Administração e TGF, que possuem percentual de classificação igual a Imagéticos, é significativamente inferior ao percentual do curso de Computação $(24,4 \%$ e $22,2 \%<38,3 \%)$. No entanto, os cursos de Administração e TGF, que possuem percentual de classificação igual à Verbal, é significativamente superior ao do curso de Computação (75,6\% e 77,8\% > 61,7\%).

Esta informação era esperada, pois geralmente os alunos de Computação atuam mais com imagens, telas, definição de layouts e isto contribuiu para que tenham o estilo cognitivo imagético mais aguçado.

Em relação aos cursos de Administração e TGF possuírem um percentual de verbais superior ao da Computação, justifica-se pelo fato de que possuem maiores interações e trocas, em função do volume de leituras, de teorias aprendidas que necessitam ser discutidas e debatidas, condicionando assim, para a valorização do estilo cognitivo verbal.

Ao comparar os três cursos nas dimensões holístico (W) e analítico (A), utilizando o mesmo teste encontram-se algumas diferenças que são apresentadas na Tabela 7.

Ressalta-se, que utilizando as informações do reteste, encontra-se aluno classificado como analítico no curso de Computação. 
Tabela 7 - Estilos cognitivos dos estudantes de EAD nas dimensões holístico (W) e analítico (A)

\begin{tabular}{lccc}
\hline & A (\%) & W (\%) & Total (\%) \\
\hline Administração & - & 100 & 100 \\
Computação & 5,1 & 94,9 & 100 \\
TGF & - & 100 & 100 \\
Total & 2,9 & 97,1 & 100 \\
\hline
\end{tabular}

Analisando-se a Tabela 7, verifica-se que há diferença significativa: os cursos de Administração e TGF, que possuem percentual de classificação igual a analítico é significativamente inferior ao da Computação $(0,0 \%<5,1 \%)$.

Sabe-se que o curso de Computação exige do aluno uma atuação analítica, pois é necessária a depuração de diferentes problemas e análise de melhores alternativas para desenvolvimento das atividades, e isso se comprova com este resultado.

Entretanto, ao analisar a dimensão cognitiva holística, percebe-se que o percentual do curso de Administração e TGF é significativamente superior ao curso de Computação (100\% $>94,9 \%)$.

Isto reforça a importância e necessidade de visão sistêmica para os alunos de Administração e TGF, uma vez que necessitam conhecer o todo e ter habilidade para extrair o importante, de forma que agreguem valor ao seu conhecimento.

\section{Curso de Administração}

Ao analisar as variáveis numéricas para a variável dependente verbal-imagético (V/I), utilizando o Teste t e nível de significância $p<0.05$, observam-se algumas diferenças significativas, conforme apresentadas na Tabela 8. 
Tabela 8 - Diferenças significativas nas dimensões verbal e imagético (V/I)

\begin{tabular}{ll}
\hline \multicolumn{1}{c}{ Variáveis independentes } & \multicolumn{1}{c}{ Descrição } \\
\hline $\begin{array}{l}\text { Quantidade de mensagens } \\
\text { postadas no fórum }\end{array}$ & $\begin{array}{l}\text { A média de mensagens postadas no fórum por alunos } \\
\text { predominantemente Verbal é superior a dos alunos classificados } \\
\text { como predominantemente Imagéticos. }\end{array}$ \\
Resposta & $\begin{array}{l}\text { A média de resposta dada no fórum por alunos } \\
\text { predominantemente Verbal é superior a dos alunos classificados } \\
\text { como predominantemente Imagéticos. }\end{array}$ \\
Questões para discussão & $\begin{array}{l}\text { A média de questões para discussão postadas no fórum por } \\
\text { alunos predominantemente Imagéticos é superior a dos alunos } \\
\text { classificados como predominantemente Verbal. }\end{array}$ \\
Argumentação & $\begin{array}{l}\text { A média de argumentações dadas no fórum por alunos } \\
\text { predominantemente Verbal é superior a dos alunos classificados } \\
\text { como predominantemente Imagéticos. }\end{array}$ \\
Diversa & $\begin{array}{l}\text { A média de diversa dos alunos predominantemente Verbal é } \\
\text { superior a dos alunos classificados como predominantemente } \\
\text { Imagéticos. }\end{array}$ \\
\hline
\end{tabular}

Analisando a Tabela 8 percebe-se que há uma predominância dos verbais sobre os imagéticos com diferença significativamente superior no curso de Administração, com exceção da variável questões para discussão, em que os imagéticos sobressaem. Isso mostra que, mesmo sendo os verbais mais comunicativos textualmente, não arriscam proposições no fórum.

Em relação às dimensões holístico/analítico, não foram efetuadas análises, uma vez que nenhum aluno se classificou como analítico.

\section{Curso de Computação}

Analisando as variáveis independentes à luz das dimensões verbal/imagético, obteveram-se algumas diferenças significativas, tendo como nível de significância $p<0.05$, conforme observado na Tabela 9. 
Tabela 9 - Diferenças significativas nas dimensões verbal e imagético (V/I)

\begin{tabular}{|c|c|}
\hline Variáveis Independentes & Descrição \\
\hline Média obtida & $\begin{array}{l}\text { A média das médias obtidas pelos alunos Imagéticos foi } \\
\text { superior aos classificados como Verbal. }\end{array}$ \\
\hline $\begin{array}{l}\text { Número de acesso à sala } \\
\text { virtual }\end{array}$ & $\begin{array}{l}\text { A média de número de acessos à sala virtual obtida alunos } \\
\text { Verbais foi superior aos Imagéticos. }\end{array}$ \\
\hline $\begin{array}{l}\text { Mensagens postadas no } \\
\text { fórum }\end{array}$ & $\begin{array}{l}\text { A média de mensagens postadas no fórum por alunos } \\
\text { Imagéticos foi superior aos classificados como Verbal. }\end{array}$ \\
\hline $\begin{array}{l}\text { Mensagens postadas na } \\
\text { lista }\end{array}$ & $\begin{array}{l}\text { A média de mensagens postadas na lista por alunos } \\
\text { classificados como Verbal é superior aos classificados como } \\
\text { Imagéticos. }\end{array}$ \\
\hline Sugestão & $\begin{array}{l}\text { A média de sugestões dadas no fórum por alunos } \\
\text { classificados como Imagético é superior aos classificados } \\
\text { como Verbal. }\end{array}$ \\
\hline Pergunta & $\begin{array}{l}\text { A média de perguntas feitas no fórum por alunos } \\
\text { classificados como Verbal é superior aos classificados como } \\
\text { Imagéticos. }\end{array}$ \\
\hline Resposta & $\begin{array}{l}\text { A média de respostas dadas no fórum por alunos } \\
\text { classificados como Imagético é superior aos classificados } \\
\text { como Verbal. }\end{array}$ \\
\hline Contra-argumentação & $\begin{array}{l}\text { A média de contra-argumentação manifestada no fórum por } \\
\text { alunos classificados como Verbal é superior aos } \\
\text { classificados como Imagético. }\end{array}$ \\
\hline Diversa & $\begin{array}{l}\text { A média de mensagens identificadas como diversa postada } \\
\text { por alunos classificados como Verbal é superior à média dos } \\
\text { Imagéticos. }\end{array}$ \\
\hline
\end{tabular}

Analisando a Tabela 9, nota-se um leve equilíbrio entre verbais e imagéticos do curso de Computação em relação às variáveis numéricas do fórum.

A exceção está na média obtida, em que os imagéticos são significativamente superiores aos verbais. Este resultado reforça a idéia de que os alunos de Computação trabalham mais com esquemas representativos visuais e, com isso, tendem a se sobressaírem nas avaliações que privilegiam este estilo, obtendo médias superiores aos verbais. 
Em relação às dimensões holístico/analítico as diferenças significativas são apresentadas na tabela 10 .

Tabela 10 - Diferenças significativas nas dimensões holístico e analítico (W/A)

\begin{tabular}{ll}
\hline \multicolumn{1}{c}{ Variáveis } & \multicolumn{1}{c}{ Descrição } \\
\hline Mensagens postadas na lista & $\begin{array}{l}\text { A média de mensagens postadas na lista por alunos } \\
\text { classificados como Analítico é superior aos classificados } \\
\text { como Holísticos. }\end{array}$ \\
Sugestão & $\begin{array}{l}\text { A média de sugestão dada por alunos Holísticos foi } \\
\text { superior aos classificados como Analíticos. }\end{array}$ \\
Resposta & $\begin{array}{l}\text { A média de sugestões dadas no fórum por alunos } \\
\text { Questósticos foi superior aos classificados como Analíticos. }\end{array}$ \\
Contra-argumentação & $\begin{array}{l}\text { A média de questões para discussão postadas no fórum } \\
\text { por alunos Holísticos foi superior aos Analíticos. }\end{array}$ \\
& A média de contra-argumentação no fórum dos alunos \\
& Holísticos foi superior aos alunos Analíticos.
\end{tabular}

O aluno holístico do curso de Computação tem larga vantagem sobre o analítico quando analisadas as variáveis numéricas do fórum. Este resultado é surpresa, uma vez que se esperava que os alunos de Computação fossem mais analíticos do que holísticos, em função das exigências do curso.

Mediante a ANOVA multivariada, e mantendo o nível significância $\mathrm{p}<0.05$, foi analisado o efeito de V/I e W/A sobre as variáveis dependentes; com isso foi possível destacarem-se as diferenças significativas de um conjunto de dimensões independentes (V/I ou W/A), com exceção para a variável média obtida (Tabela 11). 
Tabela 11 - Características das dimensões cognitivas para variáveis dependentes

\begin{tabular}{lc}
\hline \multicolumn{1}{c}{ Variáveis } & Características \\
\hline Média obtida * & $\mathrm{I}>\mathrm{V}$ \\
Quantidade de mensagens na lista & $\mathrm{A}>\mathrm{W}$ \\
Sugestão & $\mathrm{A}<\mathrm{W}$ \\
Pergunta & $\mathrm{V}>\mathrm{I}$ \\
Resposta & $\mathrm{I}>\mathrm{V}$ \\
\hline
\end{tabular}

* Somente para o curso de Computação, analisando V/I e W/A simultaneamente para a variável dependente média obtida, verifica-se que uma dimensão afeta a outra, ou seja, V/I $(\mathrm{p}<0.001 ; \mathrm{I}>\mathrm{V})$ não há diferença devido a variável W/A $(\mathrm{p}=0,34)$ e a interação ser significativa ( $p=0,001)$, portanto, a diferença entre $V$ e I não é a mesma para $W$ e $A$, assim:

Em A I = 7,81 $\pm 2,33$ e V $=4,66 \pm 3,27 \quad p=0,001$

Em W I $=6,8 \pm 2,67$ e V $=6,44 \pm 7,3 \quad p=0,04$

Logo, a interação foi significativa demonstrando que há uma diferença de magnitude entre as distâncias de V e I, conforme o resultado de W/A.

Para as demais variáveis uma dimensão tem diferença significativa sobre a outra isoladamente.

\section{Curso TGF}

As diferenças significativas obtidas por meio da análise das variáveis independentes para as dimensões verbal e imagético são apresentadas na Tabela 12. 
Tabela 12 - Diferenças significativas nas dimensões verbal e imagético (V/I)

\begin{tabular}{|c|c|}
\hline Variáveis & Descrição* \\
\hline Número de acessos à sala virtual & $\begin{array}{l}\text { A média do número de acessos à sala virtual por alunos } \\
\text { classificados como Verbal é superior aos alunos } \\
\text { classificados como Imagéticos. }\end{array}$ \\
\hline Sugestão & $\begin{array}{l}\text { A média de sugestões dadas no fórum por alunos } \\
\text { classificados como Verbal é inferior aos alunos } \\
\text { Imagéticos. }\end{array}$ \\
\hline Pergunta & $\begin{array}{l}\text { A média de perguntas feitas no fórum por alunos } \\
\text { Verbais é superior aos alunos classificados como } \\
\text { Imagéticos. }\end{array}$ \\
\hline Resposta & $\begin{array}{l}\text { A média de respostas dadas no fórum por alunos } \\
\text { Verbais é inferior aos alunos classificados como } \\
\text { Imagéticos. }\end{array}$ \\
\hline Questões para discussão & $\begin{array}{l}\text { A média de questões para discussão postadas no fórum } \\
\text { por alunos classificados como Imagéticos é inferior a } \\
\text { dos alunos Verbais. }\end{array}$ \\
\hline Diversa & $\begin{array}{l}\text { A média de mensagens postadas no fórum e } \\
\text { classificadas como diversa por alunos Verbais é } \\
\text { superior a dos alunos Imagéticos. }\end{array}$ \\
\hline
\end{tabular}

$* \mathrm{p}<0.05$

Comparando este resultado com o resultado dos alunos de Administração, que teoricamente deveriam ter um estilo semelhante, encontram-se informações divergentes, mostrando e reforçando a idéia de que as pessoas são diferentes, têm comportamentos e atitudes diferentes e naturalmente estudam e aprendem de maneira diferenciada uma das outras.

Para as dimensões holístico/analítico, não foram efetuadas análises, tendo em vista que nenhum aluno classificou-se como analítico.

Para ilustrar as variáveis numéricas analisadas, tomaram-se, como referências, as disciplinas Administração I, Linguagem de Programação Estruturada I e Técnicas de Programação Visual, para apresentar os números obtidos, conforme apresentado no Quadro 8. 


\begin{tabular}{|lccccccc|}
\hline & \multicolumn{2}{c}{ Adminsitração I } & \multicolumn{2}{c|}{$\begin{array}{c}\text { Pinguagem } \\
\text { Programação } \\
\text { Estruturada I }\end{array}$} & $\begin{array}{c}\text { Técnicas de } \\
\text { Programação } \\
\text { Visual }\end{array}$ \\
\hline & Máx. & Min. & Máx. & Min. & Máx. & Min. \\
\hline Média obtida & 9,9 & 1,8 & 10 & 1,0 & 10 & 6,3 \\
Número de acessos à sala virtual & 703 & 0 & 1.153 & 14 & 419 & 79 \\
Quant. mensag. postadas portfólio & 24 & 0 & 16 & 1 & 16 & 12 \\
Quant. mensag. postadas fórum & 52 & 1 & 8 & 0 & 11 & 2 \\
Quant. mensag. postadas lista & 21 & 0 & 46 & 0 & 17 & 0 \\
Sugestão & 1 & 0 & 8 & 0 & 5 & 0 \\
Pergunta & 8 & 0 & 19 & 0 & 3 & 0 \\
Resposta & 26 & 0 & 13 & 0 & 22 & 2 \\
Questão para discussão & 17 & 0 & 1 & 0 & 0 & 0 \\
Argumentação & 0 & 0 & 0 & 0 & 0 & 0 \\
Contra-argumentação & 0 & 0 & 1 & 0 & 0 & 0 \\
Diversa & 20 & 1 & 23 & 0 & 8 & 0 \\
\hline
\end{tabular}

\section{Quadro 8 - Quantificação das variáveis numéricas e independentes}

Analisando a participação dos alunos no ambiente de aprendizagem e a categorização no fórum de discussão, percebe-se que há pouquíssima participação dos alunos; no entanto, ressalta-se que o ambiente de aprendizagem, denominado pela Instituição de Sala Virtual, possui várias ferramentas; entretanto, as mesmas não são de uso mandatório. O professor responsável pela disciplina tem autonomia para administrar o sistema, podendo utilizá-las ou não.

Percebeu-se, também, que o ambiente não é amplamente utilizado pelo fato da Instituição dispor de um telefone 0800 (ligação gratuita), através do qual os alunos podem fazer contato direto com os tutores, para qualquer tipo de esclarecimento. Este procedimento provavelmente tem limitado a participação do aluno na sala virtual.

Neste sentido, é louvável a iniciativa da Instituição de disponibilizar diferentes canais de comunicação; no entanto, é interessante que a mesma, juntamente com coordenadores e professores, planejem uma maneira efetiva de estimular a participação dos alunos na sala 
virtual, pois isto facilitará/proporcionará maior interação, participação e, conseqüentemente, colaboração e cooperação, princípios estes que permeiam a EAD.

Comparando este resultado com o estudo de Schrire (2004), em que analisou as discussões do fórum de um curso de doutorado, cuja participação era incentivada pelo professor, porém não mandatória, concluiu que apesar da maioria das discussões propostas (92,3\%) terem sido iniciadas pelo professor, as ferramentas de colaboração eletrônica contribuem para o processo de aprendizagem e que as abordagens instrucionais de colaboração são mais efetivas do que a abordagem individual. Com isso, percebe-se a importância do fórum, mesmo em diferentes níveis de maturidade acadêmica.

\subsection{Análise dos dados etnográficos segundo as dimensões cognitivas}

Utilizando o teste do $\chi^{2}$ e nível de significância $\mathrm{p}<0.05$ para comparar a variável gênero com a combinação das dimensões cognitivas de acordo com o curso, foi possível identificarem-se certas diferenças significativas, conforme as tabelas seguintes.

Tabela 13 - Diferenças significativas nas dimensões cognitivas para a variável gênero, no curso de Administração

\begin{tabular}{lccc}
\hline & \multicolumn{2}{c}{ V/I } & Total \\
\cline { 2 - 3 } & $\mathbf{I ~ ( \% )}$ & $\mathbf{V ~ ( \% )}$ & $\mathbf{( \% )}$ \\
\hline Feminino & 40 & 60 & 100 \\
Masculino & 15,4 & 84,6 & 100 \\
\hline
\end{tabular}

A tabela 13 com $\chi^{2}=50,01 \mathrm{p}<0.001$ apresenta diferença significativa, cujo percentual de mulheres com classificação I (imagético) é significativamente superior ao percentual de homens com a mesma classificação. Já o percentual de mulheres classificadas como V 
(verbal) é significativamente inferior ao percentual de homens da mesma classificação.

Este resultado diverge do estudo de Lemes (1998), que analisou os estilos cognitivos campo-dependente e campo-independente em alunos de Ciências Exatas e Ciências Humanas, aplicando o instrumento Group Embedded Figures Test (GEFT), e afirma que os homens obtêm pontuações superiores às mulheres, uma vez que as mulheres têm mais dificuldade para visualizar figuras.

Não foi realizada análise para as dimensões W/A pelo fato de não haver nenhum aluno classificado como A (analítico).

Tabela 14 - Diferenças significativas nas dimensões cognitivas para a variável gênero, no curso de Computação

\begin{tabular}{lccc}
\hline & \multicolumn{2}{c}{ W/A } & \multirow{2}{*}{$\begin{array}{c}\text { Total } \\
\text { (\%) }\end{array}$} \\
\cline { 2 - 3 } Feminino & $\mathbf{A ~ ( \% )}$ & W (\%) & 100 \\
Masculino & 7,7 & 92,3 & 100 \\
\hline
\end{tabular}

A Tabela 14 com $\chi^{2}=4,27 \mathrm{p}=0.04$, observa-se que o percentual de mulheres analíticas (A) é significativamente superior ao percentual de homens com a mesma classificação. No entanto, o percentual de mulheres holísticas (W) é significativamente inferior ao percentual de homens desta dimensão.

Este resultado está em conformidade com o de Lemes (1998) e o de Bariani (1998).

Não houve diferença significativa para a dimensão V/I.

Para verificar se as dimensões cognitivas impactavam o gênero dos alunos do curso TGF, utilizou-se o teste exato de Fisher, e se encontrou diferença significativamente inferior no percentual de mulheres classificadas como I (imagéticas) em relação aos homens desta dimensão. No entanto, encontrou-se diferença, significativamente superior, em mulheres da dimensão V (verbal), comparando-se com homens da mesma classificação (Tabela 15). 
Tabela 15 - Diferenças significativas nas dimensões cognitivas para a variável gênero, no curso de TGF

\begin{tabular}{|c|c|c|c|}
\hline & \multicolumn{2}{|c|}{$\mathbf{V} / \mathbf{I}$} & \multirow{2}{*}{$\begin{array}{c}\text { Total } \\
(\mathbf{\%})\end{array}$} \\
\hline & I (\%) & V (\%) & \\
\hline Feminino & - & 100 & 100 \\
\hline Masculino & 25 & 75 & 100 \\
\hline
\end{tabular}

Embora tenha encontrado várias semelhanças entre os cursos de Administração e TGF, este resultado diverge do obtido na Administração, uma vez que lá as mulheres de percentual verbal é que é significativamente superior aos homens.

Comparando estes resultados acerca das diferenças entre os gêneros nos diferentes cursos, verifica-se que os mesmos são semelhantes ao obtido por Logan e Thomas (2002) que, embora utilizando instrumentos diferentes, encontraram diferenças significativas entre homens e mulheres.

As dimensões W/A não foram analisadas por não haver nenhum aluno A (analítico).

Tomando como referência $\mathrm{p}<0.05$ e utilizando o teste $\chi^{2}$, comparou-se a variável etnia com as dimensões cognitivas para cada curso pesquisado. Os resultados são apresentados nas tabelas seguintes.

Tabela 16 - Diferenças significativas nas dimensões cognitivas para a variável etnia, no curso de Administração

\begin{tabular}{lccc}
\hline & \multicolumn{2}{c}{ V/I } & $\begin{array}{c}\text { Total } \\
\mathbf{( \% )}\end{array}$ \\
\cline { 2 - 3 } & $\mathbf{I ~ ( \% )}$ & $\mathbf{V ~ ( \% )}$ & 100 \\
Branca & 20 & 80 & 100 \\
Negra & 100 & - & 100 \\
Parda & - & 100 & 100 \\
Amarela & 100 & - & \\
\hline
\end{tabular}

Observa-se diferença significativa; o percentual de negros e amarelos com 
classificação I (imagéticos) é significativamente superior ao percentual de brancos e pardos com a mesma classificação. Já o percentual de negros e amarelos com classificação V (verbal) é significativamente inferior ao percentual de brancos e pardos desta classificação.

A comparação da variável independente etnia com as dimensões W/A (holístico/analítico) não foi realizada por não haver resposta A (analítico).

Tabela 17 - Diferenças significativas nas dimensões cognitivas (V/I) para a variável etnia, no curso de Computação

\begin{tabular}{lccc}
\hline & \multicolumn{2}{c}{ V/I } & $\begin{array}{c}\text { Total } \\
\mathbf{( \% )}\end{array}$ \\
\cline { 2 - 3 } Branca & $\mathbf{I ~ ( \% )}$ & $\mathbf{V ~ ( \% )}$ & 100 \\
Negra & 32,9 & 67,1 & 100 \\
Parda & 33,3 & 66,7 & 100 \\
\hline
\end{tabular}

Verifica-se que o percentual de brancos com classificação I (imagético) é significativamente inferior ao percentual de pardos da mesma classificação. No entanto, o percentual de brancos com classificação V (verbal) é significativamente superior ao percentual de pardos com esta classificação.

Para as dimensões W/A (holístico/analítico), utilizou-se o teste exato de Fisher, em que o percentual de pardos com classificação A (analítico) é significativamente inferior ao de brancos da mesma classificação. Já o percentual de pardos classificados como W (holístico) é significativamente superior ao de brancos desta classificação (Tabela 18). 
Tabela 18 - Diferenças significativas nas dimensões cognitivas (W/A) para a variável etnia, no curso de Computação

\begin{tabular}{lccc}
\hline & \multicolumn{2}{c}{ W/A } & Total \\
\cline { 2 - 3 } & $\mathbf{A ~ ( \% )}$ & W (\%) & $\mathbf{( \% )}$ \\
\hline Branca & 5,8 & 94,2 & 100 \\
Negra & - & 100 & 100 \\
Parda & 5,1 & 94,9 & 100 \\
\hline
\end{tabular}

Mediante a tabela 19 é possível observar os dados do curso TGF, em que se utilizou o teste exato de Fisher e o nível de significância $\mathrm{p}<0.05$; com isso, verifica-se que há diferença significativamente inferior no percentual de pardos com classificação I (imagético) em relação aos brancos. Já o percentual de pardos classificados como V (verbal) é significativamente superior ao de brancos.

Tabela 19 - Diferenças significativas nas dimensões cognitivas para a variável etnia, no curso TGF

\begin{tabular}{|c|c|c|c|}
\hline & \multicolumn{2}{|c|}{ V/I } & \multirow{2}{*}{$\begin{array}{c}\text { Total } \\
\text { (\%) }\end{array}$} \\
\hline & I (\%) & V (\%) & \\
\hline Branca & 100 & - & 100 \\
\hline Parda & - & 100 & 100 \\
\hline
\end{tabular}

A análise das dimensões W/A (holístico/analítico) não foi realizada por não haver resposta A (analítico).

Os resultados obtidos e apresentados nas Tabelas 16, 17, 18 e 19 confirmam e complementam o resultado obtido por Kranc (1997), que afirma existir diferença significativa nos resultados cognitivos considerando as etnias. 


\subsection{Estilos cognitivos e comparações entre cursos}

Com base nos resultados obtidos e comparando os três cursos, verificou-se que há diferenças significativas entre os estilos cognitivos dos alunos; que homens e mulheres diferem em suas preferências cognitivas, que a etnia é diferente e significativa em grupos distintos. Entretanto, encontraram-se algumas semelhanças entre os alunos do curso de Administração e TGF, fato esperado em função da semelhança entre cursos; no entanto, diferem significativamente dos alunos da Computação.

Tomando como referência a variável média obtida no curso de Computação, verificouse que os imagéticos possuem média significativamente superior aos verbais; este resultado está em não-conformidade com o estudo de Brenner (1997), que concluiu que os estilos cognitivos não impactam a habilidade para o sucesso acadêmico dos alunos de educação a distância. Assim como também não confere com os resultados obtidos por Workman (2004), que relata que os estilos cognitivos não têm relação significativa com o desempenho atual do aluno.

Entretanto, ao comparar os resultados obtidos nesta variável para os cursos de Administração e TGF, os mesmos são semelhantes aos dois estudos acima citados.

Ao analisar o teste e reteste do instrumento VICS-E-CSA-WA, perceberam-se algumas limitações, uma vez que o reteste não retornou os mesmos resultados do teste. Acredita-se que isto tenha ocorrido em função de ser um instrumento novo, estando em fase de validação, e provavelmente as diferenças culturais também possam ter influenciado.

Verificou-se que nos três cursos estudados, 70\% das variáveis independentes obtiveram valores significativos, o que pode evidenciar boas perspectivas de pesquisa sobre o tema estilos cognitivos em EAD, em que as diferenças encontradas revelam a necessidade de cursos mais customizados, onde as características individuais dos alunos sejam mais 
privilegiadas.

O quadro 9 sintetiza alguns dos resultados obtidos, revelando as diferenças significativas encontradas em cada variável por curso.

\begin{tabular}{|ll|}
\hline & Diferença significativa encontrada \\
\hline $\mathbf{H}_{\mathbf{1}}$ - Hipótese $\mathbf{1}$ & Administração, Computação e TGF \\
V/I & Computação \\
W/A & \\
$\mathbf{H}_{2}$ - Hipótese 2 & Administração, Computação* e TGF \\
Gênero & \\
Demais hipóteses & \\
$\mathbf{H}_{3}$ - Média obtida & Computação \\
$\mathbf{H}_{\mathbf{4}}$ - Número de acessos à sala virtual & Computação e TGF \\
$\mathbf{H}_{5}$ - Quantidade de mensagens postadas no portfólio & Nenhuma diferença encontrada \\
$\mathbf{H}_{\mathbf{6}}$ - Quantidade de mensagens postadas no fórum & Administração, Computação \\
$\mathbf{H}_{\mathbf{7}}$ - Quantidade de mensagens postadas na lista & Computação \\
$\mathbf{H}_{\mathbf{8}}$ - Sugestão & Computação e TGF \\
$\mathbf{H}_{9}$ - Pergunta & Computação e TGF \\
$\mathbf{H}_{\mathbf{1 0}}$ - Resposta & Administração, Computação e TGF \\
$\mathbf{H}_{11}$ - Questão para discussão & Administração e TGF \\
$\mathbf{H}_{\mathbf{1 2}}$ - Argumentação & Administração \\
$\mathbf{H}_{13}$ - Contra-argumentação & Computação \\
$\mathbf{H}_{\mathbf{1 4}}$ - Diversa & Administração, Computação e TGF \\
Outras & \\
Etnia & Administração, Computação e TGF \\
\hline
\end{tabular}

\section{Quadro 9 - Síntese das diferenças significativas entre os cursos por variável}

* Apresentou diferença significativa somente na dimensão W/A.

Ao analisar detalhadamente os resultados obtidos e apresentados juntamente com a síntese do Quadro 9, observou-se:

- que das 16 variáveis analisadas, a quantidade de mensagens postadas no portfólio foi a única que não obteve diferença significativa entre uma dimensão e outra em todos os cursos;

- que no curso de Administração, oito (8) variáveis apresentaram diferença significativa;

- que o curso de Computação apresentou 12 variáveis com diferença significativa; 
- que o curso TGF obteve diferença significativa em 9 variáveis analisadas.

Ao combinar os cursos Administração com Computação, encontraram-se seis (6) variáveis comuns com diferença significativa; Administração com TGF, foram também seis (6) variáveis comuns com diferença significativa; e para a combinação de Computação com TGF encontraram-se oito (8) variáveis comuns com diferença significativa.

Analisando a variável média obtida no curso de Computação, verificou-se que I > V, podendo atribuir tal diferença, possivelmente ao tipo de avaliação elaborada, uma vez que provavelmente está privilegiando o aluno imagético.

Em relação à variável número de acessos à sala virtual, percebeu-se que no curso de Computação, assim como no TGF, há necessidade de maior incentivo ao aluno imagético, pois o número de verbais é significativamente superior; este pouco acesso do imagético pode estar associado à interface do ambiente e/ou falta de incentivo para visitar a sala virtual diariamente.

Observou-se que o aluno imagético da Computação gosta muito do fórum (I > V) e conseqüentemente, participa ativamente, dando sugestões e respostas; no entanto, percebeu-se que não gosta muito da lista $(\mathrm{V}>\mathrm{I})$; assim, é interessante que o aluno imagético seja estimulado a participar também da lista. Para o curso TGF, o aluno verbal deve ser incentivado a ser mais ousado, a participar mais ativamente, ou seja, dar mais sugestões.

Verificou-se que o aluno verbal do curso TGF dá poucas respostas; assim, sugere-se alterar a forma de apresentação da pergunta para que possa dar respostas mais freqüentemente. Já na Administração as perguntas elaboradas não estão motivando o aluno imagético a dar respostas; portanto, é interessante a elaboração de perguntas que atendam às preferências do imagético além da constante provocação a participar.

Para a variável questão para discussão, verificou-se que na Administração é necessário provocar o verbal e no curso TGF, o imagético, de forma que os mesmos 
participem mais do fórum, que levantem questões para discussão a serem comentadas e discutidas pelo grupo.

Com relação à argumentação, percebeu-se que na Administração é necessário estimular o imagético a dar respostas mais elaboradas, contextualizadas, ou seja, ter uma argumentação mais consistente.

A análise da variável contra-argumentação mostrou que é preciso deixar claro para o aluno imagético da Computação que não basta apenas concordar, que ele pode e deve contraargumentar quando achar necessário.

Este estudo tomou como referência a importância da instituição universitária de EAD, no sentido de conhecer e testar novas maneiras de conhecer o aluno, visando um curso mais personalizado e, naturalmente, melhoria na qualidade da aprendizagem.

Buscou-se explorar mais profundamente as características cognitivas da população em estudo, a fim de propiciar subsídios às Instituições de EAD para que planejem os seus cursos de forma a atender às características dos alunos, possibilitando uma aprendizagem mais eficaz, pois, conforme relatado no início deste estudo, futuramente só vão se manter as instituições que tiverem qualidade, ou melhor, qualidade na aprendizagem, pois a fronteira geográfica não será mais problema, e a demanda reprimida, que hoje existe, não existirá mais.

Os resultados do presente estudo revelam que as pessoas são diferentes, possuem estilos, atitudes e comportamentos que diferem uns dos outros, podendo variar e/ou mudar conforme o momento, pois não são características fixas.

A predominância de estilo cognitivo verbal na amostra pesquisada pode parcialmente justificar a pouca participação na sala virtual, pois provavelmente os alunos preferem ligar no telefone (0800) para falar diretamente com os tutores. Este é um fato surpresa, pois esperava que alunos de EAD tivessem maior interação on-line.

O fato de no Brasil não existirem muitos estudos desta natureza com alunos de EAD, 
dificulta a balização dos resultados para proposições de melhores estratégias. No entanto, serve de parâmetro para novas iniciativas.

Os resultados obtidos mostram que os alunos são diferentes e, com isso, necessitam de estratégias que atendam às características individuais de cada um; ficando clara a importância da elaboração de estratégias de aprendizagem que abranjam o maior número possível de alunos, visando à melhoria da qualidade da aprendizagem do aluno de EAD.

Uma análise mais detalhada dos resultados mostra que a predominância do estilo cognitivo independe do perfil do aluno. No entanto, ficou claro que os diferentes cursos de EAD possuem alunos com preferências cognitivas diferentes.

Este resultado deixa evidente a necessidade de estratégias de aprendizagem diversificadas, pois, se o professor ensinar exclusivamente de uma maneira que favoreça o modo menos preferencial de seus alunos dentre os estilos cognitivos, o nível de desconforto pode se tornar suficientemente grande para interferir no rendimento do processo. Por outro lado, se o professor ensinar exclusivamente com o estilo preferido por seus alunos, eles poderão não desenvolver a destreza mental de que necessitam para enriquecer seu potencial de realização na escola e como profissionais, uma vez que o estudante mais completo é aquele que consegue criar diferentes estratégias, em diferentes situações; daí a relevância do autoconhecimento e do autodomínio.

Cabe ressaltar que fatores sociais, culturais e pré-existentes ao estudante de EAD podem atuar na formação de seu estilo cognitivo, principalmente por se tratar de uma população ativa que está predominantemente na faixa dos 30 a 40 anos.

Ao avaliar a participação dos alunos no ambiente on-line, percebeu-se pouco engajamento e, como já relatado, as ferramentas disponíveis na sala virtual não são de uso obrigatório; no entanto, algumas considerações podem ser tecidas acerca da discussão on-line, tais como: 
- o professor deve planejar e participar das discussões, apresentando claramente os objetivos das mesmas, além de propor questões bem elaboradas; deveria também provocar e motivar a participação do aluno, uma vez que estas ações poderão contribuir para a construção do conhecimento do aluno, atingindo assim, os objetivos da aprendizagem;

- a motivação intrínseca do aluno e o seu conhecimento prévio a respeito do assunto em discussão pode influenciar sua participação na mesma;

- segundo Zhu (2006), a presença do professor na discussão é um dos fatores que influencia a interação, além de outras variáveis; assim, para que os estudantes aprendam na discussão on-line, o professor deve trabalhar com as variáveis que têm maior impacto na aprendizagem e no desempenho do aluno.

Verificou-se, neste estudo, que o estilo cognitivo verbal é predominante nos três cursos pesquisados e de acordo com Graff (2006), que relata que o comportamento interativo on-line do estudante, está relacionado ao estilo cognitivo. Desta forma, era esperado um comportamento mais participativo dos alunos no fórum, mesmo sem a obrigatoriedade, pois a forma textual é agradável ao “verbalizador”.

A expectativa de maior participação dos alunos verbais é sustentada quando se analisa o estudo de Riding (1994) que sugere que os verbais tendem a focar as coisas externas, preferindo ambientes estimulantes e um grupo social no qual possam encontrar uma extensão deles mesmos. Já os imagéticos focam mais as coisas internas, são mais passivos e preferem um ambiente estático, preferem observar os grupos sociais à distância e podem ser menos sociáveis.

O fato da maioria absoluta dos estudantes pesquisados neste estudo, serem predominantemente verbal contradiz o que diz Felder e Soloman (2007) “... a maioria das pessoas são aprendizes visuais, o que significa que muitos estudantes não absorvem a informação como desejariam se a mesma não for apresentada visualmente”. Entretanto, é 
importante destacar que se trata de uma outra cultura, de um outro público pesquisado e de uma amostra restrita.

Apesar de não ter identificado nenhum aluno analítico no curso de Administração e TGF, obteveram-se resultados interessantes, mostrando que novos estudos podem ser realizados para identificar as causas deste resultado. 


\section{CONSIDERAÇÕES FINAIS}

A Educação a Distância vive um momento de busca por ferramentas e instrumentos que auxiliem as Instituições de Ensino Superior a Distância a encontrar meios para que possam melhorar e garantir a qualidade dos cursos ofertados, pois em um futuro bem próximo, só se manterão neste “mercado" de EAD as instituições que comprovarem a qualidade dos cursos e da aprendizagem, pois já não existirá mais a fronteira geográfica e muito menos esta demanda que existe atualmente, que faz com que muitas instituições não prezem os critérios de qualidade e sim os aspectos monetários da atividade.

A busca por conhecer os estilos cognitivos dos estudantes de EAD é uma forma de explorar positivamente as características individuais de cada um, para que esta informação subsidie o planejamento, a elaboração e a execução de cursos a distância, a fim de melhorar o processo ensino-aprendizagem.

O conhecimento dos estilos cognitivos dos alunos de EAD, por parte dos professores, irá facilitar e favorecer o desenvolvimento de estratégias de aprendizagem diversificadas e mais efetivas para cada aluno, e o aluno, ao conhecer seu estilo cognitivo, poderá criar estratégias que favoreçam suas preferências, fortalecendo sua aprendizagem.

Considerando os resultados obtidos, pode-se concluir que as pessoas são diferentes, possuem estilos cognitivos diferentes, independentemente de gênero, idade, curso (...); com isso, pode-se confirmar a primeira hipótese proposta.

Com relação à segunda hipótese, verificou-se que o perfil do aluno de EAD é influenciado pelo gênero: homem e mulher possuem perfis diferentes.

Para as hipóteses $\mathrm{H}_{3}$ a $\mathrm{H}_{14}$ (12 variáveis) que tratam da influência dos estilos cognitivos no perfil do aluno de EAD, verificou-se que no curso de Administração, cinco (5) variáveis apresentaram diferença significativa; Computação: nove (9) variáveis e TGF foram 
seis (6) variáveis com diferença significativa; isso evidencia que o estilo cognitivo influencia o perfil do aluno. Pode-se destacar, por exemplo, que no curso de Computação, das variáveis que compõem o fórum, cinco (5) obtiveram diferença significativa, confirmando que os os estilos cognitivos influenciam o perfil do aluno de EAD.

Em relação aos estilos cognitivos, identificou-se que o estilo predominante entre os estudantes pesquisados é o verbal; no entanto, deve ser ponderado que é importante valorizar as características deste estilo; entretanto, é necessário incentivar o aluno a ousar, a ser versátil, pois se sabe da exigência de profissionais mais sistêmicos que atendam as diversificadas exigências profissionais, pois a flexibilidade de estilos pode favorecer o desempenho profissional.

Ressalta-se que os resultados obtidos neste estudo não permitem generalizações, uma vez que se tratae de uma amostra pequena.

Dentre as contribuições deste estudo podem ser citadas:

- identificação dos estilos cognitivos de alunos de EAD nos diferentes cursos, o que evidencia a necessidade de se adotarem estratégias de aprendizagem diferentes em cada curso, propiciando cursos mais customizados.

- foi possível fornecer subsídios para elaboração de estratégias de aprendizagem mais efetivas, pois, de posse da identificação do estilo cognitivo do aluno, podem-se prever alguns componentes de seu comportamento. Por exemplo: se o aluno de determinado curso é predominantemente imagético, então se deve elaborar um material didático que valorize esta preferência, explorando imagens, diagramas, gráficos, esquemas, além de auxiliar o tutor na condução de atividades baseadas no fórum. Tal como se viu neste estudo, o aluno verbal de Administração posta muito mais mensagens que o imagético; sabendo disso, o tutor poderá, desde o início, estimular e provocar o imagético a participar do fórum; verificou-se que o aluno verbal do curso TGF acessa muito mais a sala virtual 
do que o imagético; com esta informação a coordenação poderá verificar se há algum problema com a interface do ambiente, e o tutor poderá propor alguma atividade que “force” o aluno a entrar diariamente no fórum. Conforme apresentado neste estudo, vários outros elementos podem ser valorizados com o conhecimento das preferências do aluno, em que instituição, professor e alunos só têm a ganhar.

E, como sugestão para novas pesquisas, destacam-se:

- identificar os estilos cognitivos dos alunos de EAD, utilizando outros instrumentos psicométricos confiáveis e válidos em amostras maiores;

- identificar os estilos cognitivos dos alunos de EAD, nos cursos de Administração, Computação e TGF, em outras instituições de ensino, com o objetivo de comparar os estilos cognitivos dos estudantes em diversas instituições de ensino;

- identificar os estilos cognitivos de alunos de EAD de outros cursos.

Esta pesquisa buscou conhecer os estilos cognitivos dos estudantes de EAD e contribuir para a compreensão deste complexo fenômeno, esperando que outros pesquisadores aprofundem a problemática aqui abordada, uma vez que os indicativos deste estudo mostram a importância do (re)conhecimento dos estilos cognitivos e da sua influência no processo ensino-aprendizagem. 


\section{REFERÊNCIAS}

ALLEN, I.E.; SEAMAN, J. (2003). Sizing the opportunity: the quality and extent of online education in the United States, 2002 and 2003. Disponível em: $<$ www.sloanc.org/resources/survey.asp>. Acesso em: 23 Oct. 2006.

ALMEIDA, M.E.B. (2003). Educação a distância na internet: abordagens e contribuições dos ambientes digitais de aprendizagem. Educação e Pesquisa, São Paulo, v.29, n.2, p.327-340, jul./dez.

ALSTETE, J.; BEUTELL, N.J. (2004). Performance indicators in online distance learning courses: a study of management education. Quality Assurance in Education, Bradford, v.12, n.1, p.6-14.

ALLPORT, G.W. (1937). Personalidade: padrões e desenvolvimento. São Paulo: EPU, EDUSP.

AMARAL, S.F. (2004). Educação à distância. Disponível em:<www.unicamp.br/ unicamp/ canal_aberto/clipping/outubro2004/clipping041007_folha.html>. Acesso em: 21 jul. 2006.

ANUÁRIO brasileiro estatístico de educação aberta e a distância. (2005). São Paulo: Instituto Monitor.

. (2006). São Paulo: Instituto Monitor.

ARAÚJO, J.C.S. (1991). Para uma análise das representações sobre as técnicas de ensino. In: VEIGA, I.P.A. (Org.). Técnicas de ensino. Porquê não?. Campinas: Papirus. p.11-34.

AUSUBEL, D.P.; SULLIVAN, E.V. (1970). Theory and problems of child development. New York: Grune and Stratton.

BARIANI, I.C.D. (1998). Estilos cognitivos de universitários e iniciação científica. Tese (Doutorado) - Faculdade de Educação, Universidade Estadual de Campinas, Campinas, 1998.

BRASIL. (1996). Lei de diretrizes e bases da educação nacional - lei nº. 9394, de 20 de dezembro de 1996. Brasília.

. Ministério da Educação. Instituto Nacional de Estudos e Pesquisas Educacionais Anísio Teixeira (2006). Censo escolar 2006 (preliminar). Brasília. Disponível em:<www.inep.gov.br>. Acesso em: 24 nov. 2006.

BRENNER, J. (1997). An analysis of student's cognitive styles in asynchronous distance education courses at a Community College. Richlands: Southwest Virginia Community Coll. Disponível em:<http://eric.ed.gov >. Acesso em: 10 Dec. 2006.

CAPPER, J. (1990). Review of research on interactive videodisc for training. Alexandria: Institute for Defense Analyses. 
CARMINES, E.G.; ZELLER, R.A. (1979). Reliability and validity assessment. California: SAGE.

CHARP, S. (2002). Online learning. THE Journal: technological horizons in education, Santa Ana, v.29, n.8, p.8-9, Mar.

COFFIELD, F. et al. (2004). Should we be using learning styles? What research has to say to pratice. London: Learning and Skills Research Centre.

DAVIS, J.; GRAFF, M. (2006). Wholist-analitic style: a matter reflection. Personality and Individual Differences, Amsterdam, v.41, n.6, p.989-997, Oct.

DRAGO, W.A.; WAGNER, R.J. (2004). Vark preferred learning styles and online education. Management Research News, Bradford, v.27, n.7, p.1-13.

DUNN, R.; DUNN, K. (1987). Dispelling outmoded beliefs about student learning. Educational Leadership. v.44, n.6, p.55-61.

DURLING, D. (1996). Teaching with style: computer aided instruction, personality and design education. Milton Keynes: The Open University.

FELDER, R.B. (2006). Estilos de aprendizagem. Disponível em:

<www2.ncsu.edu/unity/lockers/ users/f/felder/public/RMF.html>. Acesso em: 17 out. 2006.

FELDER, R.; SOLOMAN, B. (2007). Learning styles and strategies. Disponível em: <www.ncsu.edu/felder-public/ILSdir/styles.htm>. Acesso em: 27 Jan. 2007.

FISCINA, F.L.F. (2003). A Internet na educação à distância como ferramenta integral para o crescimento e aprendizagem profissional: o caso SEC-IAT/BA. Dissertação (Mestrado) - . Programa de Pós-Graduação em Engenharia de Produção, Universidade Federal de Santa Catarina, Florianópolis, 2003.

FUKS, H.; GEROSA, M.A.; LUCENA; C.J.P. (2002). Usando a categorização e estruturação de mensagens textuais em cursos pelo ambiente AulaNet. Revista Brasileira de Informática na Educação, Florianópolis, n.10, p.33-44, abr.

GALETTI, A.M. (2006). Desenvolvimento e avaliação psicométrica da escala de seguimento de jogadores: uma medida de avaliação para jogadores patológicos em tratamento. Dissertação (Mestrado) - Faculdade de Medicina, Universidade de São Paulo, São Paulo, 2006.

GOLDSTEIN, K.; BLACKMAN, S. (1978). Cognitive style: five approaches and relevant research. New York: John Wiley.

GRAFF, M. (2006). Constructing and maintaining an effective hypertext-based learning environment: web-based learning and cognitive style. Education + Training, Bradford, v.48, n.2/3, p.143-155. 
HAYES, J.; ALLINSON, C. (1994). Cognitive style and its relevance to management practice. British Journal of Management, Oxford, v.5, n.1, p.53-71, Mar.

KIRTON, M.J. (1976). Adaptors and innovators: a description and measure. Journal of Applied Psychology, Washington, v.61, n.5, p.622-629, Oct.

KRANC, B.M. (1997). The Impact of individual characteristics on telecommunications distance learning cognitive outcomes in adult/nontradicional student. Ph.D. Thesis Education. Raleigh: North Carolina State University, North Carolina, 1997.

KURI, N.P. (2004). Tipos de personalidade e estilos de aprendizagem: proposições para o ensino de engenharia. Tese (Doutorado) - Programa de Pós-Graduação em Engenharia de Produção, Universidade Federal de São Carlos, São Carlos, 2004.

LEMES, S.S. (1998). Os Estilos cognitivos - dependência e independência de campo - na formação e no desempenho acadêmico em duas diferentes áreas do conhecimento: exatas e humanas. Tese (Doutorado) - Instituto de Psicologia, Universidade de São Paulo, São Paulo, 1998.

LITTO, F.M. (2006a). Perspectivas da educação a distância no Brasil: três cenários a ponderar [1997-2002]. Disponível em:

<www.futuro.usp.br/producao_cientifica/artigos/fl_perpectivas ead.htm>. Acesso em: 19 jul. 2006.

. (2006b).Educação a distância. Disponível em: <www.unicamp.br/ unicamp/ canal_aberto/clipping/outubro2004/clipping041007_folha.html>. Acesso em: 21 ago. 2006.

LOGAN, K.; THOMAS, P. (2002). Learning styles in distance education students learning to program. In: WORKSHOP OF THE PSYCHOLOGY OF PROGRAMMING INTEREST GROUP, 14., 2002, Brunel. Proceedings... Disponível em:<www.ppig.org>. Acesso em: 10 Dec. 2006.

LOMBARDI, T.P. (2006). Estratégias de aprendizagem para alunos problemáticos. Tradução de Amélia Marques. Disponível em:<http://www.malhatlantica.pt/ecaecm/aprendizagem.htm>. Acesso em: 10 ago. 2006.

MASSA, L.J.; MEYER, R.E. (2005). Three obstacles to validating the verbal-imager subtest of the cognitive style analysis. Personality and Individual Differences, Amsterdam, v.39, n.4, p.845-848, Sept.

MESSICK, S. (1976). Individuality in Learning: implications of cognitive styles and creativity for human development. San Francisco, CA: Jossey Bass.

MESSICK, S. (1984). The Nature of cognitive style: problems and promise in educational practice. Educational Psychologist, Lafayette, v.19, n.2, p.59-74.

MINISTÉRIO DA EDUCAÇÃO. (2006). Universidade aberta do Brasil. Disponível em:<www.mec.gov.br>. Acesso em: 20 out. 2006. 
MORAN, J.M. (2002). O que é educação a distância. Disponível em: <www.eca.usp.br /prof/moran/dist.htm>. Acesso em: 21 ago. 2006.

MUNRO, R.A.; RICE-MUNRO, E.J. (2004). Learning styles, teaching approaches and technology. The Journal for Quality and Participation, England, v.27, n.1, p.26-32, Spring.

NEUHAUSER, C. (2002). Learning style and effectiveness of online and face-to-face instruction. The American Journal Of Distance Education, University Park, v.16, n.2, p.99-113.

NISKIER, A. (1999). Educação à distância - a tecnologia da esperança. São Paulo: Loyola.

OLIVEIRA, J.B.A.; CHADWICK, C. (2001). Aprender e ensinar. São Paulo: Global.

PACHECO, G.P. (2001). Estilos individuais no processo de aprendizagem. Dissertação (Mestrado) - Programa de Pós-Graduação em Engenharia de Produção, Universidade Federal de Santa Catarina, Florianópolis, 2001.

PARKINSON, A.; MULLALLY, A.A.P.; REDMOND, J.A. (2004). Teste-retest reliability of Riding's Cognitive Style Analysis Test. Personality and Individual Differences, Amsterdam, v.37, n.8, p.1273-1278, Oct.

PARKINSON, A.; REDMOND, J.A. (2002). Do Cognitive styles affect learning performance in different computer media?. In: ANNUAL CONFERENCE ON INNOVATION AND TECHNOLOGY IN COMPUTER SCIENCE EDUCATION, 7., 2002, Denmark. Proceedings... New York: ACM. p.39-43.

PASQUALI, L. (1997). Psicometria: teoria e aplicações. Brasília: Editora Universidade de Brasília.

. (2000). Princípios de elaboração de escalas psicológicas. In: GORENSTEIN, C.; ANDRADE, L.H.S.G.; ZUARDE, A.W. Escalas de avaliação clínica em psiquiatria e psicofarmacologia. São Paulo: Lemos.

PENNINGS, A.H.; SPAN, P. (1991). Estilos cognitivos e estilos de aprendizagem. In: Leandro S.Almeida (Editor). Cognição e Aprendizagem. Porto, Associação dos Psicólogos Portugueses.

PETERS, O. (2003). A Educação a distância em transição: tendências e desafios. São Leopoldo; UNISINOS.

PETERSON, E.R.; DEARY, I.J.; AUSTIN, E.J. (2003a). The Reliability of Riding's Cognitive Style Analysis Test. Personality and Individual Differences, Amsterdam, v.34, n.5, p.881-891, Apr.

(2003b). On The Sssessment of cognitive style: four red herrings. Personality and Individual Differences, Amsterdam, v.34, n.5, p.899-904, Apr. 
. (2005a). A New Measure of verbal-imagery cognitive style: VICS. Personality and Individual Differences, Amsterdam, v.38, n.6, p.1269-1281, Apr.

. (2005b). Are Intelligence and personality related to verbal-imagery and wholisticanalytic cognitive styles?. Personality and Individual Differences, Amsterdam, v.39, n.1, p.201-213, July.

POTASHNIK, M.; CAPPER, J. (1998). Educação a distância: crescimento e diversidade. Finanças e Desenvolvimento, Rio de Janeiro, v.18, n.1, p. 42-45.

REZAEL, A.R.; KATZ, L. (2004). Evaluation of the reability and validity of the cognitive style. Personality and Individual Differences, Amsterdam, v.36, n.6, p.1317-1327, Apr.

RICHARDSON, R.J. (1999). Pesquisa social: métodos e técnicas. São Paulo: Atlas.

RIDING, R.J. (1991). Cognitive style analysis. Birmingham: Learning and Training Technology.

RIDING, R.J. (1994). Personal style awareness and personal development. Birmingham: Learning and Training Technology.

RIDING, R.J.; AL-SANABANI, S. (1998). The Effect on cognitive style, age, gender and structure on the recall of prose passages. International Journal of Education Research, Amsterdam, v.29, n.3, p.173-185, Aug.

RIDING, R.J.; CHEEMA, I. (1991). Cognitive styles - an overview and integration.

Educational Psychology, London, v.11, n.3, p.193-215.

RIDING, R.J.; RAYNER, S.G. (1998). Cognitive styles and learning strategies. London: David Fulton.

RIDING, R.J.; WATTS, M. (1997). The Effect of cognitive style on the preferred format of instructional material. Educational Psychology, London, v.17, n. 1-2, p.179-183, Mar-Jun.

ROBERTS, A. (2006). Cognitive styles and student progression in architectural design education. Design Studies, Amsterdam, v.27, n.2, p.167-181, Mar.

SARACHO, O.N. (1998). Research directions for cognitive style and education.

International Journal of Education Research, Amsterdam, v.29, n.3, p.287-290, Aug.

SHIRAHIGE, E.T. (1999). Estilo cognitivo: uma proposta de estudo no cotidiano da escola, junto a uma classe de $4^{\text {a }}$ série. Tese (Doutorado) - Faculdade de Educação, Universidade de São Paulo, São Paulo, 1999.

SCHRIRE, S. (2004). Interaction and cognition in asynchronous computer conferencing. Instructional Science, Berlin, v.32, n.6, p.475-502, Nov.

SILVA, E.L.; MENEZES, E.M. (2001). Metodologia da pesquisa e elaboração de dissertação. 3.ed. Florianópolis: Laboratório de Ensino a Distância da UFSC. 
SOUZA, A.R.B. (2005). Movimento didático na educação a distância: análise e prospecção. Tese (Doutorado) - Programa de Pós-Graduação em Engenharia de Produção, Universidade Federal de Santa Catarina, Florianópolis, 2005.

STEIL, A.V.; BARCIA, R.M. (2006). Atitudes de alunos e professores com relação a cursos de mestrado em engenharia de produção a distância. Gestão \& Produção, São Carlos, v.13, n.1, p.141-149, abr.

TAKAHASHI, T. (Org.). (2000). Sociedade da informação no Brasil: livro verde. Brasília: Ministério da Ciência e Tecnologia. Brasília.

TERRELL, S.R.; DRINGUS, L. (2000). An investigation of the effect of learning style on student success in an online learning environment. Journal Educational Technology Systems, Farmingdale, v.28, n.1, p.231-238.

VALENTA, A. et al. (2001). Identifying studentes attitudes and learning styles in distance education. Journal of Asynchronous Learning Networks, Alabama, v.5, n.2, p.111-127.

VERGARA, S.C. (1998). Projetos e relatórios de pesquisa em administração. 2.ed. São Paulo: Atlas.

VIANEY, J. (Org.). (2003). A Universidade virtual no Brasil: o ensino superior a distância no Brasil. Tubarão: Ed.Unisul.

VOLERY, T.; LORD, D. (2000). Critical success fators in online education. The International Journal of Educational Management, Bradford, v.14, n.5, p.216-223.

ZHU, E. (2006). Interaction and cognitive engagement: an analysis of four asynchronous online discussions. Instructional Science, Berlin, v.34, n.6, p.451-480, Nov.

YOKAICHIYA, D.K. (2005). Estruturação e avaliação de uma disciplina de bioquímica à distância baseada no modelo de aprendizagem colaborativa. Tese (Doutorado) Programa de Pós-Graduação do Instituto de Biologia, Universidade Estadual de Campinas, Campinas, 2005.

WORKMAN, M. (2044). Performance and perceived effectiveness in computer-based and computer-aided education: do cognitive style make a difference? Computyers in Humnan Behaviour, Amsterdam, v.20, n.4, p.517-534, July. 
ANEXO A

MANUAL VICS-E-CSA-WA 


\section{Verbal Imagery Cognitive Styles Test \& Extended Cognitive Style Analysis-Wholistic Analytic Test}

\section{Administration Guide}

(C) 2003 Elizabeth R Peterson,

University of Edinburgh

Revised May 2005

For more information or to contact the test author

e.peterson@auckland.ac.nz 


\section{CONTENTS}

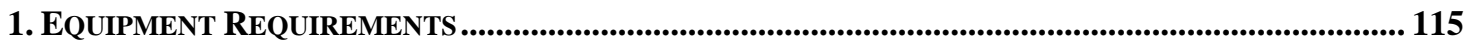

2. INSTALLATION OF THE VICS TEST AND THE EXTENDED CSA-WA ..............................................115

2.1 Installing the software............................................................................................................................... 115

2.2 Setting up the keyboard for the VICS and E-CSA-WA test .................................................... 115

$2.3 \quad$ Setting up the screen ......................................................................................................................... 117

3. CONDITIONS FOR RELIABLE ASSESSMENT ........................................................................................... 117

3.1 Basic abilities required ............................................................................................................................. 117

3.2 Setting up the room ................................................................................................................................ 117

3.3 Instructions for the participant................................................................................................................ 118

3.4 Instructions for the assessor ................................................................................................................ 118

3.5 How do I explain the concept of cognitive style to my participants? ............................................ 119

4. STARTING / RUNNING THE VICS AND EXTENDED CSA-WA ............................................................... 119

5. PRACTICAL DETAILS ABOUT THE VICS TEST AND THE EXTENDED CSA-WA.................................... 120

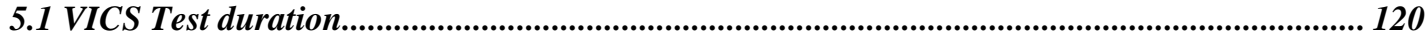

5.2 VICS test number of Items. ............................................................................................................... 120

5.3 Extended CSA-WA test duration....................................................................................................... 120

5.4 Extended CSA-WA number of test Items ................................................................................. 120

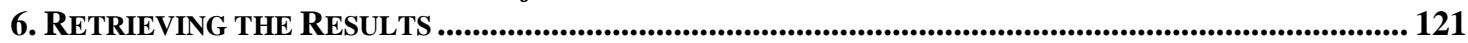

6.1 Types of report.................................................................................................................................... 121

6.2 How to produce a report................................................................................................................... 122

7. ANALYSING THE DATA ................................................................................................................................ 123

7.1 Opening the data .................................................................................................................................. 123

7.2 Definition of column headings used in the report............................................................................... 123

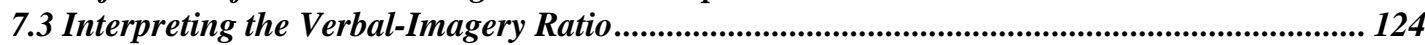

7.4 Interpreting the Wholistic Analytic Ratio......................................................................................... 125

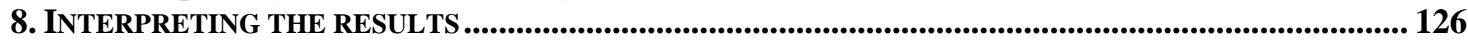

8.1 Brief introduction to cognitive styles ................................................................................................... 126

8.2 Background and reliability of the VICS test and the Extended CSA-WA.................................... 126

8.4 Assessment of Verbal-Imagery Cognitive Style Preferences.............................................................. 127

9. SENDING (EMAILING) REPORTS (MORE INFORMATION) ......................................................................... 128

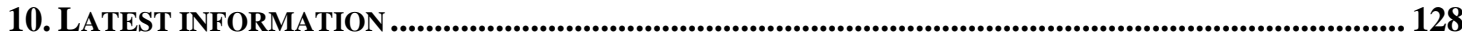

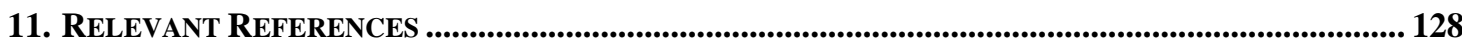




\section{Equipment Requirements}

The VICS and Extended CSA-WA run on a PC in Windows 95, 98, 2000 and XP. You will need a CD drive and a colour monitor and preferably a separate (moveable) keyboard with a number pad.

\section{Installation of the VICS Test and the Extended CSA-WA}

\subsection{Installing the software}

Email Version:

If you have been emailed the test, you will be sent a setup file. If you open this file and follow the instructions then the programme should self install.

This version of the programme seems to require the settings of the computer to be changed to English (New Zealand). This can be done through the Control Panel/Regional Options/English (New Zealand)

\subsection{Setting up the keyboard for the VICS and E-CSA-WA test}

The VICS test uses the number pad keys 1, 2 and 3 and the E-CSA-WA uses the number pad keys 1 and 2. If you only require the E-CSA-WA test follow the instructions below but ignore all references to number pad 'key 3'.

\section{A) Setting up your keyboard using a Desk Top or an external keyboard (this is the preferred test set up)}

Activate the Number Lock

Cover up the keys 4, 5, 6, 7, 8, and 9 etc with a piece of paper (see Figure 1).

For the VICS test stick the letters $\mathrm{Y}, \mathrm{N}$ and $\mathrm{M}$ on the keys 1, 2 and 3 respectively (see Figures 1and 2 below). If you are only using the E-CSA-WA test put stickers labeled $\mathrm{Y}$ and $\mathrm{N}$ over the 1 and 2 keys respectively (see Figure 3 below).

The keyboard should be placed in a convenient position for the subject to reach the number pad. If the subject is left handed, place the number pad in a comfortable position for his or her left hand. If the subject is right handed, place the keyboard in a comfortable position for his or her right hand. 


\begin{tabular}{|l|l|l|l|}
\hline $\begin{array}{l}\text { Num } \\
\text { Lock }\end{array}$ & $/$ & $*$ & - \\
\cline { 1 - 3 } & 8 & 9 & \multirow{2}{*}{+} \\
\hline 4 & 5 & 6 & \\
\hline 1 & 2 & 3 & Enter \\
\cline { 1 - 2 } 0 & & $\cdot$ & \\
\hline
\end{tabular}

Figure 1. A standard number pad on a keyboard.

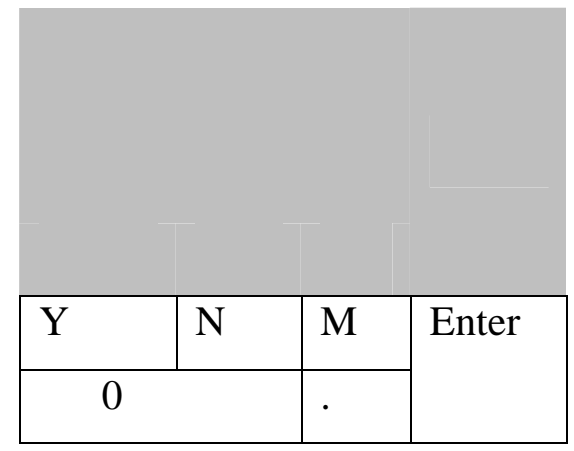

Figure 2. How your number pad should look in preparation for the VICS test.

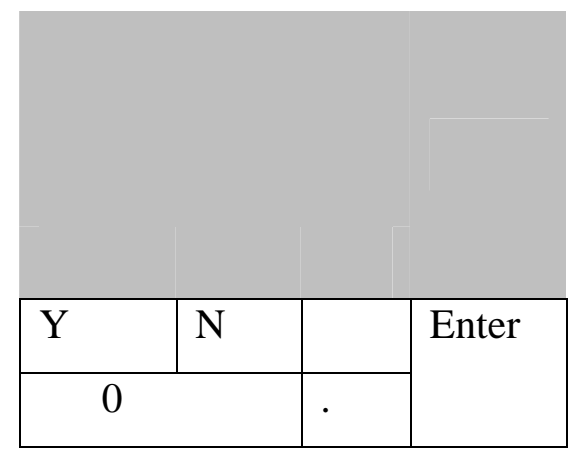

Figure 3. How your number pad should look in preparation for the E-CSA-WA test.

\section{B) Setting up your keyboard using a laptop (not the preferred option)}

If you are running the VICS test off a laptop, you will need to set it up so that the number pad is activated. On many laptops the keys M, J, K, L, U, I, O, 7, 8, 9 double as the number pad. Check your instruction manual for how to activate this number pad. For example, on a Fujitsu 
Pentium laptop you hold down the shift key and the 'Num Lk' key at the same time and this activates the number pad keys.

Stick the letters $\mathrm{Y}, \mathrm{N}, \mathrm{M}$ to the keys that double as 1, 2 and 3.

\section{Setting up the screen}

To run the test so it fits your computer screen you need to change the display. The screen resolution should be set to $1024 \underline{\times} 768$ or $800 \times 600$.

The monitor settings need to be ' 75 Hz'

To check your settings or to change them, go to start menu/ settings/control panel/display/settings/screen resolution and adjust accordingly.

\section{Conditions for Reliable Assessment}

\subsection{Basic abilities required}

In order to do the VICS test, the person being assessed must be able to read English fluently.

Notes should be made in the comments section of in the participant information screen at the beginning of the test if the person has English as a second language or they are dyslexic or colour blind.

Separate experimenter notes should also be made if the participant seems to be having difficulty with the test or for example if they seemed to respond very fast or very slow as this may affect the accuracy of the task. If this is the case, on task completion, you may like to ask the participant how they found it. This may give additional insight into whether the participant needs to be excluded from later data analysis

\subsection{Setting up the room}

For reliable assessment, participants should either be assessed individually or be unable to see or hear any other person being tested. This is important because the test measures the participant's natural speed of response and this is likely to be altered if they see or hear 
someone answering more quickly than them, or if they see or hear someone finishing before them.

Participants should be made to feel relaxed and should be free from distraction or interruption.

Cell phones should be turned off and other distractions removed.

\subsection{Instructions for the participant}

No information about how the test actually measures style should be given prior to the test. Instructions on the test are part of the programme. Some users have suggested that the researcher should mentioning to the participants on the Extended CSA-WA that they should not try and rotate the shapes in order to answer the questions.

It is preferable to give little or no information to the participant about the general field of cognitive styles until after the test is finished. This is because the test is likely to work best when the person being assessed is relatively naive as to the purpose and nature of the test.

\subsection{Instructions for the assessor}

The assessor should be relaxed, informal and friendly.

The assessor should try not to make the person doing the assessment self conscious by standing too close or watching their responses.

The assessor should give the minimum of instructions and details about the test necessary to complete the assessment (see 3.3 above).

The assessor should not suggest that the person is being timed or suggest that they respond quickly.

When explaining the test results to the participants, the assessor should be wary of categorising the participants into style groups i.e., the assessor should explain that cognitive style is a continuum and that it indicates a preference only.

Please note as both the E-CSA-WA and VICS test are new tests and validity data is not yet available (the test author is working on this now!). Hence currently we do not know if the 
individual differences identified on this test have any real world value. Therefore please avoid giving participants a style label.

Note: For smooth operation the application needs to be closed down and re opened for each additional participant.

\subsection{How do I explain the concept of cognitive style to my participants?}

I often explain cognitive style by giving the example of how people tend to fold their arms and clasp their hands the same way every time. This doesn't mean that they can't do it in different ways, it just indicates that they have a preference for doing it in one particular way. I explain that cognitive style is argued to work on a similar principle. Some of us prefer to process, represent and structure information in particular ways, we are able to process information in other ways too, but we may show a preference for one way above others. As stated above, please avoid catagorising participants and avoid giving them a style label as this is misleading. If you need to give feedback make sure it is generic and tell participants that no validity data has yet been collected on the VICS or the E-CSA-WA so the test may be incorrect but the data suggests that they have $\mathrm{x}$ or $\mathrm{y}$ tendencies etc.

\section{Starting / running the VICS and Extended CSA-WA}

Click on the Start key on the bottom left hand side of your computer screen then click on your program directory. The file will probably be called Programs/VICS/VICS-E-CSA-WA. The introductory / start up screen for the VICS and E-CSA-WA will then launch. Press OK. Click on Test/New.

Select whether you want a new subject or one already in the system.

If it is a new subject, enter the subject's demographic details. If you are running a subject for the $2^{\text {nd }}$ time click on already in the system.

Once the subject's demographic information (name, age etc) has been entered the VICS test will start. The test is designed to run with the minimum amount of intervention. (Nb please make sure the screen is set to the correct resolution and the key board is set up etc) 
Note: For the year of birth the computer will only accept the year in which the subject was born e.g. 1978. It will not accept the day and month.

Note: Please make any notes about the subject or test conditions you feel necessary in the comments box.

Note: For smooth operation the application needs to be closed down and re opened after every participant

\section{Practical details about the VICS test and the Extended CSA-WA}

\subsection{VICS Test duration}

The VICS test takes approximately 25-30 minutes to complete.

\subsection{VICS test number of Items.}

The number of stimuli used in the Verbal Imagery Cognitive Styles test and their component break down is give in the table below. The number of stimuli is shown in brackets.

\begin{tabular}{|c|c|c|c|c|c|c|c|c|c|c|c|}
\hline \multicolumn{12}{|c|}{$\begin{array}{l}\text { Verbal Imagery Cognitive Style (VICS) test } \\
\text { (232 stimuli) }\end{array}$} \\
\hline \multicolumn{6}{|c|}{ Verbal Task (116) } & \multicolumn{6}{|c|}{ Imagery Task (116) } \\
\hline \multicolumn{3}{|c|}{ Words (58) } & \multicolumn{3}{|c|}{ Pictures (58) } & \multicolumn{3}{|c|}{ Words (58) } & \multicolumn{3}{|c|}{ Pictures (58) } \\
\hline $\begin{array}{l}\mathrm{N} \\
(26)\end{array}$ & $\begin{array}{l}\text { M } \\
(26)\end{array}$ & $\begin{array}{l}\mathrm{Mx} \\
(6)\end{array}$ & $\begin{array}{l}\mathrm{N} \\
(26)\end{array}$ & $\begin{array}{l}\mathrm{M} \\
(26)\end{array}$ & $\begin{array}{l}\mathrm{Mx} \\
(6)\end{array}$ & $\begin{array}{l}\text { B } \\
(26)\end{array}$ & $\begin{array}{l}\text { S } \\
(26)\end{array}$ & $\begin{array}{l}E \\
(6)\end{array}$ & $\begin{array}{l}\text { B } \\
(26)\end{array}$ & $\begin{array}{l}\text { S } \\
(26)\end{array}$ & $\begin{array}{l}\text { E } \\
(6)\end{array}$ \\
\hline
\end{tabular}

Key: $\mathrm{N}=$ Natural, $\mathrm{M}=$ Man-made, $\mathrm{Mx}=$ Mixed, $\mathrm{B}=$ Bigger, $\mathrm{S}=$ Smaller, $\mathrm{E}=$ Equal

\subsection{Extended CSA-WA test duration}

The Extended CSA-WA test takes approximately 15 minutes to complete.

\subsection{Extended CSA-WA number of test Items}

The number of stimuli (shown in brackets) used in the Extended CSA-WA and their 
component break down is given in the table below.

\begin{tabular}{|c|c|c|c|}
\hline \multicolumn{4}{|c|}{$\begin{array}{c}\text { Extended CSA-WA } \\
\text { (80 stimuli) }\end{array}$} \\
\hline \multicolumn{2}{|c|}{ Nholistic Task (40) } & Analytic Task (40) \\
\hline Original CSA & New Wholistic & Original CSA & New Analytic \\
Wholistic Items & Items & Analytic Items & Items \\
$(20)$ & $(20)$ & $(20)$ & $(20)$ \\
\hline
\end{tabular}

\section{Retrieving the Results}

\subsection{Types of report}

The VICS test and Extended CSA-WA produce three types of reports.

\section{Researcher's Report}

This report is useful for researchers who want to do an in-depth analysis of the result using a statistical package. The research report gives the subject's response to every question and the attributes of that question.

For example, on the VICS test for each of the 232 responses per subject, it notes the presentation task, type, form, exposure, correct answer, response and reaction time.

On the WA test for each of the 80 responses, it gives the correct answer, the reaction time and whether it was a response to an original CSA item or a new item designed for the Extended CSA-WA.

\section{Summary Report}

The Summary Report will be sufficient for most people's needs. This gives summary data for each subject. 
On the VICS test and the Extended CSA-WA, this report gives the subject's and session number, the median and mean reaction times on the sections of the test (verbal, imagery, wholistic and analytic) and the number of correct responses on each section of the test.

The most important result in the summary report is the verbal-imagery ratio and the wholisticanalytic ratio. This gives an indication of the participant's verbal-imagery and wholisticanalytic style preferences. See the sections on Verbal-Imagery and Wholistic-Analytic style ratios below for more information about the meaning of these ratios and how to interpret them.

\section{Summary Report Plus}

The Summary Report Plus also gives the same basic summary data as the Summary Report above for each subject, but it also gives a few additional details such as name, age, gender, ethnicity and comments for each subject.

\section{VICS-Summary Report Plus *}

For the VICS test, the summary report plus also gives the details of the mean reaction times and accuracy for each task type, exposure, stimulus form, and type of item.

\subsection{How to produce a report}

Close the program after each testing participant's session.

Re start the VICS program

On the main VICS screen press Test/Reports.

Select the test you wish to generate.

Select the subjects for whom you wish to generate results.

Click 'Find Directory' and choose where you want the results to be saved.

Give the file a name then press 'Save'. 
Press 'Generate' to produce the report.

You will then be given an option to send the result to Elizabeth Peterson. This is part of the license agreement. Note, please send your final results only. If the results are not your final results then ignore this screen and close this window by pressing the ' $\mathrm{X}$ ' in the top right had corner (see Section 9 for more details).

To open a generated report you need to go to the directory that you saved the report into in step 4. The report will be saved as an Excel file but can be imported into SPSS and other statistical packages.

\section{Analysing the Data}

\subsection{Opening the data}

Once you have generated a report (see Producing a Report above), you can import the file into various statistical packages e.g., SPSS.

Note: the column headings may need to be moved separately or entered manually when converting the Excel file to SPSS or any other statistical package.

\subsection{Definition of column headings used in the report}

Below is a list of the column headings used in the generated reports

Test ID

Subject

Session

Presentation number

Task Type

Stimulus format

Correct Response

Response Time

Med V RT
The identification number you give to the test

Subject Number

Test Session number

Order in which the stimuli were presented

The task the subject was on (Verbal or Imagery)

Whether the item was in the word form or picture form

Whether the participant made the correct response

The time taken to respond to the stimulus

Median Reaction Time on the verbal task 


\begin{tabular}{|c|c|}
\hline Med I RT & Median Reaction Time on the imagery task \\
\hline Mean V & Mean Reaction Time on the verbal task \\
\hline Mean I & Mean Reaction Time on the imagery task \\
\hline No V Correct & Number of verbal items answered correctly \\
\hline No I Correct & Number of imagery items answered correctly \\
\hline Med V & Median Reaction Time on the verbal task \\
\hline Med I & Median Reaction Time on the imagery task \\
\hline Mean V & Mean Reaction Time on the verbal task \\
\hline Mean I & Mean Reaction Time on the imagery task \\
\hline Mean Pic & Mean Reaction Time on the picture items \\
\hline Mean Words & Mean Reaction Time on the word items \\
\hline Mean Exp 1 & Mean Reaction Time on the items in Exposure 1 \\
\hline Mean Exp 2 & Mean Reaction Time on the items in Exposure 2 \\
\hline Err V & No of errors on the verbal items \\
\hline Err Img & No of errors on the imagery items \\
\hline Err Pic & No of errors on the picture items \\
\hline Err Wrd & No of errors on the word items \\
\hline Err Bigger & No of errors on the bigger items \\
\hline Err Smaller & No of errors on the smaller items \\
\hline Err Manmade & No of errors on the manmade items \\
\hline Err Natural & No of errors on the natural items \\
\hline Err Mixed & No of errors on the mixed items \\
\hline Err Exp 1 & No of errors on the items in exposure 1 \\
\hline Err Exp 2 & No of errors on the items in exposure 2 \\
\hline Handedness & Whether the participant was left or right handed or ambidextrous \\
\hline English & Whether the participant spoke English as their first language \\
\hline
\end{tabular}

\subsection{Interpreting the Verbal-Imagery Ratio}

My research on 376 University students suggests that most university students seem to have VI style ratio between .8 and 1.0 which probably suggest little or no style preference.

Scores that are closer to 0 would indicate a tendency towards a verbal preference and scores 
that are closer towards 2 (or above) indicate a tendency for an imagery preference

(VICS test Ratios from a university student sample $\mathrm{N}=376, \mathrm{M}=.99, \mathrm{SD}=.408$ )

Please note that participants who have an error rate of greater than $30 \%$ should be excluded from the analysis as this may indicate that they did not take the test seriously. The items are designed to be easy and under normal circumstances the individual should get most of the correct. Therefore if care is take accuracy should be high. High error rates may indicate that the buttons were pressed randomly or the respondent was working too fast to be accurate.

Please Note the VI ratio should not be used to allocate people to style categories because the reliability of the data will be reduced (see Peterson et al., 2003, 2005)

\subsection{Interpreting the Wholistic Analytic Ratio}

My research on 276 University students suggests that that most university students seem to have WA style ratio between .97 and 1.25 and this probably suggests little style preference. Scores that are closer to 0 would indicate a tendency towards a wholistic preference and scores that are closer towards 2 (or above) indicate a tendency for an analytic preference.

(WA test Ratios from a university student sample $\mathrm{N}=276, \mathrm{M}=1.25, \mathrm{SD} .307$ )

These ranges for the WA results are similar to Riding's (1998) Secondary School Sample of 1448 students which is reported in the CSA Research Applications Manual.

Please note that participants who have an error rate of greater than $30 \%$ should be excluded from the analysis as this may indicate that they did not take the test seriously. The items are designed to be easy and under normal circumstances the individual should get most of the correct. Therefore if care is take accuracy should be high. High error rates may indicate that the buttons were pressed randomly or the respondent was working too fast to be accurate. 
because the reliability of the data will be reduced (see Peterson et al., 2003, 2005)

\section{Interpreting the results}

\subsection{Brief introduction to cognitive styles}

Cognitive styles are an individual's preferred or habitual ways of taking in and processing information and they are believed to be a missing element in the study of individual differences (Riding \& Rayner, 1998).

Advocates of the style construct believe that by taking account of the ways in which people differ in their cognitive style we may be able to explain differences in the way people teach and learn, differences in social relationships (at home and in the work place) and many other aspects of human performance. Style researchers ultimately aim to unlock the potential of style and in doing so enhance potential and personal well-being.

\subsection{Background and reliability of the VICS test and the Extended CSA-WA}

The VICS test measures verbal versus imagery preferences for the way information is represented, and the Extended CSA-WA test measures preferences for structuring information in a wholistic versus an analytic way.

These two higher order cognitive style dimensions (verbal-imagery and wholistic-analytic) were suggested by Riding and Cheema in 1991 following their review of the styles literature. Riding (1991) subsequently designed the Cognitive Style Analysis (CSA) test which measured these dimensions by comparing how fast, on average, individuals respond on a verbal task compared to an imagery task and how fast they respond, on average, on a wholistic task compared to an analytic task.

Peterson et al. (2003 a; 2003 b) found that, despite some empirical evidence for the validity of the CSA, the verbal-imagery style preference ratios and wholistic-analytic style preference ratios (which are used to determine a person's cognitive style preference) have poor test retest reliability $(\mathrm{r}$ 's <.32). 
Peterson et al. (2003 a) showed that an Extended version of the CSA's Wholistic Analytic dimension (Extended CSA-WA) improved the test's reliability to a satisfactory level (internal consistency $\mathrm{r}=.72$; test re-test reliability $\mathrm{r}=.55$ ) and they designed a new test of verbal imagery cognitive style (VICS) (Peterson; Deary e Austin, 2005a) with acceptable internal consistency $(\mathrm{r}>.72)$ and test re-test reliability $(\mathrm{r}=.56)$.

For the publications relating to the VICS test or for more information log on to http://www.arts.auckland.ac.nz/staff/index.cfm?P=7020

\subsection{Assessment of Verbal-Imagery Cognitive Style Preferences}

The VICS test primarily records the speed at which participants respond and their accuracy.

The VICS test is designed so that the participant should be responding with high levels of accuracy. Any participant who responds with less than $70 \%$ accuracy either did not understand the instructions, or they were trying to respond too quickly and made too many errors. Participants that do make high numbers of errors should be excluded from any group analysis and their results interpreted with caution.

\subsection{The Style Ratio}

To examine whether participants have a verbal or imagery style preference, a measure is required which directly compares each participant's performance on the verbal items to their performance on the imagery items. To do this the VICS test records the participant's median reaction time to the verbal items and compares it with his or her median reaction time to the imagery items. This process of creating a verbal-imagery ratio (based on the median reaction times on the verbal and imagery tasks) results in each participant having a score somewhere along a verbaliser-imager continuum.

Note also, the VICS test is set up to investigate whether participants have a verbal or imagery preference by calculating a ratio in a variety of other ways (e.g., pictures vs words, exposure 1 vs exposure 2, verbal task in words vs imagery task in pictures etc.). However Peterson et al., 
(submitted) found that the verbal-imagery task ratio (which is generated automatically at the end of the test) was the most stable over time.

\section{Sending (Emailing) Reports (more information)}

When you generate a report, the computer will present you with an option to send the report to Elizabeth Peterson (the test author). Your license agreement contains a clause which requires you to do this. The reason for this clause is so that the test author can keep a file of test norms and get an indication of the kind of results the test is generating. It is hoped that by collecting this data all test users will benefit.

Please send final reports only and please send copies of all three reports (Research Report, Summary Report and Summary Report Plus).

If the results are not your final results then ignore this screen and close this window by pressing the ' $\mathrm{X}$ ' in the top right had corner.

\section{Latest information}

To find out the latest information on the VICS test and the Extended CSA-WA or to contact the test author please log on to http://www.arts.auckland.ac.nz/staff/index.cfm?P=7020

\section{Relevant References from the test author}

- Peterson, E. R., Deary, I. J., \& Austin, E. J. (2003).The reliability of the Cognitive Styles Analysis test. Personality and Individual Differences, 34, 881-891.

- Peterson, E. R., Deary, I. J., \& Austin, E. J. (2003). On the assessment of cognitive style: Four red herrings. Personality and Individual Differences, 34, 899-904.

- Peterson, E. R., Deary, I. J., \& Austin, E. J (2005). A new reliable measure of verbalimagery cognitive style. Personality and Individual Differences, 38, 1269-1281.

- Peterson, E. R., Deary, I.J., \& Austin, E. J (2005). Are Intelligence and Personality related to Verbal-Imagery and Wholistic-Analytic Cognitive Styles? Personality and Individual Differences, 39, 201-213. 
APÊNDICE A

\section{TERMO DE CONCORDÂNCIA}




\section{TSP}

\section{TERMO DE CONCORDÂNCIA}

$\mathrm{Eu}$,

registro acadêmico $\mathrm{n}^{\mathrm{o}}$ , aluno(a) regularmente matriculado(a) no Ano do Curso de oferecido pelo , localizado na cidade de concordo em participar da pesquisa de mestrado “Avaliação da Influência dos Estilos Cognitivos no Perfil do Aluno de Educação a Distância” sob a responsabilidade da aluna Elaine Maria dos Santos, a qual é orientada pelo Prof. Dr. José Dutra de Oliveira Neto, vinculados ao Programa de Pós-Graduação em Engenharia de Produção da Escola de Engenharia de São Carlos (EESC) da Universidade de São Paulo.

23 de setembro de 2006. 